NBER WORKING PAPER SERIES

\title{
DISEASE AND DEVELOPMENT: THE EFFECT OF LIFE EXPECTANCY ON ECONOMIC GROWTH
}

\author{
Daron Acemoglu \\ Simon Johnson \\ Working Paper 12269 \\ http://www.nber.org/papers/w12269
}
NATIONAL BUREAU OF ECONOMIC RESEARCH
1050 Massachusetts Avenue
Cambridge, MA 02138
May 2006

We thank Josh Angrist, David Autor, Abhijit Banerjee, Tim Besley, Anne Case, Sebnem Kalemli-Ozcan, Torsten Persson, Arvind Subramanian, David Weil, Pierre Yared and especially Angus Deaton for helpful suggestions and discussion. We also thank seminar participants at Brookings, Brown, Chicago, Harvard-MIT Development Seminar, LSE, Maryland, Northwestern, the NBER Summer Institute, Princeton, the Seventh BREAD Conference on Development Economics, and theWorld Bank for comments and the staff of the National Library of Medicine and MIT's Retrospective Collection for their patient assistance. The views expressed herein are those of the author(s) and do not necessarily reflect the views of the National Bureau of Economic Research.

(C2006 by Daron Acemoglu and Simon Johnson. All rights reserved. Short sections of text, not to exceed two paragraphs, may be quoted without explicit permission provided that full credit, including $\odot$ notice, is given to the source. 
Disease and Development: The Effect of Life Expectancy on Economic Growth

Daron Acemoglu and Simon Johnson

NBER Working Paper No. 12269

May 2006

JEL No. I10, O40, J11

\begin{abstract}
$\underline{\text { ABSTRACT }}$
What is the effect of increasing life expectancy on economic growth? To answer this question, we exploit the international epidemiological transition, the wave of international health innovations and improvements that began in the 1940s. We obtain estimates of mortality by disease before the 1940s from the League of Nations and national public health sources. Using these data, we construct an instrument for changes in life expectancy, referred to as predicted mortality, which is based on the pre-intervention distribution of mortality from various diseases around the world and dates of global interventions. We document that predicted mortality has a large and robust effect on changes in life expectancy starting in 1940, but no effect on changes in life expectancy before the interventions. The instrumented changes in life expectancy have a large effect on population; a $1 \%$ increase in life expectancy leads to an increase in population of about $1.5 \%$. Life expectancy has a much smaller effect on total GDP both initially and over a 40-year horizon, however. Consequently, there is no evidence that the large exogenous increase in life expectancy led to a significant increase in per capita economic growth. These results confirm that global efforts to combat poor health conditions in less developed countries can be highly effective, but also shed doubt on claims that unfavorable health conditions are the root cause of the poverty of some nations.
\end{abstract}

Daron Acemoglu

Department of Economics

MIT, E52-380B

50 Memorial Drive

Cambridge, MA 02142

and NBER

daron@mit.edu

Simon Johnson

Sloan School of Management

MIT, E52-562

50 Memorial Drive

Cambridge, MA 02142

and NBER

sjohnson@mit.edu 


\title{
1 Introduction
}

Improving health around the world today is an important social objective, which has obvious direct payoffs in terms of longer and better lives for millions. ${ }^{1}$ There is also a growing consensus that improving health can have equally large indirect payoffs through accelerating economic growth. ${ }^{2}$ For example, Gallup and Sachs (2001, p. 91) argue that wiping out malaria in subSaharan Africa could increase that continent's per capita growth rate by as much as $2.6 \%$ a year, and a recent report by the World Health Organization (2001) states:

\begin{abstract}
"in today's world, poor health has particularly pernicious effects on economic development in sub-Saharan Africa, South Asia, and pockets of high disease and intense poverty elsewhere" (p. 24) and

"...extending the coverage of crucial health services... to the world's poor could save millions of lives each year, reduce poverty, spur economic development and promote global security" (p. i).
\end{abstract}

The evidence supporting this recent consensus is not yet conclusive, however. Although cross-country regression studies show a strong correlation between measures of health (for example, life expectancy or infant mortality) and both the level of economic development and recent economic growth, these studies have not established a causal effect of health and disease environments on economic growth. Since countries suffering from short life expectancy and ill-health are also disadvantaged in other ways (and often this is the reason for their poor health outcomes), such macro studies may be capturing the negative effects of these other, often omitted, disadvantages. While a range of micro studies demonstrate the importance of health for individual productivity, as discussed below, these studies do not resolve the question of whether health differences are at the root of the large income differences we observe today and whether improvements in health will increase economic growth substantially.

This paper investigates the effect of life expectancy at birth - as a general measure of the health of the population - on economic growth. We exploit the large improvements in life expectancy, especially among the relatively poor nations, driven by international health interventions, more effective public health measures, and the introduction of new chemicals and drugs starting in the 1940s. ${ }^{3}$ This episode, which we refer to as the international epidemiological transition, led to an unprecedented improvement in life expectancy in a large number

\footnotetext{
${ }^{1}$ See Becker, Phillipson and Soares (2005) and Deaton (2003 and 2004) for recent analyses.

${ }^{2}$ See, among others, Bloom and Sachs (1998), Gallup and Sachs (2001), World Health Organization (2001), Alleyne and Cohen (2002), Bloom and Canning (2005), and Lorentzon, Wacziarg, and McMillan (2005).

${ }^{3}$ There were some effective medical and public health innovations prior to 1940 . But the positive effects from these innovations were concentrated in richer countries.
} 
of countries. ${ }^{4}$ Figure 1 shows this by plotting life expectancy in countries that were initially (circa 1940) poor, middle income, and rich. It illustrates that while in the 1930s life expectancy was low in many poor and middle-income countries, this transition brought their levels of life expectancy close to those prevailing in richer parts of the world. ${ }^{5}$ As a consequence of these developments, health conditions in many parts of the less-developed world today, though still in dire need of improvement, are significantly better than the corresponding health conditions were in the West at the same stage of development. ${ }^{6}$

The international epidemiological transition provides us with an empirical strategy to isolate potentially-exogenous changes in health conditions. The effects of the international epidemiological transition on a country's life expectancy were related to the extent to which its population was initially (circa 1940) affected by various specific diseases, for example, tuberculosis, malaria, and pneumonia, and to the timing of the various health interventions.

The early data on mortality by disease are available from standard international sources, though they have not been widely used in the economics literature. These data allow us to create an instrument for changes in life expectancy based on the pre-intervention distribution of mortality from various diseases around the world and the dates of global intervention (e.g., discovery and mass production of penicillin and streptomycin, or the discovery and widespread use of DDT against mosquito vectors). The only source of variation in this instrument, which we refer to as predicted mortality, comes from the interaction of baseline cross-country disease prevalence with global intervention dates for specific diseases. We document that there were large declines in disease-specific mortality following these global interventions. More im-

\footnotetext{
${ }^{4}$ The term epidemiological transition was coined by demographers and refers to the process of falling mortality rates after about 1850, associated with the switch from infectious to degenerative disease as the major cause of death (Omran, 1971). Some authors prefer the term "health transition," as this includes the changing nature of ill health more generally (e.g., Riley, 2001). Our focus is on the rapid decline in mortality (and improvement in health) in poorer countries after 1940, most of which was driven by the fast spread of new technologies and practices around the world (hence the adjective "international"). The seminal works on this episode include Stolnitz (1955), Omran (1971), and Preston (1975a).

${ }^{5}$ This figure is for illustration purposes and should be interpreted with caution, since convergence is not generally invariant to nonlinear transformations. Our empirical strategy below does not exploit this convergence pattern; instead, it relies on potentially-exogenous changes in life expectancy.

In these figures and throughout the paper, the initially rich countries are those with income per capita in 1940 above the level of Argentina (the richest Latin American country at that time, according to Maddison's data, in our base sample). These are, in ascending order, Belgium, Netherlands, Sweden, Denmark, Canada, Germany, Australia, New Zealand, Switzerland, the United Kingdom and the United States. The initially poor countries are those with income per capita below that of Portugal, which was the poorest European nation in our base sample. These are, in ascending order: China, Bangladesh, India, Pakistan, Myanmar, Thailand, El Salvador, Honduras, Indonesia, Brazil, Sri Lanka, Malaysia, Nicaragua, Korea, Ecuador, and the Philippines. Because of data quality issues, African nations are not included in our base sample, but they are used in robustness checks in Section 7. See Appendix Table A1 for a list of initially rich, middle-income and poor countries.

${ }^{6}$ For example, life expectancy at birth in India in 1999 was 60 compared to 40 in Britain in 1820, when income per capita was approximately the same level as in India today (Maddison, 2001, p. 30). From Maddison (2001, p. 264), income per capita in Britain in 1820 was $\$ 1707$, while it stood at $\$ 1746$ in India in 1998 (all figures in 1990 international dollars).
} 
portantly, we show that the predicted mortality instrument has a large and robust effect on changes in life expectancy starting in 1940, but has no effect on changes in life expectancy prior to this date (i.e., before the key interventions).

The instrumented changes in life expectancy have a fairly large effect on population; a $1 \%$ increase in life expectancy is related to an approximately $1.3-1.8 \%$ increase in population. The magnitude of this estimate indicates that the decline in fertility rates was insufficient to compensate for increased life expectancy, a result which we directly confirm by looking at the relationship between life expectancy and total births.

On the other hand, we find no statistically significant effect on total GDP (though our two standard error confidence intervals do include economically significant effects). More importantly, relative growth rates for GDP per capita (and GDP per working age population) show some decline in countries experiencing large increases in life expectancy. In fact, our estimates exclude any positive effects of life expectancy on GDP per capita within a 40-year horizon. This is consistent with the overall pattern in Figure 2, which, in contrast to Figure 1 , shows no convergence in income per capita between initially poor, middle-income and rich countries. Similarly, we find no evidence of an increase in human capital investments associated with improvements in life expectancy.

The most natural interpretation of our results comes from neoclassical growth theory. The first-order effect of increased life expectancy is to increase population, which initially reduces capital-to-labor and land-to-labor ratios, thus depressing income per capita. This initial decline is later compensated by higher output as more people enter the labor force. This compensation can be complete and may even exceed the initial level of income per capita if there are significant productivity benefits from longer life expectancy. Yet, the compensation may also be incomplete if the benefits from higher life expectancy are limited and if some factors of production, for example land, are supplied inelastically. A smaller initial effect on GDP than the longer-run effect is also consistent with the neoclassical growth model when the accumulation of capital is slow.

The role of changes in capital-labor ratios in the above discussion also suggests that we should expect less negative (or more positive) effects on income per capita in economies that have higher investment rates. We investigate this by estimating models that allow for interactions between life expectancy and initial GDP per capita or initial investment rates (for which the data are less reliable), and find some support for this hypothesis.

Our findings do not imply that improved health has not been a great benefit to lessdeveloped nations during the postwar era. On the contrary, they suggest that global efforts can significantly improve health conditions in less developed countries, and they may be able to do so without large long-run costs in terms of income per capita. The accounting approach of Becker, Philipson and Soares (2005), which incorporates information on longevity and health 
as well as standards of living, would then suggest that these interventions have considerably improved "overall welfare" in these countries. What these interventions have not done, and in fact were not intended to do, is to increase output per capita in these countries.

Furthermore, our results, though suggestive, may not directly apply to the present date because of the different nature of diseases now prevalent in poor countries, in particular, because of HIV/AIDS. Many of the diseases brought under greater control during the international epidemiological transition were primarily killers of children. ${ }^{7}$ In contrast, arguably the most serious health problem in the poorest parts of the world today, HIV/AIDS, affects those at the peak of their labor productivity. Preventing HIV/AIDS could conceivably have different effects from those we estimate here.

It is also important to note that the micro estimates have established beyond reasonable doubt that improved health leads to better individual economic outcomes. ${ }^{8}$ Nevertheless, these estimates do not directly answer the question of how important differences in disease environments and health conditions are in accounting for cross-country income disparities, and are difficult to compare with our results, because they do not incorporate general equilibrium effects (in addition, there still remains a great deal of uncertainty about the precise size of the relevant effects). The most important general equilibrium effect arises because of diminishing returns to effective units of labor (for example, because land and/or physical capital are supplied inelastically). In the presence of such diminishing returns, micro estimates will exaggerate the aggregate productivity benefits from improved health, especially when health improvements are accompanied by population increases. This may be an important concern since existing estimates of production functions, theory and also our our results suggest that there are indeed diminishing returns to labor. ${ }^{9}$

Our paper is most closely related to two recent contributions, Weil (2005) and Young (2005). Weil calibrates the effects of health using a range of micro estimates, and finds that

\footnotetext{
${ }^{7}$ The exception is tuberculosis. The age profile of deaths from tuberculosis pre-1940 was closer to that of AIDS today - with a heavy burden on young adults. The greatest impact of the remaining diseases were on children, but not necessarily on infants (e.g., endemic malaria typically has highest fatality rates for children between ages 1 and 5). Our analysis of the (somewhat less reliable) data on infant mortality shows no evidence of a differential effect of the international epidemiological transition on infant mortality or survival rates (these results are not reported to save space).

${ }^{8}$ See Strauss and Thomas (1998) for an excellent survey of the research until the late 1990s. For some of the more recent research, see Behrman and Rosenzweig (2004), Bleakley (2002, 2004), Miguel and Kremer (2004), and Schultz (2002).

${ }^{9}$ Another general equilibrium effect arises when healthier individuals have higher earnings partly because they are successful in competing against less healthy individuals in the labor market (for example, for scarce high-paying jobs); when such competition effects are present, all individuals becoming healthier would have smaller effects than those implied by the micro estimates. See Persico, Postlewaite and Silverman (2004) for evidence suggesting that the major effect of height on economic outcomes may be through a "competitive advantage" in adolescence.
} 
these effects could be quite important in the aggregate (see also Bloom and Canning, 2005). ${ }^{10}$ The major difference between Weil's approach and ours is that the conceptual exercise in his paper is concerned with the effects of improved health holding population constant. In contrast, our estimates look at the general equilibrium effects of improved health from the most important health transition of the 20th century, which takes the form of both improved health and increased life expectancy (and thus population). Young evaluates the effect of the recent HIV/AIDS epidemic in Africa. Using micro estimates and calibration of the neoclassical growth model, he shows that the decline in population resulting from HIV/AIDS may increase income per capita despite significant disruptions and human suffering caused by the disease. ${ }^{11}$

In addition, our work is related to the literature on the demographic transition both in the West and in the rest of the world, including the seminal contribution of McKeown (1976) and studies by Arriaga and Davis (1969), Preston (1975a, 1980), Caldwell (1986), Kelley (1988), Fogel $(1986,2004)$, and Deaton $(2003,2004)$. More recent work by Cutler and Miller (2005) finds that the introduction of clean water accounts for about half of the decline in US mortality in the early 20th century (see also Cutler and Miller, 2006).

The rest of the paper is organized as follows. In the next section, we present a simple model to illustrate the factors that determine the effect of increased life expectancy on economic growth. Section 3 describes the health interventions and the data on disease mortality rates and life expectancy that we constructed from a variety of primary sources. Section 4 presents our estimating framework and the ordinary least square (OLS) relationship between life expectancy and a range of outcomes. Section 5 discusses the construction of our instrument and shows the first-stage relationships, robustness checks, falsification exercises, and other supporting evidence. Section 6 presents the main results. Section 7 presents a number of robustness checks and additional results, and Section 8 concludes. Appendices A and B provide information on data sources, data construction and the diseases used in this study. Appendix C, which provides further details and some additional results, is available upon request.

\section{Motivating Theory}

To frame the empirical analysis, we first derive the medium-run and long-run implications of increased life expectancy in the closed-economy neoclassical (Solow) growth model. All labor and land are supplied inelastically. We represent all of health in terms of life expectancy. ${ }^{12}$

\footnotetext{
${ }^{10}$ Weil's baseline estimate uses the return to the age of menarche from Knaul's (2000) work on Mexico as a general indicator of "overall return to health". Using Behrman and Rosenzweig's (2004) estimates from returns to birthweight differences in monozygotic twins, he finds smaller effects.

${ }^{11}$ For more pessimistic views on the economic consequences of HIV/AIDS, see Arndt and Lewis (2000), Bell, Devarajan, and Gersbach (2003) and Kalemli-Ozcan (2006).

${ }^{12}$ Life expectancy here and throughout the paper is interpreted as a proxy (index) for the overall health of the population. In practice, the decline in mortality from infectious disease and the corresponding increase
} 
Economy $i$ has the constant returns to scale aggregate production function

$$
Y_{i t}=\left(A_{i t} H_{i t}\right)^{\alpha} K_{i t}^{\beta} L_{i t}^{1-\alpha-\beta} \text {, }
$$

where $\alpha+\beta \leq 1, K_{i t}$ denotes capital, $L_{i t}$ denotes the supply of land, and $H_{i t}$ is the effective units of labor given by

$$
H_{i t}=h_{i t} N_{i t},
$$

where $N_{i t}$ is total population (and hence employment), while $h_{i t}$ is human capital per person.

Without loss of any generality, we normalize $L_{i t}=L_{i}=1$ for all $i$ and $t$. Let us also first assume that $A_{i t}=A_{i}$ for all $i$ and $t$. Capital depreciates at the rate $\delta$ and the savings/investment rate of country $i$ is constant and equal to $s_{i}$, which implies:

$$
K_{i t+1}=s_{i} Y_{i t}+(1-\delta) K_{i t}
$$

Suppose that there exists $\bar{t}<\infty$ such that for all $t \geq \bar{t}$, human capital per person and population are constant, i.e.,

$$
h_{i t}=h_{i} \text { and } N_{i t}=N_{i} \text { for all } t \geq \bar{t}
$$

This implies that there exists a steady state, with $K_{i t}=K_{i}$, satisfying

$$
K_{i}=\frac{s_{i}}{\delta} Y_{i}
$$

Substituting into (1) and taking logs we obtain a simple relationship between income per capita, the savings rate, human capital, technology, and population:

$$
\begin{aligned}
y_{i} & \equiv \log \left(\frac{Y_{i}}{N_{i}}\right) \\
& =\frac{\alpha}{1-\beta} \log A_{i}+\frac{\alpha}{1-\beta} \log h_{i}+\frac{\beta}{1-\beta} \log s_{i}-\frac{\beta}{1-\beta} \log \delta-\frac{1-\alpha-\beta}{1-\beta} \log N_{i} .
\end{aligned}
$$

This equation shows that income per capita is affected positively by technology, $A_{i}$, human capital, $h_{i}$, and the investment rate, $s_{i}$, and negatively by population, $N_{i}$.

For industrialized economies where land plays a small role in production (because only a small fraction of output is produced in agriculture), we can reasonably presume $1-\alpha-\beta \simeq 0$

in life expectancy resulting from the international epidemiological transition have been closely associated with increased overall health and reduced morbidity (in particular, fewer incidences of illness from infectious disease, including less incapacity from tuberculosis, malaria, pneumonia, and lower incidence of illness in childhood). For example, before 1958 there were 817,000 cases of malaria in Venezuela, but after DDT spraying and other eradication efforts, there were only 800 cases. In Taiwan, there were about 1 million cases of malaria in 1954; a similar anti-malaria campaign was so effective that by 1969 there were only 9 cases. Most of these cases of malaria in both countries were associated with sickness and morbidity, not necessarily mortality (Lancaster, 1990, Chapter 15). See also Riley (1993 and 2001) on the relationship between mortality and health in the 19th-century Britain. 
and population drops out of equation (2). Nevertheless, for many less-developed countries, where agriculture is still important, we should expect $1-\alpha-\beta>0$ and the direct effect of an increase in population may be to reduce income per capita even in the steady state (i.e., even once the capital stock has adjusted to the increase in population). ${ }^{13}$

Greater life expectancy will first lead to greater population (both directly and also potentially indirectly by increasing total births), so we posit:

$$
N_{i t}=\bar{N}_{i} X_{i t}^{\lambda}
$$

where $X_{i t}$ is life expectancy in country $i$ at time $t$. Better health and longer life spans may also increase productivity through a variety of channels, including more rapid human capital accumulation or direct positive effects on (total factor) productivity. ${ }^{14}$ To capture the beneficial effects of these variables on productivity emphasized in the literature, let us assume the following isoelastic relationships:

$$
A_{i t}=\bar{A}_{i} X_{i t}^{\gamma} \text { and } h_{i t}=\bar{h}_{i} X_{i t}^{\eta}
$$

where $\bar{A}_{i}$ and $\bar{h}_{i}$ are some baseline differences across countries.

To focus on long run (steady-state) relationships, suppose that $X_{i t}=X_{i}$ (at least for $t \geq \bar{t}$ for some $\bar{t}<\infty)$, so that there exists a steady state relationship:

$$
\begin{aligned}
y_{i}= & \frac{\alpha}{1-\beta} \log \bar{A}_{i}+\frac{\alpha}{1-\beta} \log \bar{h}_{i}+\frac{\beta}{1-\beta} \log s_{i}-\frac{\beta}{1-\beta} \log \delta \\
& -\frac{1-\alpha-\beta}{1-\beta} \log \bar{N}_{i}+\frac{1}{1-\beta}(\alpha(\gamma+\eta)-(1-\alpha-\beta) \lambda) x_{i}
\end{aligned}
$$

where $x_{i} \equiv \log X_{i}$ is $\log$ life expectancy and recall that $y_{i} \equiv \log \left(Y_{i} / N_{i}\right)$.

An increase in life expectancy therefore leads to a significant increase in long-run income per capita when there are limited diminishing returns (i.e., $1-\alpha-\beta$ is small) and when life expectancy creates a substantial externality on technology (high $\gamma$ ) and/or encourages significant increases in human capital (high $\eta$ ). On the contrary, when $\gamma$ and $\eta$ are small and $1-\alpha-\beta$ is large, an increase in life expectancy can reduce income per capita even in the steady state.

\footnotetext{
${ }^{13}$ See Galor and Weil (2000), Hansen and Prescott (2002), and Galor (2005) for models in which at different stages of development the relationship between population and income may change because of a change in the composition of output or technology. In these models, during an early Malthusian phase, land plays an important role as a factor of production and there are strong diminishing returns to capital. Later in the development process, the role of land diminishes, allowing per capita income growth. Hansen and Prescott (2002), for example, assume a Cobb-Douglas production function during the Malthusian phase with a share of land equal to 0.3 .

${ }^{14}$ On the potential effects of life expectancy and health on productivity, see Bloom and Sachs (1998). On their effects on human capital accumulation, see, among others, Kalemli-Ozcan, Ryder, and Weil (2000), KalemliOzcan (2002) or Soares (2005), which point out that when people live longer, they will have greater incentives to invest in human capital.
} 
Equation (5) applies to the "long run" once the capital stock has adjusted to the increase in population. It is also interesting to look at what happens to output in the "medium run" where the capital stock is constant (or before it has fully adjusted). This medium-run scenario would be particularly relevant to countries that have low savings rates and can only attract limited foreign capital. To illustrate this point, consider the extreme case where the capital stock is fixed at some value $\bar{K}_{i}$. Then:

$$
\frac{Y_{i}}{N_{i}}=\bar{K}_{i}^{\beta}\left(A_{i} h_{i}\right)^{\alpha} N_{i}^{-(1-\alpha)}
$$

or substituting for (4) and (3), we have:

$$
\begin{aligned}
y_{i} \equiv & \beta \log \bar{K}_{i}+\alpha \log \bar{A}_{i}+\alpha \log \bar{h}_{i}+ \\
& -(1-\alpha) \log \bar{N}_{i}+(\alpha(\gamma+\eta)-(1-\alpha) \lambda) x_{i} .
\end{aligned}
$$

Comparing this equation to equation (5), we see that the medium-run effect of an increase in life expectancy is more negative (or less positive). This is intuitive: the response to an increase in $N_{i}$ before the capital stock adjusts to its new steady-state level will be a reduction in the capital-labor ratio, further reducing income per capita.

Our empirical strategy below is to estimate equations similar to (5) and (6), and compare the estimates to the parameters in these equations.

It is also evident that how quickly an economy approaches the long-run equilibrium depends on its savings and investment rate. Therefore, this framework also suggests that we should investigate the impact of the interaction between life expectancy and the investment rate on the evolution of income per capita.

\section{Background and Data}

\subsection{International Epidemiological Transition}

Early improvements in public health began in Western Europe, the United States and a few other places from the mid-nineteenth century. ${ }^{15}$ Initially progress was through empirically observing what worked, but soon came major breakthroughs connected with the germ theory of disease. By 1900, tropical medicine had also made impressive progress, most notably with Ronald Ross's demonstration that mosquitoes transmitted malaria and with practical advances against yellow fever in the Caribbean.

Nevertheless, through 1940 most of the progress in improving mortality was confined to relatively rich countries, with some - but more limited - impact in Southern and Eastern Eu-

\footnotetext{
${ }^{15}$ Cutler, Deaton, Lleras-Murray (2006, pp. 11-12) also point out that new drugs, primarily antibiotics and sulphonamide drugs, had an important impact on US mortality between the 1930s and 1960.
} 
rope. In most of the Americas, Africa, and Asia, there were even more limited improvements. ${ }^{16}$ In part, this was because there were few effective drugs against major killers, so most of the measures were relatively expensive public works (e.g., to drain swamps). Colonial authorities showed little enthusiasm for such expenditure.

The situation changed dramatically from around 1940 mainly because of four factors. First, there was a wave of global drug innovations. Many of these products offered cures effective against major killers in developing countries. The most important was the discovery and subsequent mass production of penicillin, which provided an effective treatment against a range of bacterial infections (National Academy of Sciences, 1970, Easterlin, 1999). Penicillin, which was only used in small quantities even in the most developed countries through the mid1940s (Conybeare, 1948, p. 66), became widely available by the early 1950s (see, e.g., Valentine and Shooter, 1954). ${ }^{17}$ Further antibiotic development quickly followed, most notably with the discovery of streptomycin, which was effective against tuberculosis. Between 1940 and 1950, the major bacterial killers became treatable and, in most cases, curable. Diseases that could now be treated, for most people without serious side effects, included pneumonia, dysentery, cholera, and venereal diseases. Antibiotics also reduced deaths indirectly caused by (and attributed to) viruses, such as influenza, which often kill by weakening the immune system and allowing secondary bacterial infections to develop. Also important during the same period was the development of new vaccines, for example, against yellow fever. ${ }^{18}$

The second reason for the dramatic improvement in health was the discovery of DDT (Dichlorodiphenyl trichloroethylene), which allowed a major breakthrough in attempts to control one of the major killers of children in less-developed regions of the world, malaria. ${ }^{19}$ Desowitz describes the impact of DDT as follows:

\footnotetext{
${ }^{16}$ During the 1920s and 1930s, there were measures to reduce mortality from smallpox and cholera in Indonesia, smallpox and plague in the Philippines, malaria in India, malaria and respiratory and diarrheal diseases in the British Guyana (see, for example, Preston 1980, Mandle 1970). Gwatkin (1980, p. 616) states: "But such increases [in life expectancy] were modest compared with those that came later, for soon after World War II annual gains in life expectancy averaging over a year were recorded for periods of up to a decade in such diverse places as Taiwan, Malaysia, Sri Lanka, Mauritius, Jamaica, and Mexico".

${ }^{17}$ Fleming isolated penicillin in the 1930 s but could not produce it in any significant quantity; Florey and Chain made the breakthroughs essential for using penicillin as a drug and they shared the Nobel prize with Fleming in 1945 (see, e.g., Chain, 1980). The first large-scale use of penicillin was in 1943, by Allied armies in North Africa. Andrew Moyer's patent in 1948 is often regarded as a major step in its mass production. The invention of penicillin led to a wave of discovery of other antibiotics, including streptomycin, chloromycetin, aureomycin, and terramycin (The National Academy, 1970, p. 147). Waksman discovered streptomycin in 1944 and was awarded the Nobel Prize in 1952 (see, Keers, 1978, for details and also on the importance of streptomycin).

${ }^{18}$ The yellow fever vaccine was invented by Max Theiler in 1930 and became widely available in the 1940s. Theiler was awarded a Nobel Prize in 1951. A great deal more vaccine invention followed in the 1950s and 1960s (e.g., against small pox and measles), but antibiotics already provided usually effective treatment against those diseases.

${ }^{19}$ DDT was first synthesized in 1874 , but the discovery of its insecticide properties was much later-in 1939 , by Paul H. Müller; he received a patent for the insecticide in 1940, and was awarded a Nobel Prize in 1948 (Alilio et al, 2004, p. 270).
} 
"There was nothing quite like [DDT] before and has been nothing quite like it since. Here was a chemical that could be sprayed on the walls of a house and for up to six months later any insect that alighted or rested on that wall would die. It was virtually without toxicity to humans. And, for the icing on the chemical cake, it was dirt-cheap to manufacture" (1991, pp. 62-63).

Aggressive use of inexpensive DDT led to the rapid eradication of malaria in Taiwan, much of the Caribbean, the Balkans, parts of northern Africa, northern Australia, large parts of South Pacific, and all but eradicated malaria in Sri Lanka and India (see, e.g., Davis, 1956).

The third pillar of the improvements in public health was the establishment of the World Health Organization (WHO), which greatly facilitated the spread of medical and public health technology to poorer countries. ${ }^{20}$ From the 1950s, the WHO, together with other UN-related bodies, most significantly, UNICEF, was the driving force behind the public health (e.g., antimalaria campaigns) and immunization drives (e.g., against smallpox). ${ }^{21}$ The US military also played a significant role in developing treatments for diseases like cholera and spreading the use of DDT and penicillin. ${ }^{22}$

The fourth factor was a change in international values. As Preston (1975a) emphasizes, after the 1930s:
"Universal values assured that health breakthroughs in any country would spread rapidly
to all others where the means for implementation existed" (p. 243).

The consequence of the combination of these four factors was a dramatic improvement in life expectancy in much of the world, especially in the lesser developed parts of the globe, starting in the 1940s. Most of the key changes were available in almost all countries by 1950 . As a result, by the late 1940s and early 1950s, there were significant improvements in health conditions and life expectancy in Central America, South Asia, and parts of Eastern and Southern Europe compared to richer countries. ${ }^{23}$

\footnotetext{
${ }^{20}$ It is notable that Brazil and China, both poor countries at the time, took the initiative in pushing for the formation of the WHO (WHO, 1998). A central goal of the organization was to diffuse medical practices and technology to poorer countries. Between the world wars, the League of Nations was responsible for international disease interventions and worked with other European organizations, for example, against typhus in Eastern Europe (see also Office International d'Hygiene Publique, 1933). However, in contrast with the WHO, the League of Nations showed less interest in and had limited resources for combating diseases in less-developed countries, and focused on monitoring epidemics that might spread to the West.

${ }^{21}$ Lee et al (1996) report: "[Founded in 1946]... Unicef was given the task of utilising its resources 'for child health purposes generally'. When the WHO came on to the scene two years later it was accepted that coordination on health matters was needed. This led to the creation of the WHO/Unicef joint committee on health policy, with the WHO, importantly, designated as the lead health organisation."

${ }^{22}$ Captain Phillips of the U.S. Navy was involved in developing intravenous rehydration methods in Cairo after 1946 and Taipei after 1955 (Savarino, 2002); he was also the first to try oral glucose saline on two cholera patients (Bhattacharya, 1994).

${ }^{23}$ Davis (1956) was probably the first to write about this in the economics literature. He stressed that "these
} 


\subsection{Coding Diseases}

Central to our empirical strategy is to construct cross-country mortality rates for various diseases before the 1940s. For this purpose, we have collected comparable data on 15 of the most important infectious diseases across a wide range of countries. In all cases, the primary data source is national health statistics, as collected and republished by the League of Nations (until 1940) and the World Health Organization and the United Nations (after 1945). We have tried several different ways of constructing these data, all of which produce similar results.

We confirm the validity of these numbers using the qualitative and quantitative evidence in Lancaster (1990, especially, Chapter 48), the maps and discussion of Cliff, Haggett, and Smallman-Raynor (2004) and the maps of disease incidence published by the American Geographical Society (1951a, b, c, and d) immediately after World War II. Appendix A provides details on sources and construction. Further details are contained in Appendix C. Information on the etiology and epidemiology of each disease is obtained from the comprehensive recent surveys in Kiple (1993) and other sources (see Appendix B). To the extent possible, we have also checked our data against those reported in Preston and Nelson (1974).

The other building block for our approach is global intervention dates for each specific disease, that is, dates of significant events potentially reducing mortality around the world from the disease in question. These events are described below (and in Appendix B) and the relevant dates were obtained from WHO Epidemiological Reports, as well as National Academy of Sciences (1970), Preston (1975a), Kiple (1993), Easterlin (1999), and Hoff and Smith (2000).

The 15 diseases we focus on are tuberculosis, malaria, pneumonia, influenza, cholera, typhoid, smallpox, whooping cough, measles, diphtheria, scarlet fever, yellow fever, plague, typhus fever, and dysentery. The most important killers in this list are tuberculosis, malaria, and pneumonia, which we discuss in this section. Information about the remaining diseases is summarized in Appendix B.

Tuberculosis was probably the largest single cause of death around the world in 1940 . It is primarily caused by Mycobacterium tuberculosis, transmitted through the air. Vaccination had been available from the 1920s, but the breakthrough cure was the 1944 invention of streptomycin. $^{24}$ The drug spread quickly and has remained important. Following the above discussion of the invention and introduction of penicillin and streptomycin, we code the intervention against tuberculosis in the 1940s.

areas do not need to become economically developed to reduce their death rates drastically" (p. 305) and that this pattern in the relatively poor parts of the world had no precedent in richer countries. See Stolnitz (1955) and Preston (1975a) for early discussions of this large decline in mortality in the demography literature.

${ }^{24}$ Previously tuberculosis could be treated by surgery, but even in the UK resources for this were limited and not available to many patients (Conybeare, 1948, p. 61). One discussant of Conybeare (1948) made the point, based on data from the UK's Statisical Reviews, that comparing 1939 with 1931-35, "in the general population tuberculosis had not recently been a decreasing risk at all." This was on the eve of the dramatic impact of streptomycin (Keers, 1978). 
Malaria is caused by four types of parasites, transmitted by the bite of an infected female Anopheles mosquito. Control of mosquito vectors had been underway since the late nineteenth century, but became much more effective with the discovery that DDT was an effective insecticide (see Expert Committee on Malaria, 1947, pp. 26-28). The use of DDT became widespread in the late 1940s (particularly following a successful demonstration in Greece) and was intensified following the 1955-57 WHO decision to campaign systematically to eradicate malaria (see Bradley, 1992, WHO, 2004). ${ }^{25}$ In our baseline instrument, the intervention against malaria is taken to be the extensive use of DDT during the 1940s (chloroquine was also invented during the 1940s and quickly replaced mepacrine as the antimalarial drug of choice, until chloroquineresistant parasites developed). In our alternative instrument, we code it as taking place in the 1950s because of the WHO campaign to eradicate malaria.

Pneumonia is caused by a variety of infectious agents and toxins, including various bacterial and viral pathogens. Frequently, it appears as a secondary bacterial infection that causes death. The primary causes are often tuberculosis, influenza, and more recently AIDS. Antibiotics, for example penicillin, proved highly effective against bacterial pneumonia in the 1940s (although by now resistant strains have developed). ${ }^{26}$ Also, from the 1940 s there were partially effective vaccines against pneumonia. In our baseline instrument, the intervention against pneumonia takes place in the 1940s.

\subsection{Life Expectancy, Population, and GDP Data}

Data on life expectancy at birth, total births, and infant mortality are obtained from historical UN data (various issues of the Demographic Yearbook) and League of Nations reports. ${ }^{27}$

Since we need population and GDP data before World War II, we use the data compiled by Maddison (2003). Postwar demographic data are from UN data sources (see Appendix A).

Our base sample consists of 59 countries, from Western Europe, Oceania, the Americas, and Asia. East European and Russia are excluded from the base sample (because of concerns about the quality of their GDP data), but are included in robustness checks. ${ }^{28}$ Because of the

\footnotetext{
${ }^{25}$ While it is generally accepted that DDT played a major role in the dramatic declines in malaria prevalence, there is some controversy in the demography literature about whether broader public health interventions of the 1940s were also essential (see, e.g., Langford, 1996).

Following the WHO campaign, it became apparent that some mosquitos could develop resistance to insecticides. However, the view from the WHO was that spraying with DDT remained effective, if used properly. E. J. Pampana (1954), chief of the Malaria Section of the WHO, called for a change in strategy, but still centered around residual-insecticide spraying.

${ }^{26}$ Sulphonamides were also used against pneumonia, but were soon superceded by penicillin (Conybeare 1948, p. 65, National Academy of Sciences, 1970, pp. 144-146). In any case, these drugs were not widely available, even in the UK, until the very end of the 1930s (Conybeare, 1948).

${ }^{27}$ All of these data are rough estimates. For example, life expectancy is calculated by combining data on agespecific death rates at a point in time, but often approximations are made using standard life tables. Preston (1975a) previously used some of the pre-war data for the 1930s. See Appendices A and C for more details.

${ }^{28}$ The only communist country in our sample is China. Excluding China has no effect on any of our results.
} 
poorer quality of the available data, Africa is not in our baseline sample, but results including Africa are reported in Section 7 and are very similar to the baseline estimates.

We focus on the period 1940 to 1980 as our base sample, with observations for 1940, 1950, 1960, 1970 and 1980. We look at pre-1940 changes in our falsification exercises. Post-1980 is excluded because the emergence of AIDS appears to have led to a divergence in life expectancy between some poor countries and the richer nations. ${ }^{29}$ Nevertheless, we report additional robustness checks by extending our sample through 2000 (particularly as this allows us to look at longer potential lags in the impact of health on economic outcomes).

Table 1 provides basic descriptive statistics on the key variables (see also the raw data in Appendix Table A1). The first column is for the whole world, while the second column refers to our base sample. A comparison of these two columns indicates that, despite the absence of Africa from our base sample, averages of life expectancy, population, GDP and GDP per capita are similar between the whole world and our sample. The next three columns show numbers separately for the three groups of countries used in Figures 1 and 2-initially rich, middleincome, and poor countries (measured in terms of GDP per capita in 1940). These columns show the same patterns as Figures 1 and 2: there is a large convergence in life expectancy among the three groups of countries between 1940 and 1980, but no convergence in GDP per capita. The three columns also give information on predicted mortality, which will be our instrument for life expectancy.

\section{Estimation Framework and OLS Estimates}

\subsection{Estimation Framework}

Our empirical approach is to estimate equations similar to equations (5) and (6) above. We interpret these equations as providing the conditional expectation function for our variables of interest. Thus, adding an error term, our estimating equation becomes

$$
y_{i t+k}=\pi x_{i t}+\zeta_{i}+\mu_{t}+\mathbf{Z}_{i t}^{\prime} \boldsymbol{\beta}+\varepsilon_{i t+k}
$$

where $y$ is $\log$ income per capita, $\zeta_{i}$ is a fixed effect capturing potential technology differences and other time-invariant omitted effects, $\mu_{t}$ incorporates time-varying factors common across all countries, $\mathbf{Z}$ is a vector of other controls, and $x$ is $\log$ life expectancy at birth as defined above. The coefficient $\pi$ is the parameter of interest. ${ }^{30}$ Including a full set of country fixed

\footnotetext{
${ }^{29}$ In addition, malaria reappeared in the 1970s and 1980s because of reduced international efforts, the international ban on the use of DDT, and the emergence of insecticide resistant mosquitoes and drug-resistant strains of malaria. Tuberculosis has also returned as a secondary infection associated with AIDS.

${ }^{30}$ Given equations (5) and (6) above and the regression models used in the existing literature, we use log life expectancy on the right hand side throughout. The results are very similar if we use the level of life expectancy instead (results available upon request).
} 
effects, the $\zeta_{i}$ 's, is important, since many country-specific factors will simultaneously affect health and economic outcomes; fixed effects at least remove the time-invariant components of these factors. ${ }^{31}$

Notice also that in equation (7) the left-hand side variable has timing potentially different from the right-hand side variables. This allows us to investigate potential differences between medium-run and long-run effects. In particular, for $k>0$, this equation would estimate the effect of life expectancy differences at time $t$ on future (date $t+k$ ) income per capita differences.

Before investigating the effect of life expectancy on income per capita, we look at its effects on population, total births, and total income. The equations for these outcome variables are identical to (7), with the only difference being the dependent variable.

The most serious challenges in estimating the causal effect of life expectancy on income per capita or population are potential omitted variable bias and reverse causality. In particular, in equation (7), typically the (population) covariance term $\operatorname{Cov}\left(x_{i t}, \varepsilon_{i t+k}\right)$ is not equal to 0 , because even conditional on fixed effects, health could be endogenous to economics.

Our empirical strategy is to exploit the potentially-exogenous source of variation in life expectancy because of global interventions. More specifically, our first-stage relationship is

$$
x_{i t}=\psi M_{i t}^{I}+\tilde{\zeta}_{i}+\tilde{\mu}_{t}+\mathbf{Z}_{i t}^{\prime} \tilde{\boldsymbol{\beta}}+u_{i t}
$$

where $M_{i t}^{I}$ is predicted mortality, which will be discussed below. The key exclusion restriction is $\operatorname{Cov}\left(M_{i t}^{I}, \varepsilon_{i t+k}\right)=0$.

Notice that equation (7) does not allow for mean-reverting dynamics in the outcome variables. A more general model is:

$$
y_{i t+k}=\rho y_{i t-1}+\pi x_{i t}+\zeta_{i}+\mu_{t}+\mathbf{Z}_{i t}^{\prime} \boldsymbol{\beta}+\varepsilon_{i t+k}^{m} .
$$

Though conceptually attractive, this equation is considerably harder to estimate because of the simultaneous presence of fixed effects and a lagged dependent variable (see, e.g., Wooldridge, 2002, Chapter 11). This, and the fact that even if the data generating process were given

${ }^{31}$ Many authors estimate growth regressions of the following form:

$$
g_{i t}=\tilde{\alpha} y_{i t-1}+\pi x_{i t-1}+\mathbf{Z}_{i t}^{\prime} \boldsymbol{\beta}+\varepsilon_{i t}
$$

where $y_{i t-1}$ is log income per capita, $g_{i t}$ is growth between $t-1$ and $t$, and $x_{i t-1} \log$ life expectancy at birth or some other measure of health. Since $g_{i t} \simeq \Delta y_{i t}$, this is equivalent to

$$
y_{i t}=(1+\tilde{\alpha}) y_{i t-1}+\pi x_{i t-1}+\mathbf{Z}_{i t}^{\prime} \boldsymbol{\beta}+\varepsilon_{i t}
$$

This way of rewriting the above equation highlights that growth regressions are analogous to the levels regressions like (7) or (9). But since typical growth regressions do not include country fixed effects, the correlation of $x_{i t-1}$ with other potential determinants of income per capita is likely to lead to biased estimates. Our approach partially circumvents this problem by including country fixed effects and thus removing the time-invariant component of such correlation. In Section 7, we also estimate equation (9), which by the same argument here, is equivalent to a growth regression with fixed effects. 
by (9), instrumental-variables estimate of (7) would lead to consistent estimates of $\pi$ as long as $\operatorname{Cov}\left(M_{i t}^{I}, \varepsilon_{i t+k}\right)=0$, motivates our initial focus on (7). Nevertheless, for completeness, we report estimates from (9) in subsection 7.2.

Finally, we also estimate a more demanding specification of the form:

$$
y_{i t+k}=\pi x_{i t}+\zeta_{i}+\mu_{t}+\sum_{t=1940}^{1980} \lambda_{t} y_{i, 1930}+\mathbf{Z}_{i t}^{\prime} \boldsymbol{\beta}+\varepsilon_{i t+k}^{d},
$$

where $y_{i, 1930}$ denotes the 1930 ("initial") value of the dependent variable (e.g., log population, $\log$ GDP, etc.), and the summation term represents a full set of interaction between this initial value and time dummies. This specification controls flexibly for mean-reversion, and is also useful as a check against differential trends in the dependent variable.

\subsection{OLS Estimates}

Tables 2 and 3 report OLS regressions for the main variables of interest. These results are useful both to show the (conditional) correlations in the data and for comparison to the instrumental variables (IV) estimates reported below. All regressions in these tables and throughout the paper include a full set of year dummies and country fixed effects, so all estimates exploit only the within-country variation. Moreover, throughout, all standard errors are robust and allow for arbitrary serial correlation of the residual at the country level (i.e., they correspond to the fully robust variance-covariance matrix, see Wooldridge, 2002, p. 275).

Table 2 focuses on log population (Panels A and B) and on log number of births (Panels C and D). We report results in pairs; first, we estimate versions of equation (7) using our baseline panel, which consists of observations at 10 year intervals between the indicated dates (19401980, 1930-1980, etc.). Second, we estimate "long-difference" models, essentially the same equation using only two data points - at the beginning and the end of the sample period. The first approach uses all the available data, while the second approach exploits only the longerrun changes. The latter may be useful both because it may be less vulnerable to problems caused by serial correlation in the error term and also because it enables us to be agnostic on how quickly life expectancy should affect the outcome variables. Also for comparison with previous work, we report results for the period 1960 to 2000.

A number of features are notable in Table 2. First, the 1960-2000 sample gives very similar results to our baseline sample of 1940-1980. For example, for the panel between 1960 and 2000, the estimate of the effect of log life expectancy on log population is between 1.46 and 1.69 (standard errors of, respectively, 0.29 and 0.43 ), whereas the estimate for our base sample of 1940-1980 is 1.21 (standard error $=0.20$ ). Second, excluding the (initially) richest countries from the sample (column 4) makes little difference; now the estimate is 1.24 (standard error $=0.28$ ). Third, in columns 5-10, we look at the effect of life expectancy on future levels 
of population. In terms of equation (7), this corresponds to the case where $k>0$. These results are broadly similar to the contemporaneous results. In all cases, a 1 percent increase in life expectancy is associated with approximately a 1-1.7 percent increase in population. The estimates using the long-differences in Panel B are slightly larger (and slightly less precise), but broadly similar.

To interpret the effect of (log) life expectancy on (log) population, it is useful to consider a simple continuous-time statistical model. Suppose each individual faces a Poisson death rate of $1 / a$. This implies that life expectancy is $a$. Denote the flow of total births as a function of life expectancy by $B(a)$ - a constant birth rate would correspond to $B(a)$ being proportional to $a$. Equating the flow of deaths, $N / a$, with the flow of total births, $B(a)$, gives the steady-state population level as:

$$
\ln N=\ln a+\ln B(a) .
$$

This implies that in a regression of $\log$ population on log life expectancy, when the total number of births remains constant, we should expect an elasticity of 1 . Naturally if there were no change in fertility, there would be an increase in the total number of births because of the increase in population. The elasticity we estimate here suggests that the birth rate did not decline enough to reduce or keep constant the number of births. This is confirmed in Panels $\mathrm{C}$ and $\mathrm{D}$ of Table 2, which show an overall increase in the total number of births in response to the change in life expectancy.

Table 3 presents results that are parallel to those in Table 2, but now the dependent variables are log GDP (Panels A and B) and log GDP per capita (Panels C and D). Again, all regressions have a full set of country and time fixed effects, and we show both panel and long-difference estimates.

Panels A and B in Table 3 indicate a positive relationship between log life expectancy and $\log$ GDP. For example, the results in columns 1-4 indicate an effect of life expectancy on GDP with an elasticity of approximately $0.7-1.7 .^{32}$

Columns 5-10 again look at leads. With the exception of column 6, which corresponds to a 20-year lead, the estimates are similar to those in columns 1-4. Overall, the results in Table 3 suggest the presence of a positive and typically significant effect of life expectancy on total GDP. Nevertheless, as pointed out above, these results do not correspond to the causal effect of life expectancy on total output, and might reflect the fact that life expectancy increases precisely when countries are adopting other measures that increase income, or alternatively,

\footnotetext{
${ }^{32}$ Interestingly, the (conditional) correlation between life expectancy and income per capita in the period 19602000 appears to be twice as large as that during our base sample period (1.70 versus 0.73$)$. This is consistent with the fact that a large part of the variation in life expectancy during our base sample period is exogenous, driven by the international epidemiological transition, so the upward bias in the OLS estimate resulting from reverse causality and common shocks to income per capita and health should have less effect during the 1940-80 period than during 1960-2000.
} 
as emphasized by demographers, it may be that the increase in income raises life expectancy.

While Panels A and B show a positive relationship between life expectancy and total income, the rest of Table 3 suggests that the positive effect on population size outweighs the increase in GDP; the net effect on GDP per capita, though typically not significant, is generally negative. There is no evidence of a positive effect of life expectancy on GDP per capita in Table 3. Nevertheless, since these estimates are not necessarily causal, the true effect of life expectancy on income per capita might be larger or smaller than those shown in Table $3 .^{33}$ The rest of the paper investigates this question.

\section{$5 \quad$ Predicted Mortality and First Stages}

\subsection{The Predicted Mortality Instrument}

Prior to the international epidemiological transition, there was considerable variation in the prevalence of diseases across the world. For example, during the 1940s, while malaria was endemic in parts of South Asia and Central America, it was relatively rare in much of Western Europe and in the Southern Cone of Latin America. We therefore expect variation in the effects of global interventions on life expectancy in different countries depending on the baseline distribution of diseases. For example, DDT should reduce malarial infections and mortality, and increase life expectancy, in Central America and South Asia relative to Western Europe or the Southern Cone of Latin America.

Motivated by this reasoning, our instrument, predicted mortality, is constructed as

$$
M_{i t}^{I}=\sum_{d \in \mathcal{D}}\left(\left(1-\Delta_{d t}\right) M_{d i 40}+\Delta_{d t} M_{d F t}\right)
$$

where $M_{d i t}$ denotes mortality in country $i$ from disease $d$ at time $t, \Delta_{d t}$ is a dummy for intervention for disease $d$ at time $t$ (it is equal to 1 for all dates after the intervention), and $\mathcal{D}$ includes the 15 diseases listed above. It is measured as the number of deaths per 100 individuals per annum. $M_{d i 40}$ refers to the pre-intervention mortality from this disease in the same units, while $M_{d F t}$ is the mortality rate from disease $d$ at the health frontier of the world at time $t$. In our baseline instrument, we take $M_{d F t}$ to be equal to zero. ${ }^{34}$ Predicted mortality, $M_{i t}^{I}$, thus uses a country's pre-intervention (1940) mortality rate from the 15 diseases until there is a

\footnotetext{
${ }^{33}$ If, instead, we estimate a version of equation (7) or the growth regression in footnote 31 without country dummies, we obtain a strong positive association between life expectancy and income per capita or growth as in many previous studies (e.g., Bloom and Sachs, 1998, Gallup and Sachs, 2001), though as noted above this association is not informative about the causal relationship between life expectancy and income per capita or economic growth.

${ }^{34}$ We also calculated an alternative measure of predicted mortality using the average mortality rate from disease $d$ at time $t$ among the richest countries, but since these rates are close to zero, this alternative measure is very similar to our baseline predicted mortality series, and gives identical results.
} 
global intervention, and after the global intervention, the mortality rate from the disease in question declines to the frontier mortality rate.

Equation (12) makes it clear that the only source of variation in predicted mortality comes from the interaction of the baseline distribution of diseases with global interventions (in particular, note that $M_{d i 40}$ applies until the time of global intervention). Whether a country has successfully eradicated a disease or has been quick at adopting international technologies will have no effect on $M_{i t}^{I}$; the dummy $\Delta_{d t}$ turns on for all countries at the same time. This makes our exclusion restriction, that $\operatorname{Cov}\left(M_{i t}^{I}, \varepsilon_{i t+k}\right)=0$, plausible (where recall that $\varepsilon_{i t+k}$ is the error term in the second stage equation, (7)). Since variations in $M_{i t}^{I}$ are unrelated to any actions or economic events in the country, there is no obvious reason for it to be correlated with economic or population shocks in the country in question. The only potential threat to the exclusion restriction would be that the baseline mortality rates, the $M_{d i 40}$ 's, are correlated with future changes in population or income. To show that this is unlikely to be the case, we allow for differential trends by a range of baseline characteristics and also report results from a number of different falsification exercises.

\subsection{Alternative Instruments}

We construct a number of alternative instruments to investigate the robustness of our results. The first alternative is the global mortality instrument,

$$
M_{i t}^{I}=\sum_{d \in \mathcal{D}} \frac{M_{d t}}{M_{d 40}} M_{d i 40},
$$

where $M_{d i 40}$ denotes mortality in country $i$ from disease $d$ in $1940, M_{d t}\left(M_{d 40}\right)$ is global mortality from disease $d$ in year $t$ (1940), calculated as the unweighted average across countries in our sample. The advantage of the global mortality instrument is that it does not use any information on global intervention dates, instead relying on aggregate changes in world-wide disease-specific mortality rates. It is therefore useful in showing that none of our results depend on the coding of intervention dates.

Second, to further investigate the importance of intervention dates, we construct an alternative instrument, which uses different timings of interventions whenever there is any potential doubt about the exact dates. The details of this instrument are discussed in Appendix B.

Finally, we create yet an alternative predicted mortality series using only the three big killers, malaria, tuberculosis and pneumonia (influenza is left out of this list, because our sources do not separate deaths from viral influenza and the timing of the key intervention for influenza is less clear-cut than the other three cases).

We check the robustness of our results using these alternative instruments and in all cases, the results are very close to those with the baseline instrument. 


\subsection{Zeroth-Stage Estimates}

Our approach is predicated on the notion that global interventions reduce mortality from various diseases. Therefore, before documenting the first-stage relationship between our predicted mortality measure and log life expectancy, we show the effect of various global interventions on mortality from specific diseases. In this exercise, in addition to the 15 diseases above, we also use deaths from cancers and malignant tumors as control diseases, since these were not affected by the global interventions.

Panel A of Table 4 estimates the following "zeroth-stage regression":

$$
M_{i d t}=\theta \Delta_{d t}+\mu_{t}+\pi_{d}+\delta_{i}+v_{i t}
$$

The dependent variable is mortality in country $i$ from disease $d$ at time $t$, and the regression includes a full set of time, disease, and country dummies. The coefficient of interest, $\theta$, measures whether there is a decline in mortality from a specific disease associated with an intervention.

Table 4 reports estimates of equation (14). In all cases, as expected, the estimate of $\theta$ is negative and significant. For example, in column $1, \theta$ is estimated to be -46.04 (standard error $=9.40)$, which indicates an average reduction of 46 deaths per 100,000 population per intervention. In column 2, when we add lagged intervention, the coefficient on the intervention dummy is largely unchanged (-43.33), while the lagged intervention itself is insignificant.

More challenging is the specification in column 3, which includes contemporaneous and lead interventions. This specification is useful both as a check for pre-existing trends and for whether the dates of the interventions are coded correctly. Reassuringly, the estimate of the negative coefficient on contemporaneous intervention, $\theta$, is unaffected, while lead intervention has the opposite (positive) sign (perhaps reflecting the lower quality of the pre-1940 data on

individual disease mortality). These results show that mortality from specific diseases around the world fell sharply following the global health interventions.

Columns 4-7 investigate whether one of the main diseases is responsible for the results in columns 1-3, by excluding tuberculosis, pneumonia, malaria, and influenza one at a time. Without tuberculosis or pneumonia, the coefficient estimates are somewhat smaller, but still highly significant (-33.93 and -36.31, with standard errors of 8.66 and 8.99, respectively). Without malaria or influenza, the coefficient estimates are very similar to the baseline.

In Panel B, we look at each disease separately. The estimates in this case show how effective interventions have been in reducing mortality from each specific disease and also give an indication of how important mortality rates from different diseases were. For example, the coefficient of -108.51 for tuberculosis in column 4 and -137.92 for pneumonia in column 5 show the large declines in tuberculosis and pneumonia mortality resulting from the introduction of antibiotics. The estimate of -19.97 in column 6 shows a significant decline in malaria 
mortality, but the lower magnitude of this number indicates that mortality from malaria was less important for our entire sample than mortality from tuberculosis or pneumonia (partly because large areas of the world were not affected by malaria). The declines in mortality from the other diseases are even smaller, but with the exception of influenza and measles (not shown), they are always statistically significant.

\subsection{First-Stage Estimates}

We next turn to the first-stage relationship between life expectancy and predicted mortality. While the zeroth-stage regression in equation (14) is at the disease-country-time level, our first-stage relationship is at the country-time level, since the left-hand side variable is life expectancy (at birth).

Figure 3 shows the first-stage relationship visually. The horizontal axis is the change in predicted mortality between 1940 and 1980, while the vertical axis is the change in log life expectancy during the same time period. We focus on the 1940-1980 period, since 1940 represents a pre-intervention year and 1980 is the end of the sample for most of our specifications. A strong negative relationship is clearly visible in Figure 3. Predicted mortality declined by a large amount in India, the Philippines, Indonesia, and parts of Central America, while remaining largely unchanged in parts of Western Europe, Uruguay, Argentina, Korea, Australia, and New Zealand. Life expectancy, in turn, increases by a large amount in the first group of countries, and much less in the second group.

Figure 4 depicts that the same relationship without the richest countries. It shows that the first-stage relationship is not driven by the comparison of rich countries to middle and low-income countries.

Table 5 shows the first-stage relationship in regression form by estimating equation (8). Country and year dummies are again included, and this set of specifications does not include any covariates. The top panel uses our entire data starting from either 1940 or 1930, while the bottom panel reports the long-difference specifications.

The first column is our baseline specification. It shows an estimate of $\psi$ equal to -0.33 with a standard error of 0.06 , which is significant at less than $1 \% .{ }^{35}$ This estimate implies that an improvement in predicted mortality of 0.43 (per 100 or 430 per 100,000 p.a., which is the mean improvement between 1940 and 1950 in our base sample) leads approximately to a 13 percent increase in life expectancy (mean life expectancy in our sample in 1940 was 49.30, so this is an increase of about 6.5 years, while the actual mean improvement in life expectancy between 1940 and 1950 was 5.3 years). With long differences, the coefficient estimate is -0.44 , which is

\footnotetext{
${ }^{35}$ Note that the t-statistics in the basic first-stage relationships are above 5 , so there is no issue of weak instruments (see, for example, Stock, Wright, and Yogo, 2002). Hence, in the 2SLS regressions below we use the standard Wald confidence intervals.
} 
somewhat larger, but also slightly less precisely estimated (standard error $=0.09$ ).

Results are similar for 1930-1980 in column 2 (and also for 1940-1970 or 1930-1970 - not reported in the table). Column 3 shows analogous results when we include Eastern Europe. Column 4 excludes the initially rich countries and shows a statistically significant (though smaller) estimate of $\psi$ (e.g., -0.23 with a standard error of 0.08 in Panel A).

Our baseline sample consists of an unbalanced panel. Column 5 shows that limiting the sample to a balanced panel makes little difference. The estimate of $\psi$ is now -0.32 (standard error $=0.06)$.

Columns 6-8 investigate the robustness of the first stage to the inclusion of a range of interactions between country-specific variables and time dummies; these specifications are therefore similar to equation (10) above, except that they include interactions with initial values of institutions, log GDP per capita and continent dummies. For example, column 6 allows countries with different institutions (as measured by average constraint on the executive, from the Polity IV dataset, in 1950, 1960, and 1970) to have different changes in life expectancy in every year. This has little effect on the baseline estimates, which are now -0.27 (standard error $=0.07$ ) in Panel A and -0.35 (standard error =0.09) in Panel B. Column 7 includes interactions with initial (1930) log GDP per capita, flexibly allowing for differential trends in life expectancy for countries starting with different levels of prosperity. This also has very little effect on the estimates. Column 8 includes a full set of interactions between continent dummies and life expectancy, to control for the potential differential impact of distinct disease environments on the evolution of life expectancy. Once again, this has very little effect on the estimates, which remain highly significant and very close to the baseline.

Columns 9-12 investigate robustness to alternative instruments. Columns 9 and 10 use the global mortality instrument for the base sample and for the sample including only initially low and middle-income countries. The estimates are slightly larger and more significant. ${ }^{36}$ For example, in Panel A the estimate of $\psi$ is -0.41 (standard error $=0.08$ ). Column 11 uses the alternative timing of global interventions as described in Appendix B, again with very similar estimates. These results show that the exact coding of global interventions and whether we use aggregate trends in disease-specific mortality or information on global interventions have little effect on the first-stage relationship. Finally, column 12 shows very similar results when the instrument uses information from only tuberculosis, malaria and pneumonia.

Overall, the results in Table 5 show a large and robust effect of the predicted mortality instrument on life expectancy. We next investigate the robustness of these results further.

\footnotetext{
${ }^{36}$ The exception is column 10 in Panel B, where the estimate is significant only at $10 \%$.
} 


\subsection{Further Robustness Checks}

Appendix Table C1 investigates the importance of disease composition to see whether a specific disease is responsible for the first-stage relationships shown in Figures 4 and 5 and in Table $5 .{ }^{37}$ Columns 2, 3 and 4 of this table present results dropping data on the three main killers from our predicted mortality measure: tuberculosis, malaria and pneumonia respectively. Dropping tuberculosis or pneumonia strengthens the first stage estimates slightly, while none of the other diseases has a significant impact on the first stage coefficient. We conclude from these results that the first-stage relationship does not reflect the impact of any single disease.

The specifications in Table 5 do not allow for mean reversion in life expectancy, and also assume that it is contemporaneous predicted mortality that affects life expectancy. Failure to correctly specify the mean-reverting dynamics in life expectancy may bias our results. Moreover, in more general specifications we may find that it is lags or leads of predicted mortality that affect life expectancy. In particular, if it is the leads of (future changes in) predicted mortality that affect life expectancy, this would shed doubt on our interpretation of the first-stage relationship. Table 6 investigates these issues. Column 1 repeats our baseline specification (from column 1 of Table 5). Column 2 reports OLS estimates from the following model:

$$
x_{i t}=\nu x_{i t-1}+\psi M_{i t}^{I}+\delta_{i}^{\prime}+\mu_{t}^{\prime}+u_{i t},
$$

which allows lagged log life expectancy to affect current log life expectancy. There is indeed evidence for mean reversion; the coefficient $\nu$ in the top panel is estimated to be 0.44 (standard error $=0.09)$. Nevertheless, the negative relationship between predicted mortality and life expectancy remains. The parameter of interest, $\psi$, is now estimated at -0.18 (standard error $=$ 0.08 ), and implies a long-run impact similar to that in our baseline specification (the long-run impact in this case is $0.18 /(1-0.44) \approx 0.32)$.

Because we have a relatively short panel, OLS estimation of (15) will lead to inconsistent estimates. To deal with this problem, we follow the method of Anderson and Hsiao (1992) in column 3. This involves first-differencing (15), to obtain:

$$
\Delta x_{i t}=\nu \Delta x_{i t-1}+\psi \Delta M_{i t}^{I}+\Delta \mu_{t}^{\prime}+\Delta u_{i t}
$$

where the fixed country effects are removed by differencing. Although this equation cannot be estimated consistently by OLS either, in the absence of serial correlation in the original residual, $u_{i t}$, there will be no second order serial correlation in $\Delta u_{i t}$, so $x_{i t-2}$ will be uncorrelated with $\Delta u_{i t}$ and can be used as instrument for $\Delta x_{i t-1}$ to obtain consistent estimates. Similarly $M_{i t-1}^{I}$ is used as an instrument for $\Delta M_{i t}^{I}$. This procedure leads to very similar results to the OLS estimates. The estimate of $\psi$ is -0.27 (standard error $=0.14$ ).

\footnotetext{
${ }^{37}$ Appendix Tables C1-C4 are included in Appendix $\mathrm{C}$ and are not for publication.
} 
Although the instrumental variable estimator of Anderson and Hsiao (1982) leads to consistent estimates, it is not efficient, since, under the assumption of no serial correlation in $u_{i t}$, not only $x_{i t-2}$, but all earlier lags of $x_{i t}$ in the sample are also uncorrelated with $\Delta u_{i t}$, and can also be used as additional instruments. Arellano and Bond (1991) develop a Generalized Method-of-Moments (GMM) estimator using all of these moment conditions. When all these moment conditions are valid, this GMM estimator is more efficient than Anderson and Hsiao's (1982) estimator. GMM estimation, which we use in column 4, leads to similar but more precisely estimated coefficients. The estimate of $\psi$ in the full sample is now -0.19 (standard error $=0.06)$. Tests for second-order autocorrelation in the residuals, reported at the bottom of the column, show that there is no evidence of additional serial correlation. However, the Hansen J-test shows that the overidentification restrictions are rejected, presumably because different lags of life expectancy lead to different estimates of the mean reversion coefficient. This rejection is not a major concern for our empirical strategy since the exact magnitude of the mean reversion coefficient, $\nu$, is not of direct interest to us. Essentially because the models in (8) and (15) are the first stage in our 2SLS procedure, all we need is for $M_{i t-1}^{I}$ not to have a direct effect on the second-stage outcomes.

Columns 5-7 investigate the effect of lagged and lead mortality. In column 5, contemporaneous and lagged mortality are included together. Not surprisingly, both of these are significant, since, in many countries, global health interventions were implemented gradually over time (recall that an intervention is coded at the time of the major global breakthrough).

The more important challenge for our approach is the inclusion of lead predicted mortality. Since global interventions did not start before 1940, lead mortality should have no effect on life expectancy. Column 6 investigates this by including contemporaneous and lead mortality together. In this case, the estimate of the effect of contemporaneous predicted mortality is -0.33 (standard error $=0.06$ ), while lead mortality is not significant and has the wrong sign. Column 7 includes contemporaneous, lag, and lead predicted mortality together, and in this case both contemporaneous and lag mortality are statistically significant, while lead mortality remains highly insignificant. These results suggest that, consistent with our hypothesis, it was indeed the global interventions of the 1940s onwards that led to the increase in life expectancy in countries previously affected by these diseases.

Finally, columns 8 and 9 shows that controlling for the effect of income per capita has little impact on the relationship between predicted mortality and life expectancy, and column 10 shows very similar to our baseline estimates from the balanced panel of countries. 


\subsection{Pre-Existing Trends and Falsification}

Table 6 already showed that life expectancy responds to contemporaneous changes in predicted mortality and does not respond to future changes. This suggests that our first stage is unlikely to be driven by pre-existing trends. Nevertheless, the exercise in Table 6 uses only data from 1940 onwards. An alternative falsification exercise on pre-existing trends is to look at changes in life expectancy during the pre-period, 1900-1940, and see whether they correlate with future (post-1940) changes in predicted mortality. This is done in Figures 5 through 8 and in Table 7 .

Figure 5 shows the change in log life expectancy 1900-1940 against the change in predicted mortality 1940-1980. There is no evidence of a negative relationship similar to those in Figures 3 and 4 . In fact, there is a slight positive slope (which is statistically insignificant - see Table 7). Figure 6 shows the same relationship without the richest countries, and there is now a somewhat stronger positive relationship (again insignificant-see Table 7). There is thus no evidence of pre-existing trends that could explain our first-stage results.

Figures 7 and 8 substantiate the patterns in Figures 5 and 6 further by showing changes in $\log$ life expectancy just before the international epidemiological transition, between 1930 and 1940 against the predicted mortality instrument. These figures also show no evidence of a significant negative relationship either for the whole sample or for the subsample excluding the initially richest countries. Our measure of predicted mortality explains changes in life expectancy after 1940 but not before 1940.

Table 7 also extends our examination of potential pre-existing trends to the outcome measures, by looking for a potential relationship between our measure of post-1940 predicted mortality and changes in log population, log GDP, and log GDP per capita between 1900 and 1940. ${ }^{38}$ Columns 1 and 2 confirm the positive and insignificant relationship between change in predicted mortality between 1940 and 1980 and change in life expectancy between 1900 and 1940 shown in Figures 5 and 6. Columns 3 and 4 show that there are no differential pre-existing trends in log population between 1900 and 1940 either for the entire sample or for the sample excluding the richest countries. Columns 5-8 show similar results for log GDP and log GDP per capita.

These results therefore indicate that there were no pre-existing trends in life expectancy or in our key outcome variables prior to the international epidemiological transition. ${ }^{39}$ This gives us greater confidence in using predicted mortality as an instrument to investigate the effect of

\footnotetext{
${ }^{38}$ We do not have enough data to do this for total births. Data limitations also make our sample sizes for the other variables smaller for this exercise than for our main regressions.

${ }^{39}$ For a more qualitative confirmation that there was no pre-existing trend, see Carr-Saunders (1936). In this comprehensive review of population trends, there is no hint of the increase in life expectancy and population that was to occur shortly.
} 
life expectancy on a range of economic outcomes.

Finally, we further use Table 7 to show the reduced-form relationships between predicted mortality and some of our outcome variables. Recall that life expectancy is a proxy for overall health of the population, so the reduced-form relationships between predicted mortality and the outcome variables are as informative as the 2SLS estimates reported below. Panel B of Table 7 shows these reduced-form relationships. As already shown, there is a significant negative relationship between life expectancy and predicted mortality in the period 194080. In addition, there is a significant negative relationship between predicted mortality and population during the same period, which indicates an increase in population in previously high-mortality areas resulting from the international epidemiological transition. The other columns show a negative but insignificant relationship between predicted mortality and total GDP, and a positive relationship between predicted mortality and GDP per capita. These results imply that declines in mortality were associated with lower GDP per capita (since total GDP did not increase much and population grew substantially). The 2SLS estimates presented in the next section confirm these reduced-form relationships.

\section{Main Results}

We now present our main results, which are the 2SLS (two-stage least square) estimates of the effect of log life expectancy on six outcome variables: log population, log total births, log GDP, log GDP per capita, log GDP per working age population, and years of schooling.

For each outcome we use two estimation strategies. The first is a full panel with decadal observations between 1940 and 1980, while the second looks only at the long difference using data from 1940 and 1980. The tables have a parallel structure (except for schooling, where data availability makes this impossible). In addition, in each case, we look both for contemporaneous effects and for "longer-run" effects after 10, 20, 30, and 40 years.

\subsection{Population}

Figure 9 shows a strong negative reduced-form relationship between change in log population 1940-80 and the change in predicted mortality over the same period. This pattern, already seen in Panel B of Table 7, implies that countries with a larger decline in predicted mortality experienced a larger increase in log population, i.e., more population growth. Given the negative relationship between predicted mortality and life expectancy in Figure 4, this translates into a positive effect of life expectancy on population. This is confirmed in Table 8, which reports 2SLS results from regressing log population on log life expectancy in either a panel specification (Panel A) or in long differences (Panel B). The first stages for these regressions are reported in Table 5 and are not repeated here to save space. 
In column 1 we look at contemporaneous effects during 1940-80 and find a coefficient on $\log$ life expectancy of 1.31 , with a standard error of 0.37 (statistically significant at $1 \%$ ). This estimate is comparable to the OLS estimates in Table 2.

The coefficient increases to 1.35 when we look at 1930-80 (column 2) and is even larger when we include Eastern Europe (column 3). When we exclude the initially richest countries in column 4 , the coefficient estimate is again similar, 1.58 (standard error $=0.76$ ).

Column 5 shows that the results are generally robust (though slightly smaller) when we include the full set of interactions between year dummies and institutions (both in the first and second stages). ${ }^{40}$ These interactions are jointly significant, suggesting that initial institutional differences have some predictive power for subsequent population growth. Column 6 estimates equation (10), allowing for a full set of interactions between year dummies and initial (1930) log population. As noted above, this specification flexibly controls for both mean reversion and potential differential trends. Remarkably, the estimate of the effect of log life expectancy on log population is essentially unaffected, 1.33 (standard error $=0.35$ ), though interactions between year dummies and initial population are jointly statistically significant. The corresponding estimate in Panel B is also very similar to the baseline, 1.68 (standard error $=0.44$ ).

Column 7 repeats the baseline regression using the global mortality instrument. In Panel A, the estimate of the effect of log life expectancy on log population is 1.65 (standard error $=$ 0.40), while in Panel B, it is 1.70 (standard error $=0.48$ ).

Columns 8-11 investigate the longer-term effects of life expectancy on population growth by looking at the specifications where the dependent variable is various leads of log population (i.e., $k>0$ in terms of equation (7)). The coefficients are on the whole very similar to the baseline estimate (slightly higher for 10 and 20 year leads and slightly smaller for the 40 year lead). This suggests that changes in life expectancy led to relatively enduring increases in population. Panel B shows the same results with the long difference specifications.

Overall, we find a large, relatively precise, and robust effect of life expectancy on population. The elasticity is estimated consistently to lie between 1 and 2, which is similar to the OLS estimates.

\subsection{Births}

Table 9 presents 2SLS estimates of log life expectancy on log total births. Consistent with the magnitude of the response of population to life expectancy, Table 9 indicates that the increase in life expectancy was associated with an increase in the total number of births. In column 1, Panel A, the estimate is 2.39 (standard error $=0.69$ ). The estimates are similar in the longdifference specifications, when we include Eastern Europe, when we exclude the initially richest

\footnotetext{
${ }^{40}$ The results including the interactions between year dummies and initial log GDP per capita or continent dummies are also very similar and are not reported to save space.
} 
countries, when we include interactions between year dummies and institutions, or initial log GDP per capita, continent dummies, and initial log total births, and when we use the global mortality instrument.

Looking at the leads shows an interesting pattern whereby the effects become smaller at future dates. This suggests that there was a delayed decline in fertility in response to the increase in life expectancy (which is consistent with the evidence reviewed in Kelley, 1988).

\subsection{GDP}

Figure 10 shows the reduced-form relationship between change in log (total) GDP and change in predicted mortality during 1940-1980. Consistent with the pattern in Panel B of Table 7, there is a slight (but not statistically significant) downward slope, which indicates that countries with larger declines in predicted mortality experienced somewhat higher GDP growth between 1940 and 1980, though this effect is not very large.

Table 10 presents the related 2SLS regression evidence. In column 1, the estimate of the key parameter is -0.03 (standard error $=0.67$ ). The estimate using long differences in Panel B (corresponding to Figure 10) is positive, 0.32, but also statistically insignificant (standard error $=0.84)$. In both cases, the standard errors are large enough that economically significant positive effects cannot be ruled out. For example, the two standard error ( $95 \%$ confidence) intervals always include a response of GDP to life expectancy with an elasticity that could be as high as 1.3. Nevertheless, the standard errors will be somewhat smaller when we look at GDP per capita below, enabling us to exclude any positive effects on per capita growth.

The pattern of response of GDP to life expectancy is broadly similar when we look at different sample periods, when we include Eastern Europe, exclude the initially richest countries, when we include interactions between year dummies and institutions or initial GDP per capita, and when we use the global mortality instrument.

The estimates in columns 8-11 show that at longer horizons there is a more positive effect of life expectancy on GDP (though still not significant). For example, with the 10-year lead the coefficient is now 0.52 (standard error $=0.48$ ) and with the 20 -year lead it is 0.53 (standard error $=0.44)$. The effect starts declining after the 30-year lead. Estimates using the long differences are close to and somewhat larger (though considerably less precise) than the panel estimates in Panel A. The over-time increase in the impact of life expectancy on GDP could be a result of a combination of the larger population reaching working age, and consistent with the neoclassical growth model, capital inputs and other factors of production adjusting to the increase in population.

We interpret these estimates as suggesting that the increase in life expectancy and the associated increase in population had a relatively small effect on total GDP at first, with a 
somewhat larger effect over time. Nevertheless, the relatively large standard errors make it impossible for us to pin down the exact magnitude or timing of the impact of life expectancy on total GDP.

\subsection{GDP Per Capita and Per Working Age Population}

The response of total GDP already reveals that the effect of the increase in life expectancy on GDP per capita (or GDP per working age population) was negative. This is shown in Figure 11, which depicts a strong positive reduced-form relationship between the change in log GDP per capita and the change in predicted mortality during 1940-1980. Evidently, countries with larger declines in predicted mortality also experienced lower growth in GDP per capita. Clearly, this is the result of the larger increase in population than in GDP in these countries, which was already shown in Figures 11 and 12 and in Panel B of Table 7.

The 2SLS estimates of the effect of log life expectancy on GDP per capita in Table 11 confirm this pattern. There is a significant negative effect of life expectancy on GDP per capita in columns 1 and 2 of Panels A and B. In either case, the coefficient estimate for $\pi$ in equation (7) is around -1.30 (with standard errors ranging between 0.46 and 0.61 ).

The results in columns 3-6, which look at alternative samples and include interactions with initial institutions and initial log GDP per capita, are similarly negative and hover around statistical significance. Estimates from equation (10) in column 7, on the other hand, lead to still negative but smaller effects of log life expectancy on GDP per capita. In all cases, the two standard error bands always exclude positive effects of life expectancy on GDP per capita.

As with the results for total GDP in Table 10, the lead results indicate a more positive (less negative) impact of life expectancy on GDP per capita over the following 40 years than initially. Nevertheless, even after 40 years, there is no evidence of a positive effect of life expectancy on GDP per capita.

One concern with these results is that the increase in population is largely at young ages, so GDP per capita may be low precisely because the denominator has increased, while the working age population has not. To investigate the importance of this issue, Appendix Table C2 looks at GDP per working age population, ${ }^{41}$ and shows that the impact of life expectancy on GDP per working age population is very similar to its impact on GDP per capita.

Overall, our 2SLS estimates show no evidence that the large increase in life expectancy in many parts of the world starting in the 1940s led to a significant increase in GDP per capita. ${ }^{42}$ Instead, the increase in life expectancy was associated with a significant increase in population

\footnotetext{
${ }^{41}$ We define working age population as population between the ages of 15 and 60 . Estimates of the age distribution of the population and hence of the working age population for this time period are often rough.

${ }^{42}$ As noted in footnote 40 , the results are similar when we control for a full set of continent dummies interacted with time. For example, in the specification of Table 11, the coefficient on log life expectancy is -0.27 (standard error $=0.45)$.
} 
and a somewhat smaller increase in total GDP.

These results are broadly consistent with the neoclassical growth model. In terms of the model in Section 2, suppose that the contemporaneous effects correspond to the "medium run" impact with the capital stock held constant. The coefficient of interest, in this case, is $\pi=(\alpha(\gamma+\eta)-(1-\alpha) \lambda)$ in terms of equation (6). Recall that $\lambda$ here is the response of population to changes in life expectancy, so according to the estimates in Table 8 , we can think of $\lambda \approx 1.5$. The coefficient $\alpha$ corresponds to the share of labor. Since the countries in question here include many low-income countries where land is an important factor of production, we take the share of land as $1 / 3$, i.e., $1-\alpha-\beta \approx 1 / 3$ (see footnote 13 ), and thus set $\alpha \approx 1 / 3$ and $\beta \approx 1 / 3$. This would imply that our estimate of $\pi=(\alpha(\gamma+\eta)-(1-\alpha) \lambda) \approx-1.3$ is consistent with $\gamma+\eta$ close to zero or even slightly negative. If, on the other hand, we were to take $\lambda$ to be around 1.7 as suggested by the high-end estimates in Table $8, \gamma+\eta$ would be small but positive. ${ }^{43}$ Therefore, these results suggest that the benefits of higher life expectancy in terms of direct productivity gains and human capital gains are relatively small. This is also confirmed when we look at the longer-run effects. For example, if we take the long-run effect to be approximately -0.75 and $\beta \approx 1 / 3$, then the long-run relationship of $\pi=(\alpha(\gamma+\eta)-(1-\alpha-\beta) \lambda) /(1-\beta)$ implies a value of $\gamma+\eta$ equal to zero. Smaller negative effects, which are within the two standard error bands of the estimates in Table 11, would be consistent with positive values of $\gamma+\eta{ }^{44}$

\subsection{Years of Schooling}

The results so far do not show any evidence of large gains from increases in life expectancy in terms of economic growth per capita. Instead, the greater population associated with the increase in life expectancy appears to have somewhat reduced income per capita. This suggests that the indirect benefits of improved health in terms of greater education and greater (total factor) productivity may be limited (see the calculations in the last paragraph of the previous subsection). As a further check on this conclusion and as a way of investigating whether there are any substantial effects of life expectancy working through human capital (as posited by equation (4)), we can also directly look at whether increasing life expectancy raised human capital during and in the aftermath of the international epidemiological transition.

Table 12 estimates the corresponding 2SLS regressions using the available data on schooling starting in 1960. Data availability implies that we can only look at the effect of life expectancy

\footnotetext{
${ }^{43}$ But in turn, if $\alpha$ were higher, the implied values of $\gamma+\eta$ would be correspondingly lower. For example, Hansen and Prescott (2002) suggest a value of 0.3 for $1-\alpha-\beta, 0.1$ for $\beta$ and 0.6 for $\alpha$ in pre-industrial societies.

${ }^{44}$ The comparison of these results to the OLS estimates in Table 3 (together with the pattern discussed in footnote 32) suggests that the lack of a significant OLS relationship between life expectancy and GDP per capita is likely to be due to a combination of a short-run negative effect of life expectancy on GDP per capita and a positive effect of income on life expectancy. See also Pritchett and Summers (1998) for estimates of income per capita on life expectancy.
} 
on 10-year or 20-year leads of schooling (which is not a severe limitation since there are likely to be important lags in the effect of life expectancy on schooling). The results in Table 12 show that there is no effect of life expectancy on schooling in the OLS and in the IV either in the base sample or for only low and middle-income countries (columns 1-6). With 30-year leads, there is a positive and significant OLS estimate, but the IV estimates are again insignificant (either positive or negative depending on the sample, as shown in columns 8 and 9).

Overall, there seems to be no evidence that the increase in life expectancy has been associated with substantially greater investment in human capital, which is consistent with the finding in the previous subsection. The most likely reason why the increase in life expectancy did not translate into greater education during this episode is that the affected countries faced bottlenecks in their education systems, making it impossible for them to increase the education of the much larger cohorts of children that survived and were born as a result of the international epidemiological transition.

\section{$7 \quad$ Further Results}

The results in the previous section suggest that the increase in life expectancy led to a substantial increase in population, but not to more rapid economic growth. In this section, we investigate the robustness of these results further.

\subsection{Alternative Samples}

An important question is whether including sub-Saharan Africa in the analysis changes any of the main results documented above. This is hard to answer with great certainty as the detailed data for Africa before at least 1950 are either not available or not reliable. Although there is a sizable historical literature on medical conditions in Africa, much of this is not accompanied by statistics that are comparable with our base sample data. ${ }^{45}$ Nevertheless, it is possible to include sub-Saharan Africa after 1950 in our regressions using UN data (which are nonetheless less reliable than the non-African data, see Appendix $\mathrm{C}$ for details). This is done in columns 1-4 and 7-10 of Table 13. The results for the first and the second stages are similar to our previous results both using the baseline and the global mortality instruments. ${ }^{46}$ In this case,

\footnotetext{
${ }^{45}$ In general terms, we know that health in Africa improved, at least for a while after World War II. For example, Cutler et al (2006, p. 17) write: "life expectancy [in Africa] rose by more than 13 years from the early 1950s to the late 1980s, before declining in the face of HIV/AIDS." Estimates in Gwatkin (1980, e.g., Figure 2) also suggest that increases in life expectancy were at least as dramatic in Africa as in other developing countries, but only until average life expectancy for these societies reached 40; at that point the rate of increase slowed sharply. This could point to a failure to sustain health improvements or some other factor, and needs further investigation.

${ }^{46}$ The sample used here is limited both by lack of life expectancy data in 1940 and by the fact that Maddison does not have population or GDP data for Africa before 1950. Consequently, even though Table 13 uses information on 43 more countries than the previous tables, the additional observations are all post- 1950 .
} 
estimates using the global mortality instrument are more reliable since they do not use the baseline disease distributions in Africa.

A second alternative sample drops countries that were demographically most affected by World War II. Urlanis (2003) documents demographic effects that were both direct, through loss of population, and indirect, through reducing birth rates and increasing non-casualty death rates in a number of countries. Interestingly, however, in relatively few cases was there a firstorder effect on population. Based on Urlanis (2003), columns 5-6 and 11-12 of Table 13 report results dropping Germany, Italy, Finland, Austria, and China (Japan is not in our sample due to data issues; Eastern Europe is not in the baseline sample). The first-stage relationship between log life expectancy and predicted mortality remains strong and highly significant, and there is again a large effect on population and a smaller, insignificant effect on total GDP.

We also estimated regressions dropping countries that were involved in developing the new "miracle" drugs and chemicals of the 1940s and 1950s: the UK, the US, Germany and Switzerland. For these countries one might be concerned that the medical innovations were partly endogoneous to their disease conditions. In any case, this has hardly any effect on the estimates (not reported).

\subsection{Mean Reversion in the Second Stage}

In Appendix Table C3, for our main variable of interest, income per capita, we estimate a version of equation (9), which explicitly allows for mean reversion in the dependent variable. Recall that the presence of such mean reversion does not affect the consistency of the estimates presented so far as long as our instrument for life expectancy is valid (i.e., as long as $\left.\operatorname{Cov}\left(M_{i t}^{I}, \varepsilon_{i t+k}\right)=0\right)$, so we report these estimates mostly for completeness.

Our strategy is to estimate a transformed model that removes the effect of mean reversion in income per capita. Suppose we know the mean-reversion parameter $\rho$ in equation (9). Then, subtract $\rho y_{i t-1}$ from $y_{i t}$, which, using (9) without covariates, gives

$$
\tilde{y}_{i t}^{\rho}=\pi \tilde{x}_{i t}^{\rho}+\zeta_{i}^{\rho}+\mu_{t}^{\rho}+\tilde{\varepsilon}_{i t}^{\rho},
$$

where the transformed dependent variable is $\tilde{y}_{i t}^{\rho} \equiv y_{i t}-\rho y_{i t-1}$, and on the right hand side we have $\tilde{x}_{i t}^{\rho} \equiv x_{i t}-\rho x_{i t-1}$ (and $\tilde{\varepsilon}_{i t}^{\rho} \equiv \varepsilon_{i t}-\rho \varepsilon_{i t-1}$ ). $M_{i t}^{I}$ can be used as an instrument for $\tilde{x}_{i t}^{\rho}$ in this equation ( $\operatorname{since} \operatorname{Cov}\left(M_{i t}^{I}, \varepsilon_{i t+k}\right)=0$ for all $k$, we also have $\operatorname{Cov}\left(M_{i t}^{I}, \varepsilon_{i t}^{\rho}\right)=0$ ). Therefore, a 2SLS regression of $\tilde{y}_{i t}^{\rho}$ on $\tilde{x}_{i t}^{\rho}$ will identify the coefficient of interest, $\pi$. Although we do not know $\rho$, we can implement a two-stage version of this procedure by first estimating $\rho .{ }^{47}$ Appendix Table C3 reports results from applying this procedure using a range of values for $\rho$ that encompasses (and exceeds) the range of estimates of $\rho$. There is a robust first stage between transformed

\footnotetext{
${ }^{47}$ In regressions of log income per capita on its lag and country and time fixed effects, the estimates of $\rho$ vary between 0.4 and 0.75 depending on estimation strategy and on whether or not log life expectancy is included.
} 
log life expectancy and predicted mortality, and the second-stage estimates are similar to (but somewhat more negative than) those in Table 11. These estimates show that irrespective of the value of $\rho$, the relationship between life expectancy and GDP per capita is never positive (the point estimate is always negative).

\subsection{Interaction Results}

As discussed in Section 2, we may expect the impact of log life expectancy on GDP per capita to differ depending on the investment rate. We investigate this issue in Appendix Table C4 using two variables to measure investment rates: (1) initial (1930) log GDP per capita and (2) investment rates from the 1940s (or immediately after). Although income differences in 1930 likely had various causes, we expect them to be correlated with savings and investment rates, and these data are likely to be more reliable than estimates of investment rates around the same time.

Our empirical strategy is to include an interaction between log life expectancy and initial log GDP per capita or investment as a percent of GDP. This interaction term is instrumented by the interaction between predicted mortality and initial log GDP per capita (or investment). In all regressions, the main effects are evaluated at the sample mean. Panel A of Appendix Table C4 shows that the effect of log life expectancy on population is the same irrespective of initial log GDP p.c. or the investment rate; the interactions between log life expectancy and these baseline characteristics are insignificant both in contemporaneous and lead specifications.

The picture is different in Panels B and C, where we look at log GDP and log GDP per capita. In the regressions with contemporaneous effects, the interaction terms both with GDP per capita in 1930 and investment share of GDP in 1940s are positive, and except for the effect of the interaction with GDP per capita in 1930 on log total GDP (in Panel B), they are statistically significant. For example, the coefficient on the interaction between GDP per capita in 1930 and log life expectancy in the log GDP per capita regression (Panel C, column 1 ) is 0.79 (standard error $=0.37$ ), while the interaction with investment share of GDP for the same variable (Panel C, column 5) is 0.12 (standard error $=0.04$ ). These estimates imply that, consistent with our theoretical expectations, there is some evidence that countries with high investment rates (measured directly or proxied by high initial income per capita) suffered less adverse income effects from the increase in population. Moreover, consistent with equation (5) in Section 2, these investment rate and life expectancy interactions appear not to have had a positive impact on log GDP or log GDP per capita in the long run. Nevertheless, the results of this exercise have to be interpreted with caution, since data quality and relatively large standard errors limit the extent to which we can pin down the exact timing of changes in GDP. 


\section{Conclusion}

A newly-emerging consensus in academic and policy circles holds that disease environment and health conditions lie at the root of large income differences across countries today, and argues that improving health will not only improve lives but will by itself spur rapid economic growth.

This paper investigated these claims by estimating the effect of life expectancy at birth on economic growth. The innovation in our approach is to exploit the international epidemiological transition, which led to potentially-exogenous differential changes in mortality from a number of major diseases across the world. As a result of new chemicals, drugs, and other international interventions, mortality from tuberculosis, pneumonia, malaria, and various other diseases declined sharply in many parts of the world, while other countries that were largely unaffected by these diseases did not experience similar improvements in health and life expectancy. Exploiting these differential changes in predicted mortality as an instrument for life expectancy, we estimate the effect of life expectancy on a range of economic variables, most importantly population and GDP.

Our results indicate that the increase in life expectancy led to a significant increase in population; birth rates did not decline sufficiently to compensate for the increase in life expectancy. We find a small initial positive effect of life expectancy on total GDP, and this effect grows somewhat over the next 40 years, but not enough to compensate for the increase in population. Overall, the increases in life expectancy (and the associated increases in population) appear to have reduced income per capita at first, with this negative effect slowly wearing off over the next 40 years. There is no evidence that the increase in life expectancy led to faster growth of income per capita. This evidence sheds considerable doubt on the view that health has a first-order impact on economic growth.

It is also important to emphasize the limitations of our results. The most important limitation is that since our approach exploits the international epidemiological transition around the 1940s, the results may not be directly applicable to today's world. This is for at least two reasons. First, the international epidemiological transition was a unique event and perhaps similar changes in life expectancy today will not lead to an increase in population and the impact on GDP per capita may be more positive. Second, the diseases that take many lives

in the poorer parts of the world today are not the same as those 60 years ago; most notably HIV/AIDS is a major killer today but was not so in 1940. Most of the diseases we focus on had the greatest impact on children (with the notable exception of tuberculosis), while HIV/AIDS affects individuals at the peak of their labor productivity and could have a larger negative impact on growth. Further study of the effects of the HIV/AIDS epidemic on economic outcomes is an important area for future research. 


\section{Appendix A: Data Sources and Construction}

Population, GDP, and GDP per capita data are from Maddison (2003), specifically the downloadable data available to purchasers of his 2003 book. Working age population is defined as population between the ages of 15 and 60 and is obtained from the on-line UN demographic database from 1950 (http://esa.un.org/unpp). Population structure for 1940 is from the UN Demographic Yearbook 1948 (United Nations 1949, Table 4, pp. 108-158). We use data for 1940 or the closest available year or range of years. For 1930 we assume the same age structure as 1940 (this is relevant only for column 2 of Appendix Table C2).

Life expectancy in 1940 and earlier are from various UN Demographic Yearbooks. Key Yearbooks are the original 1948 edition (United Nations 1949) and subsequent issues for 1949-50 (United Nations 1950), for 1951 (United Nations 1951), and particularly the retrospective section of the Demographic Yearbook 1967 (United Nations, 1967). We use the most recently revised UN data available to calculate the unweighted averages of male and female life expectancy for 1940 (we also check these data against United Nations, 2000, but the coverage of this generally begins no earlier than 1948). When there is no data for 1940, but such data exist for neighboring years, e.g., 1938 and 1942, we use linear interpolation to obtain an estimate for 1940. In a few cases, we use information from neighboring countries when they have similar crude death rates (from the UN Demographic Yearbooks). Appendix C provides further details and gives the specifics for each country.

Life expectancy from 1950 onwards was downloaded from the on-line UN demographic database; these data are in five year intervals, so we use 1950-55 for 1950 and 1960-65 for 1960, etc. Life expectancy in 1900, used in the falsification tests, is from Maddison (2001, Table 1-5a, p. 30). These estimates for life expectancy in 1900 for Europe, Latin America, and Asia are consistent with the numbers in Arriaga and Davis (1969), Riley (2001), and Bengtsson et al (2004).

To classify the cause of death, we use the Abridged List of the 1938 revision of the International Classification of Disease. This list is comprehensive and has 44 categories. We omit any diseases that are not infectious or could be degenerative, e.g., "diseases of the heart" (Abridged List No. 24) and residual categories, such as "other infectious or parasitic diseases" (Abridged List No. 14). Syphilis (Abridged List No. 9) and puerperal fever/infection (Abridged List No. 35), which results from an infection after childbirth, are omitted because their prevalence depends on sexual and fertility behavior, which fall outside our focus here. Finally, we further omit diseases that were never major causes of death, even though they may have had serious effects on health (e.g., acute poliomyelitis). In all, there are 15 infectious diseases for which we can obtain comparable cross-country data on deaths per 100,000 in 1940 (or 1939 or a close year). Of these 15, 3 are reviewed in more detail in the main text and 12 are covered in Appendix B. We have checked that the data we use in or around 1940 are not significantly affected by the impact of World War II; this is generally possible as in most cases some combination of United Nations sources yields numbers for at least two early years. For European countries affected by the war, we prefer data from 1937 or 1938, where available. Also, in our robustness checks, we drop all data from countries where Urlanis (2003) deemed that war had a major demographic impact.

The classification of death rates by cause changed in 1948, and some of our data for 1950 and after are available only according to the Abbreviated List, 1948 Revision of the International Classification of Disease. For example, the UN Demographic Yearbook (1954) reports cause of death in and around 1950 for some countries using the 1938 classification and for others using the 1948 classification. The terminology of the Abridged List for the 1938 classification and the Abbreviated List for the 1948 classification is as used in the Demographic Yearbook. Most of our 15 diseases can be tracked through this reclassification, but dysentery/diarrhea-related diseases cannot - we have information on these diseases only for 1940 (which is what we need to construct the predicted mortality instrument), but they are not included in our zeroth-stage regressions in Table 4 or in our calculation of the global mortality instrument.

For our data on cause of death in 1940, we start with the Summary of International Vital Statistics, 1937-1944, published by the Federal Security Agency (1947) of the US government immediately after World War II. This source provides comparable comprehensive data on cause of death around 1940, as well as longer time series on the more important diseases (i.e., death rates by country), primarily from 
League of Nations sources; however, it did not use all the available data (Federal Security Agency, 1947, p. 2). For this reason, we fill gaps for 1940 using the original sources, which are national health statistics collected, cleaned and republished between the wars by the League of Nations Health Organization (see Federal Security Agency, 1947, pp. 1-3); we also use information from the League and its direct postwar successors for earlier and later data as discussed in Appendix C. A key issue is the area covered by the registration of deaths in various countries. Apart from the very richest countries in 1940, there was seldom universal registration of death, with a death certificate signed by a doctor. Consequently, some of the data are for major cities, while others are for all towns or for the entire population. Unfortunately, our sources do not always document clearly the precise coverage of the underlying data (for lower income countries, the data almost certainly overweigh towns relative to rural areas and diseases related to urban overcrowding are likely to be overrepresented). Nevertheless, our results are robust to using only the more reliable data.

The League of Nations Health Organization established comparable international health statistics for a large number of countries, but never to our knowledge published a comprehensive retrospective of the data. Their first relevant publication was Issue No. 7 of the Annual Epidemiological Report, which appeared in October 1923. But only from 1929 (covering the year 1927) did this publication include death rates from specific causes (League of Nations Health Organization, 1929). Early issues of this publication are also refered to as Statistics of Notifiable Diseases. The first six issues focused on Eastern Europe, particularly typhus and malaria epidemics in Russia. For a comprehensive list of publications by the League of Nations on health, see Aufricht (1951), particularly pp. 176-177. For an explanation of the structure and purpose of the League of Nations Health Organization, see League of Nations (1931). For more on the early development of internationally comparable health statistics, see Stocks (1950).

We use the death rates by disease for 1930 from League of Nations Health Organization (1933). For 1940 we use World Health Organization (1951), which provided data for 1939-46, based on the League of Nations' work. In addition, for malaria in 1930, we use data from the Leauge of Nations' Malaria Commission (League of Nations Health Organization, 1932). We also check our data against information on location of malaria in the 1940s from American Geographical Society (1951a). Data on deaths by disease for 1950 and 1960 are from the UN Demographic Yearbooks for 1954, 1962 and 1966. Data for 1970 are from the UN Demographic Yearbook for 1974 and data for 1980 are from the UN Demographic Yearbook for 1985.

We further confirmed that our data do not miss major epidemics by reviewing every available interwar issue of the League of Nations' Weekly Epidemiological Record. For example, for the distribution of cholera in 1938, see Weekly Epidemiological Record, March 3rd, 1938. For the distribution of small pox in 1930, see Weekly Epidemiological Record, August 21st, 1930; for 1938, see Weekly Epidemiological Record, March 3rd, 1938; for the early 1940s see Weekly Epidemiological Record, January 3rd, 1946. For the pre-war distribution of diphtheria, with a focus on Europe, see Weekly Epidemiological Record, December 21st, 1939. For the distribution of plague in 1938, see Weekly Epidemiological Record, March 3rd, 1938. For more detail on the pre-1940 distribution of typhus, see Weekly Epidemiological Record, September 14th, 1939. For the endemic yellow fever zone in 1951, see the Supplement to the Weekly Epidemiological Record, 25 September 1952. We also confirm that our numbers are consistent with contemporary qualitative assessments, in particular in the League of Nations and WHO's annual reports. Further details on these checks and data sources are provided in Appendix C.

Predicted mortality in 1940 is calculated by adding deaths per 100,000 from the 15 component diseases (for ease of exposition, we then convert to per 100 of population). Preston (1980) points out that data on precise cause of death should be handled with care; for example, it is notoriously difficult to determine how many deaths are due directly and indirectly to malaria. While this is an important warning in general, our analysis is about changes in total predicted mortality from infectious disease and because most of the global interventions were clustered in the late 1940s and early 1950s, this issue is less of a concern here.

Years of schooling are from the Barro-Lee dataset, downloadable from the NBER website. Our investment data are based on Maddison (1992), but we fill gaps with data for the early 1950s from Kuznets (1960). More details are provided in Appendix C. 


\section{Appendix B: List and Details On Diseases}

The main text reviewed the etiology of and global "interventions" against the three diseases in our data responsible for the most deaths: malaria, pneumonia, and tuberculosis. Here we provide details on the remaining 12 infectious diseases, in rough descending order of their contribution to global deaths around 1940 (see Kiple, 1993, Hoff and Smith, 2000, Heymann 2004, and the Centers for Disease Control and Prevention website). The relevant global interventions are (a) new drugs for treatment that became available globally (particularly antibiotics where relevant), (b) new preventive measures that became available globally (particularly vaccines and chemicals that were effective against insects) and, (c) specific WHO campaigns against diseases. It is useful to note that the timing of interventions would not be changed if we word to put greater emphasis on sulphur drugs. Sulfonamide drugs were invented in the 1930s, but were often toxic and not available in the most effective doses (see Conybeare, 1948, pp. 65-66). This changed only from 1939, when the drugs became more effective (though Loudon, 2002, puts the useful breakthrough a little earlier).

Influenza is caused by various strains of the influenza virus, including type A (the most dangerous), type B, and type C. Transmission is through coughing, sneezing, or directly through mucous membranes. Associated deaths are often due to various secondary bacterial infections. The primary control mechanism is vaccination, but the introduction of antibiotics from the 1940s reduced deaths from secondary bacterial infections. There has been no global campaign to eradicate influenza, but WHO efforts to control and track the disease started in the 1950s. For an assessment of measures taken against influenza during 1921-50, see Deutschman (1953). In our baseline instrument we take the intervention date as the 1940s (antibiotics) and in our alternative instrument we take the 1950s (WHO action).

Cholera is caused by the bacterium Vibrio cholerae, and is transmitted by drinking contaminated water or eating contaminated food. Public works to properly treat or dispose of sewage have been effective against the disease since the mid-nineteenth century. Some antibiotics reduce the symptoms, but oral rehydration or intraveneous fluids are needed to replace minerals and fluids lost due to diarrhoea. Major steps to improve the effectiveness of oral rehydration were taken during the 1950s; in part these innovations were supported by the US military. For our baseline instrument we take the intervention date as the 1950s (rehydration therapy) and in our alternative instrument we take the 1940s (antibiotics).

Typhoid is caused by the bacterium Salmonella typhi and is transmitted through feces, either directly or by flies. It can be treated effectively with antibiotics (available since the 1940s). We take the introduction of antibiotics in the 1940s as the intervention date for both our baseline and alternative instruments.

Smallpox was caused by the viruses Variola major (the more deadly) and Variola minor. The disease was highly contagious, with the virus spreading through contact or through the air. Since 1798 the primary treatment has been vaccination. The WHO passed a resolution declaring the need to eradicate the disease in 1958 and the invention of the jet injector with foot pedal in 1962 made it possible to easily vaccinate people in places without electricity. In 1979, smallpox was declared entirely eradicated. In our baseline instrument we take the 1950s as our intervention date and in our alternative instrument we take the 1960s.

Shigella dysentery is caused by the bacterium Shigella dysenteriae type 1 or by the protozoan Endamoeba histolytica and is transmitted in the same fashion as typhoid. While we do not have fully comparable international data on dysentery, there are data on deaths from diarrhea among infants under the age of 2; we convert these into per 100 population equivalent and add to our predicted mortality estimates. The disease is controlled with public health measures, antibiotics, and rehydration therapy. We take the 1940s as our intervention date for our baseline instrument (based on antibiotics) and the 1950s for our alternative instrument (based on rehydration therapy).

Whooping cough is caused by the bacteria Bordetella pertussis. It can be treated with antibiotics and prevented by vaccination (which is one component of the DTP vaccine). The vaccine became available in the 1920s. We take the 1940s as our intervention date both for our baseline and alternative instruments (based on the effectiveness of antibiotics).

Measles (rubeola) is caused by a virus of the Rubivirus genus; it spreads through airborne droplets 
from an infected person. ${ }^{48}$ Prevention is through vaccination, which became available in 1963; this is also effective if administered within three days of exposure to the disease. Currently the largest vaccine-preventable killer of children, it may be targeted for global eradication. We take the 1960s as our intervention date for both our baseline and alternative instruments.

Diphtheria is caused by the bacterium Corynebacterium diphtheriae when it has been infected by certain bacteriophages (parasites that only infect bacteria). Transmission is through the air or by touch. It can be treated with antitoxins and antibiotics. An antitoxin has been available since the 1890s and immunization spread after its introduction in the early 1920s (usually provided today in the DTP, diphtheria-tetanus-pertussis, vaccine for infants). Treatment became more effective with the introduction of antibiotics in the 1940s. We take the 1940s as our intervention date for our baseline and alternative instruments (based on antibiotics).

Scarlet fever is caused by the Streptococcus bacteria; it often develops in strep throat patients and is similarly spread by droplets from an infected person (e.g., coughing or sneezing). It generally can be treated with antibiotics, including penicillin. We take the 1940s as our intervention date for our baseline and alternative instruments (based on antibiotics).

Yellow fever is caused by the yellow fever virus, and transmitted by the bite of an infected Aedes aegepti mosquito. It is controlled by vaccination and public health measures against the mosquito vector. The vector was definitively identified by Walter Reed, head of the U.S. Army Yellow Fever Commission, in 1900-1901. The first vaccine was developed by Max Theiler in the 1937 and was widely used in the 1940s. We take the 1940s as the intervention date for our baseline instrument and the 1930s for our alternative instrument.

Plague is caused by the bacterium Yersinia pestis and is transmitted from infected animals to humans through the bite of an infected flea. The disease is controlled through antibiotics, especially streptomycin, and the elimination of rodent population near human habitations. Some protection from vaccination has been available since the end of the nineteenth century. The WHO attempts to help deal with outbreaks. We take the introduction of the antibiotics in the 1940s as the intervention date for both our baseline and alternative instruments.

Typhus is caused by any microbe of the genus Rickettsia, and is transmitted by insects (lice, fleas, mites, and ticks). Antibiotics are usually an effective treatment. Public health measures include good hygiene and sanitation. Once again, based on antibiotics, the 1940s are the intervention date for both our baseline and alternative instruments.

\footnotetext{
${ }^{48}$ This is a different disease, caused by a different virus, than German measles (rubella). Vaccines for both are included in the MMR vaccine (measles-mumps-rubella).
} 


\section{References}

Acemoglu, Daron, Simon Johnson, and James A. Robinson (2003) "Disease and Development in Historical Perspective," Journal of the European Economic Association, April, vol. 1, no.2-3, 397-405.

Alilio, Martin S., Ib C. Bygbjerg, and Joel G. Breman (2004) "Are Multilateral Malaria Research and Controls Programs the Most Successful? Lessons from the Past 100 years in Africa," American Journal of Tropical Medicine and Hygiene, 71 (Supplement 2), 268-278.

Alleyne, George A. O. and Daniel Cohen (2002) "The Report of Working Group I of the Commission on Macroeconomics and Health," WHO Commission on Macroeconomics and Health, April.

American Geographical Society (1951a) World Distribution of Malaria Vectors, New York.

American Geographical Society (1951b) Distribution of Cholera, 1816-1950, New York.

American Geographical Society (1951c) World Distribution of Plague, New York.

American Geographical Society (1951d) World Distribution of Rickettial Diseases: Louse-Borne and Flea-Borne Typhus, New York.

Anderson, Theodore W. and Cheng Hsiao (1982) "Formulation and Estimation of Dynamic Models using Panel Data," Journal of Econometrics, 18, 67-82.

Arellano, Manuel and Stephen R. Bond (1991) "Some Specification Tests for Panel Data: Monte Carlo Evidence and an Application to Employment Equations," Review of Economic Studies, 58, 277-298.

Arndt, Channing and Jeffrey D. Lewis (2000) "The Macro Implications of HIV/AIDS in South Africa: A Preliminary Assessment," South African Journal of Economics, LXVIII, 856-887.

Arriaga, Eduardo E. and Kingsley Davis (1969) "The Pattern of Mortality Change in Latin America," Demography, Volume 6, Issue 3, August, 223-242.

Aufricht, Hans (1951) Guide to League of Nations Publications: A Bibliographical Survey of the Work of the League, 1920-1947, Columbia University Press, New York.

Becker, Gary S., Tomas J. Philipson, and Rodrigo R. Soares (2005) "The Quantity and Quality of Life and the Evolution of World Inequality", The American Economic Review, March, 277-291.

Behrman, Jere R. and Mark R. Rosenzweig (2004) "The Returns to Birthweight," Review of Economics and Statistics, 86:2, May, 586-601.

Bell, Clive, Shantanyanan Devarajan, and Hans Gersbach (2003) "The Long-Run 
Economic Costs of AIDS: Theory and an Application to South Africa," working paper, June.

Bengtsson, Tommy, Cameron Campbell, James Z. Lee, et al. (2004) Life Under Pressure: Mortality and Living Standards in Europe and Asia, 1700-1900, MIT Press, Cambridge, MA.

Bhattarcharya, S.K. (1994) "History of Development of Oral Rehydration Therapy," Indian Journal of Public Health, April-June; 38(2): 39-43.

Bleakley, Hoyt (2003) "Disease and Development: Evidence from the American South," Journal of the European Economic Association, April-May, 1(2-3):376-386

Bleakley, Hoyt (2004) "Disease and Development: Evidence from Hookworm Eradication in the American South," working paper, August. (Revised version 2006)

Bleakley, Hoyt and Fabian Lange (2005) "Chronic Disease Burden and the Interaction of Education, Fertility and Growth," UCSD mimeo, January. (Revised version 2006)

Bloom, David E. and David Canning (2005) "Health and Economic Growth: Reconciling the Micro and Macro Evidence," working paper, February

Bloom, David E. and Jeffrey D. Sachs (1998) "Geography, Demography, and Economic Growth in Africa," Brookings Papers on Economic Activity, 1998:2, 207-295.

Bradley, D.J. (1992) "Malaria: Old Infections, Changing Epidemiology," Health Transition Review, vol. 2, supplementary issue, 137-152.

Bulletin of the World Health Organization (1954) Malaria Control; Lutte Contre Le Paludisme, Vol. 11, No.4-5 (entire issue).

Caldwell, J. C. (1986) "Routes to Low Mortality in Poor Countries," Population and Development Review, 12, 2:171-220.

Carr-Saunders A.M. (1936) World Population: Past Growth and Present Trends, The Clarendon Press, Oxford.

Chain, Sir Ernst (1980) A Short History of the Penicillin Discovery from Fleming's Early Observations in 1929 to the Present Time, in The History of Antibiotics: A Symposium, edited by John Parascandola, American Institute of the History of Pharmacy, Madison, Wisconsin.

Cliff, Andrew, Peter Haggett, and Matthew Smallman-Raynor (2004) World Atlas of Epidemic Diseases, Arnold Publishers/Oxford University Press.

Conybeare, John (1948) "The Effects on Mortality of Recent Advances in Treatment" Journal of the Institute of Actuaries, 57-81.

Cutler, David, Angus Deaton, Adriana Lleras-Muney (2006) "The Determinants of Mortality," Journal of Economic Perspectives, forthcoming. Also NBER working paper 11963, January.

Cutler, David and Grant Miller (2005) "The role of Public Health Improvements in Health Advances: The 20th Century United States," Demography, volume 42, number 1, 
February, 1-22.

Cutler, David and Grant Miller (2006) "Water, Water Everywhere: Municipal Finance and Water Supply in American Cities," forthcoming in Edward Glaeser and C. Goldin, Corruption and Reform: Lessons from America's Economic History, University of Chicago Press, Chicago.

Davis, Kingsley (1956) "The Amazing Decline of Mortality in Underdeveloped Areas," American Economic Review, 46, 2, May, 305-318.

Deaton, Angus (2003) "Health, Inequality, and Economic Development," Journal of Economic Literature, March, v.41, issue 1, 113-158.

Deaton, Angus (2004) "Health in an Age of Globalization," Brookings Trade Forum, edited by Susan Collins and Carol Graham, Brookings Institution Press, Washington DC. Also NBER working paper 10669.

Deutschman Z. (1953) "Trend of Influenza Mortality During the Period 1920-51," Bulletin of World Health Organization, 8, 633-645.

Desowitz, Robert S. (1991) The Malaria Capers : More Tales of Parasites and People, Research and Reality, W.W. Norton \& Company.

Easterlin, Richard (1999) "How Beneficent is the Market? A Look at the Modern History of Mortality," European Review of Economic History, 3 (3), 257-294.

Expert Committee on Malaria (1947) "Extract from the Report on the First Session," Bulletin of the World Health Organization, Vol. 1., No. 1, 1947/48.

Federal Security Agency (1947) Summary of International Vital Statistics, 1937-1944, U.S. Public Health Service, National Office of Vital Statistics.

Fogel, Robert William (1986) "Nutrition and the Decline in Mortality since 1700: Some Preliminary Findings," in Long-term Factors in American Economic Growth, S. L. Engerman and R. E. Gallman, editors, 439-55, University of Chicago Press.

Fogel, Robert William (2004) The Escape from Hunger and Premature Death, 17002100, Cambridge University Press.

Gallup, John Luke and Jeffrey D. Sachs (2001) "The Economic Burden of Malaria," American Journal of Tropical Medicine and Hygiene, 64(1, 2)S, 85-96.

Gallup, John Luke and Jeffrey D. Sachs with Andrew D. Mellinger (1999) "Geography and Economic Development," CID Working Paper No. 1, Center for International Development, Harvard University, March.

Galor, Oded (2005) "From Stagnation to Growth: Unified Growth Theory," Chapter 4 in Handbook of Economic Growth edited by Philippe Aghion and Steven Durlauf, Elsevier, North-Holland, 171-294.

Galor, Oded and Weil, David (2000) "Population, Technology, and Growth: From Malthusian Stagnation to the Demographic Transition and Beyond," The American Economic 
Review, 90(4), 806-828.

Gwatkin, Davidson R. (1980) "Indications of Change in Developing Country Mortality Trends: The End of an Era?" Population and Development Review, Vol. 6, No. 4, December, 615-644.

Hansen, Gary D. and Edward C. Prescott (2002) "Malthus to Solow," American Economic Review, 92(4), 1205-1217.

Heymann, David L. (2004) Control of Communicable Diseases Manual, American Public Health Association, Washington D.C.

Hoff, Brent and Carter Smith III (2000) Mapping Epidemics: A Historical Atlas of Disease, Franklin Watts, New York.

International Institute of Statistics (1922) Apercu Annuel de la Demographie des Divers Pays du Monde, The Hague.

Kalemli-Ozcan, Sebnem (2002) "Does the Mortality Decline Promote Economic Growth?," Journal of Economic Growth, volume 7(4), 311-349.

Kalemli-Ozcan, Sebnem (2006) "AIDS, Reversal of the Demographic Transition and Economic Development: Evidence from Africa," University of Houston, mimeo.

Kalemli-Ozcan, Sebnem, Harl E. Ryder, and David Weil (2000) "Mortality Decline, Human Capital Investment, and Economic Growth," Journal of Development Economics, Vol. 62, 1-23.

Keers, R.Y. (1978) Pulmonary Tuberculosis: A Journey Down the Centuries, Bailliere Tindall, London.

Kelley, Allen C. (1988) "Economic Consequences of Population Change in the Third World," Journal of Economic Literature, Vol. 26, No. 4, December, 1685-1728.

Kiple, Kenneth F. (1993) The Cambridge World History of Human Disease, Cambridge University Press.

Knaul, Felicia Marie (2000) "Health, Nutrition, and Wages: Age at Menarche and Earnings in Mexico," in William D. Savedoff and T. Paul Schultz, eds., Wealth from Health: Linking Social Investments to Earnings in Latin America, Washington: Inter-American Development Bank.

Kuczynski, R. R. (1948) Demographic Survey of The British Colonial Empire, Three Volumes, Issued Under the Auspices of the Royal Institute of International Affairs, Oxford University Press, London.

Kuznets, Simon (1960) "Quantitative Aspects of the Economic Growth of Nations, V. Capital Formation Proportions: International Comparisons for Recent Years," Economic Development and Cultural Change, Vol. VIII, No. 4, Part II, July.

Lancaster, H.O. (1970) Expectations of Life: A Study in the Demography, Statistics, and History of World Mortality, Springer-Verlag, New York. 
Langford, C.M. (1996) "Reasons for the Decline in Mortality in Sri Lanka Immediately After the Second World War: A Re-examination of the Evidence," Health Transition Review, 6, 3-23.

League of Nations (1931) Health Organization, Information Section, Geneva, available on the WHO website, under the heading History of International Health Organization Documents, http://whqlibdoc.who.int/hist/chronicles/health_org_1931.pdf (last checked February 24, 2006).

League of Nations Health Organization (1929), Statistics of Notifiable Diseases for the Year 1927, Information Section, April, Geneva.

League of Nations Health Organization (1932) Enquiry into the Quinine Requirements of Malarial Countries and the World Prevalence of Malaria, C.H./Malaria/185, Series of League of Nations Publications, III, Health, December.

League of Nations Health Organization (1933) Statistics for Notifiable Diseases for the Year 1931, Annual Report No.16, Geneva.

Lee, Kelley, Sue Collinson, Gill Walt, and Lucy Gilson (1996) "Who should be doing what in international health: a confusion of mandates in the United Nations?" British Medical Journal, February; 312: 302 - 307.

Lim, M.L., G.S. Murphy, M. Calloway, and D. Tribble (2005) "History of U.S. Military Contribution to the Study of Diarrheal Diseases," Military Medicine, April, 170(4 Supplement): 30-8.

Lorentzon, Peter, John McMillan, and Romain Wacziarg (2005) "Death and Development," NBER working paper No. 11620, September.

Loudon, Irvine (2002) "The use of historical controls and concurrent controls to assess the effects of sulphonamides, 1936-1945," The James Lind Library (www.jameslindlibrary.org).

MacDonald, G. (1956) "Theory of the Eradication of Malaria," Bulletin of the World Health Organization, 15, 369-387.

McEvedy, Colin and Richard Jones (1978) Atlas of World Population History, Facts on File, New York.

McKeown, Thomas (1976) The Modern Rise of Population, Academic Press, New York.

Maddison, Angus (1992) "A Long-Run Perspective on Saving," Scandinavian Journal of Economics, 94(2), 181-196.

Maddison, Angus (2001) The World Economy: A Millennial Perspective, OECD, Development Centre Studies, 2001.

Maddison, Angus (2003) The World Economy: Historical Statistics, OECD, Development Centre Studies, 2003.

Mandle, Jay R. (1970) "The Decline in Mortality in British Guiana, 1911-1960," Demography, Volume 7, Issue 3, August, 301-315. 
Masters, William A. and Margaret S. McMillan (2001) "Climate and Scale in Economic Growth," Journal of Economic Growth, Volume 6, Number 3, September, 167-186.

Miguel, Edward and Michael Kremer (2004) "Worms: Identifying Impacts on Education and Health in the Presence of Treatment Externalities," Econometrica, Volume 72, Issue 1, 159-217.

National Academy of Sciences (1970) The Life Sciences, Committee on Research in Life Sciences of the Committee on Science and Public Policy, Washington DC.

Office International d'Hygiene Publique (1933) Vingt-Cinq Ans d'Activite de L'Office International d'Hygiene Publique, Paris.

Omran, Abdel R. (1971) "The Epidemiologic Transition," The Milbank Memorial Fund Quarterly, 1971, 49(4), 509-538.

Pampana, E. J. (1954) "Changing Strategy in Malaria Control," Bulletin of the World Health Organization, 11, 513-520.

Persico, Nicola, Andrew Postlewaite, and Dan Silverman (2004) "The Effect of Adolescent Experience on Labor Market Outcomes: The Case of Height," Journal of Political Economy, 112, 1019-1053

Preston, Samuel H. (1975a) "The Changing Relation Between Mortality and Level of Economic Development," Population Studies, 29(2), 231-248.

Preston, Samuel H. (1975b) "Health Programs and Population Growth," Population and Development Review, Vol. 1, No. 2, December, 189-199.

Preston, Samuel H. (1980) "Causes and Consequences of Mortality Declines in Less Developed Countries during the Twentieth Century," in Population and Economic Change in Developing Countries, edited by Richard A. Easterlin, The University of Chicago Press, Chicago and London.

Preston, Samuel H. (1996) "American Longevity: Past, Present, and Future," Syracuse University, Center for Policy Research, Policy Brief, No. 7/1996.

Preston, Samuel H. and Verne E. Nelson (1974) "Structure and Change in Causes of Death: An International Summary," Population Studies, 28, 1, March, 19-51.

Pritchett, Lant and Lawrence H. Summers (1998) "Wealthier Is Healthier," Journal of Human Resources, Vol. 31, pp. 841-868.

Riley, James C. (1989) Sickness, Recovery, and Death: A History and Forecast of Ill Health, University of Iowa Press.

Riley, James C. (1993) "Measuring Morbidity and Mortality," Chapter IV.4 in The Cambridge World History of Human Disease, edited by Kenneth F. Kiple, Cambridge University Press.

Riley, James C. (1997) Sick, Not Dead: The Health of British Workingmen during the Mortality Decline, The Johns Hopkins University Press, Baltimore. 
Riley, James C. (2001) Rising Life Expectancy: A Global History, Cambridge University Press.

Savarino, S.J. (2002) "A Legacy in 20th-century Medicine: Robert Allan Phillips and the Taming of Cholera," Clinical Infectious Diseases, September 15; 35(6): 713-20.

Schultz, T. Paul (1993) "Mortality Decline in the Low-Income World: Causes and Consequences," The American Economic Review, 83, 2, May, 337-342.

Schultz, T. Paul (2002) "Wage Gains Associated with Height as a Form of Health Human Capital," The American Economic Review, 92(2), May, 349-353.

Schultz, T. Paul and Aysit Tansel (1997) "Wage and Labor Supply Effects of Illness in Cote d'Ivoire and Ghana: Instrumental Variable Estimates for Days Disabled" Journal of Development Economics, volume 53, pp. 251-286.

Soares, Rodrigo R. (2005) "Mortality Reductions, Educational Attainment, and Fertility Choice," The American Economic Review, July, 95(3), 780-795.

Stock, James H., Jonathan H. Wright and Motohiro Yogo (2002) "A Survey of Weak Instruments and Weak Identification in Generalized Method of Moments" Journal of Business and Economics Statistics, Vol. 20, 518-529.

Stocks, Percy (1950) "Contributions of Statistics to World Health," Bulletin of World Health Organization, 2, 731-741.

Stolnitz, George J. (1955) "A Century of International Mortality Trends: I," Population Studies, July, 24-55.

Stolnitz, George J. (1965) "Recent Mortality Trends in Latin America, Asia and Africa: Review and Re-interpretation," Population Studies, 19, 2, November, 117-138.

Strauss, John and Duncan Thomas (1998) "Health, Nutrition, and Economic Development," Journal of Economic Literature, June, Vol. XXXVI, pp.766-817.

Swaroop S. and R. Pollitzer (1955) "Cholera Studies," Bulletin of the World Health Organization, 12, 311-358.

Thomas, Duncan and John Strauss (1997) "Health and Wages: Evidence on Men and Women in Urban Brazil" Journal of Econometrics, Vol. 77, pp. 159-185.

United Nations (1949, 1950, 1951, 1966, 1974, 1985) Demographic Yearbook, separate editions for 1948, 1949-50, 1951, 1966, 1974, 1985, Lake Success, New York.

United Nations (2000) Demographic Yearbook: Historical Supplement 1948-1997, CDRom, New York and Geneva.

Urlanis, B. (2003) Wars and Population, University Press of the Pacific, Honolulu, Hawaii, reprint of 1971 edition.

Valentine, F. C. O. and R. A. Shooter (1954) Findlay's Recent Advances in Chemotherapy, Volume III, Antibiotics, The Blakiston Company, New York. 
Weil, David N. (2005) "Accounting for the Effect of Health on Growth," NBER working paper 11455, July.

Wooldridge, Jeffery M. (2002) Econometric Analysis of Cross Section and Panel Data, MIT Press, Cambridge.

World Health Organization (1951) Annual Epidemiological and Vital Statistics, 193946, Geneva.

World Health Organization (1998) "Milestones on the Way Towards the World Health Organization," at www.who.int/archives/who50/en/milestones.htm.

World Health Organization (2001) Macroeconomics and Health: Investing in Health for Economic Development, on the web at http://www3.who.int/whosis/cmh.

World Health Organization (2004) Fifty Years of the World Health Organization in the Western Pacific Region, Report of the Regional Director to the Regional Committee for the Western Pacific.

Young, Alwyn (2005) "The Gift of the Dying: The Tragedy of AIDS and the Welfare of Future African Generations," Quarterly Journal of Economics, Volume CXX, Issue 2, May, 423-466. 
Table 1

Descriptive Statistics

\begin{tabular}{|c|c|c|c|c|c|}
\hline & Whole World & Base Sample & $\begin{array}{l}\text { Initially Rich } \\
\text { Countries }\end{array}$ & $\begin{array}{c}\text { Initially Middle } \\
\text { Income Countries }\end{array}$ & $\begin{array}{c}\text { Initially Poor } \\
\text { Countries }\end{array}$ \\
\hline Life expectancy in 1900 & $\begin{array}{l}30.90 \\
(8.83)\end{array}$ & $\begin{array}{l}37.04 \\
(10.45)\end{array}$ & $\begin{array}{l}49.36 \\
(3.67)\end{array}$ & $\begin{array}{l}36.92 \\
(8.13)\end{array}$ & $\begin{array}{l}28.77 \\
(5.42)\end{array}$ \\
\hline Life expectancy in 1940 & $\begin{array}{c}47.77 \\
(11.53)\end{array}$ & $\begin{array}{l}49.30 \\
(12.68)\end{array}$ & $\begin{array}{l}65.14 \\
(1.86)\end{array}$ & $\begin{array}{l}50.94 \\
(9.38)\end{array}$ & $\begin{array}{l}40.63 \\
(8.40)\end{array}$ \\
\hline Life expectancy in 1980 & $\begin{array}{l}61.14 \\
(11.02)\end{array}$ & $\begin{array}{l}66.19 \\
(7.49)\end{array}$ & $\begin{array}{l}74.31 \\
(1.13)\end{array}$ & $\begin{array}{l}69.66 \\
(4.58)\end{array}$ & $\begin{array}{l}61.93 \\
(7.19)\end{array}$ \\
\hline Predicted mortality in 1940 & n.a. & $\begin{array}{l}0.48 \\
(0.28)\end{array}$ & $\begin{array}{l}0.17 \\
(0.05)\end{array}$ & $\begin{array}{l}0.48 \\
(0.22)\end{array}$ & $\begin{array}{l}0.53 \\
(0.32)\end{array}$ \\
\hline Log population in 1940 & $\begin{array}{l}8.94 \\
(1.55)\end{array}$ & $\begin{array}{l}9.07 \\
(1.55)\end{array}$ & $\begin{array}{l}9.35 \\
(1.34)\end{array}$ & $\begin{array}{l}8.82 \\
(1.41)\end{array}$ & $\begin{array}{l}9.15 \\
(1.79)\end{array}$ \\
\hline Log population in 1980 & $\begin{array}{l}8.89 \\
(1.62)\end{array}$ & $\begin{array}{l}9.71 \\
(1.31)\end{array}$ & $\begin{array}{l}9.76 \\
(1.29)\end{array}$ & $\begin{array}{l}9.44 \\
(1.26)\end{array}$ & $\begin{array}{l}10.00 \\
(1.75)\end{array}$ \\
\hline Log GDP in 1940 & $\begin{array}{l}9.78 \\
(1.68)\end{array}$ & $\begin{array}{l}9.89 \\
(1.61)\end{array}$ & $\begin{array}{l}11.08 \\
(1.40)\end{array}$ & $\begin{array}{l}9.75 \\
(1.49)\end{array}$ & $\begin{array}{l}9.19 \\
(1.71)\end{array}$ \\
\hline Log GDP in 1980 & $\begin{array}{l}10.00 \\
(1.98)\end{array}$ & $\begin{array}{l}11.34 \\
(1.40)\end{array}$ & $\begin{array}{l}12.47 \\
(1.33)\end{array}$ & $\begin{array}{l}11.42 \\
(1.36)\end{array}$ & $\begin{array}{l}10.89 \\
(1.52)\end{array}$ \\
\hline Log GDP per capita in 1940 & $\begin{array}{l}7.65 \\
(0.69)\end{array}$ & $\begin{array}{l}7.73 \\
(0.71)\end{array}$ & $\begin{array}{l}8.64 \\
(0.15)\end{array}$ & $\begin{array}{l}7.84 \\
(0.34)\end{array}$ & $\begin{array}{l}6.95 \\
(0.33)\end{array}$ \\
\hline Log GDP per capita in 1980 & $\begin{array}{l}7.99 \\
(1.08)\end{array}$ & $\begin{array}{l}8.54 \\
(0.90)\end{array}$ & $\begin{array}{l}9.62 \\
(0.13)\end{array}$ & $\begin{array}{l}8.89 \\
(0.45)\end{array}$ & $\begin{array}{l}7.79 \\
(0.74)\end{array}$ \\
\hline
\end{tabular}

Mean values of variables; standard deviation in parentheses. Base sample is 59 countries. Initially rich countries had log GDP per capita over 8.4 in 1940; middle income had log GDP per capita between 7.37 and 8.4 in 1940; and low income countries had log GDP per capita below 7.37 in 1940. Predicted mortality is per 100 per annum. "n.a." denotes not available. See text and Appendix A for details and definitions. 
Table 2

Life Expectancy, Population, and Births: OLS Estimates

\begin{tabular}{|c|c|c|c|c|c|c|c|c|c|c|}
\hline & \multirow{2}{*}{$\begin{array}{c}\text { All Countries } \\
\text { No leads } \\
(1)\end{array}$} & \multicolumn{2}{|c|}{ Base Sample } & \multirow{2}{*}{$\begin{array}{c}\text { Low \& Middle } \\
\text { Income } \\
\text { Countries Only } \\
\text { No leads } \\
\text { (4) }\end{array}$} & \multicolumn{2}{|c|}{ All Countries } & \multicolumn{4}{|c|}{ Base Sample } \\
\hline & & $\begin{array}{c}\text { No leads } \\
\text { (2) }\end{array}$ & $\begin{array}{c}\text { No leads } \\
\text { (3) }\end{array}$ & & $\begin{array}{l}10 \text { year lead } \\
(5)\end{array}$ & $\begin{array}{c}20 \text { year lead } \\
(6)\end{array}$ & $\begin{array}{c}10 \text { year lead } \\
\text { (7) }\end{array}$ & $\begin{array}{c}20 \text { year lead } \\
(8)\end{array}$ & $\begin{array}{c}10 \text { year lead } \\
(9)\end{array}$ & $\begin{array}{c}20 \text { year lead } \\
(10)\end{array}$ \\
\hline \multicolumn{11}{|c|}{ Panel A: Dependent variable is log population } \\
\hline & $\begin{array}{c}\text { Panel, 1960- } \\
2000\end{array}$ & $\begin{array}{c}\text { Panel, 1960- } \\
2000\end{array}$ & $\begin{array}{c}\text { Panel, 1940- } \\
1980\end{array}$ & $\begin{array}{c}\text { Panel, 1940- } \\
1980\end{array}$ & $\begin{array}{c}\text { Panel, 1960- } \\
1990\end{array}$ & $\begin{array}{c}\text { Panel, 1960- } \\
1980\end{array}$ & $\begin{array}{c}\text { Panel, 1960- } \\
1990\end{array}$ & $\begin{array}{c}\text { Panel, 1960- } \\
1980\end{array}$ & $\begin{array}{c}\text { Panel, 1940- } \\
1980\end{array}$ & $\begin{array}{c}\text { Panel, 1940- } \\
1980\end{array}$ \\
\hline Log Life Expectancy & $\begin{array}{c}1.46 \\
(0.29)\end{array}$ & $\begin{array}{l}1.69 \\
(0.43)\end{array}$ & $\begin{array}{l}1.21 \\
(0.20)\end{array}$ & $\begin{array}{l}1.24 \\
(0.28)\end{array}$ & $\begin{array}{l}1.72 \\
(0.26)\end{array}$ & $\begin{array}{l}1.61 \\
(0.34)\end{array}$ & $\begin{array}{l}1.34 \\
(0.46)\end{array}$ & $\begin{array}{l}0.97 \\
(0.46)\end{array}$ & $\begin{array}{l}1.33 \\
(0.22)\end{array}$ & $\begin{array}{l}1.26 \\
(0.21)\end{array}$ \\
\hline Number of observations & 600 & 294 & 282 & 249 & 480 & 360 & 235 & 176 & 282 & 282 \\
\hline Number of countries & 120 & 59 & 59 & 48 & 120 & 120 & 59 & 59 & 59 & 59 \\
\hline \multicolumn{11}{|c|}{ Panel B: Dependent variable is log population } \\
\hline & $\begin{array}{c}\text { Just } 1960 \text { and } \\
2000\end{array}$ & $\begin{array}{l}\text { Just } 1960 \text { and } \\
2000\end{array}$ & $\begin{array}{c}\text { Just } 1940 \text { and } \\
1980\end{array}$ & $\begin{array}{c}\text { Just } 1940 \text { and } \\
1980\end{array}$ & $\begin{array}{c}\text { Just } 1960 \text { and } \\
1990\end{array}$ & $\begin{array}{l}\text { Just } 1960 \text { and } \\
1980\end{array}$ & $\begin{array}{c}\text { Just } 1960 \text { and } \\
1990\end{array}$ & $\begin{array}{c}\text { Just } 1960 \text { and } \\
1980\end{array}$ & $\begin{array}{c}\text { Just } 1940 \text { and } \\
1980\end{array}$ & $\begin{array}{c}\text { Just } 1940 \text { and } \\
1980\end{array}$ \\
\hline Log Life Expectancy & $\begin{array}{c}1.60 \\
(0.42)\end{array}$ & $\begin{array}{c}1.74 \\
(0.57)\end{array}$ & $\begin{array}{c}1.62 \\
(0.22)\end{array}$ & $\begin{array}{c}1.86 \\
(0.36)\end{array}$ & $\begin{array}{c}1.92 \\
(0.35)\end{array}$ & $\begin{array}{c}1.70 \\
(0.41)\end{array}$ & $\begin{array}{c}1.42 \\
(0.57)\end{array}$ & $\begin{array}{c}0.98 \\
(0.58)\end{array}$ & $\begin{array}{c}1.71 \\
(0.24)\end{array}$ & $\begin{array}{c}1.62 \\
(0.21)\end{array}$ \\
\hline Number of observations & 240 & 118 & 94 & 72 & 240 & 240 & 118 & 118 & 94 & 94 \\
\hline Number of countries & 120 & 59 & 47 & 36 & 120 & 120 & 59 & 59 & 47 & 47 \\
\hline \multicolumn{11}{|c|}{ Panel C: Dependent variable is log number of births } \\
\hline & $\begin{array}{c}\text { Panel, 1960- } \\
1990\end{array}$ & $\begin{array}{c}\text { Panel, 1960- } \\
1990\end{array}$ & $\begin{array}{c}\text { Panel, 1940- } \\
1980\end{array}$ & $\begin{array}{l}\text { Panel, 1940- } \\
1980\end{array}$ & $\begin{array}{c}\text { Panel, 1960- } \\
1990\end{array}$ & $\begin{array}{c}\text { Panel, 1960- } \\
1980\end{array}$ & $\begin{array}{c}\text { Panel, 1960- } \\
1990\end{array}$ & $\begin{array}{c}\text { Panel, 1960- } \\
1980\end{array}$ & $\begin{array}{c}\text { Panel, 1930- } \\
1970\end{array}$ & $\begin{array}{c}\text { Panel, 1930- } \\
1970\end{array}$ \\
\hline Log Life Expectancy & $\begin{array}{c}1.90 \\
(0.40)\end{array}$ & $\begin{array}{c}2.02 \\
(0.46)\end{array}$ & $\begin{array}{c}1.87 \\
(0.28)\end{array}$ & $\begin{array}{c}1.85 \\
(0.36)\end{array}$ & $\begin{array}{c}1.65 \\
(0.42)\end{array}$ & $\begin{array}{c}0.75 \\
(0.47)\end{array}$ & $\begin{array}{c}1.39 \\
(0.49)\end{array}$ & $\begin{array}{c}0.30 \\
(0.57)\end{array}$ & $\begin{array}{c}1.46 \\
(0.20)\end{array}$ & $\begin{array}{c}1.14 \\
(0.23)\end{array}$ \\
\hline Number of observations & 460 & 188 & 233 & 198 & 345 & 230 & 141 & 94 & 234 & 187 \\
\hline Number of countries & 115 & 47 & 47 & 36 & 115 & 115 & 47 & 47 & 47 & 47 \\
\hline \multicolumn{11}{|c|}{ Panel D: Dependent variable is log number of births } \\
\hline & $\begin{array}{c}\text { Just } 1960 \text { and } \\
1990\end{array}$ & $\begin{array}{c}\text { Just } 1960 \text { and } \\
1990\end{array}$ & $\begin{array}{c}\text { Just } 1940 \text { and } \\
1980\end{array}$ & $\begin{array}{c}\text { Just } 1940 \text { and } \\
1980\end{array}$ & $\begin{array}{c}\text { Just } 1960 \text { and } \\
1980\end{array}$ & $\begin{array}{l}\text { Just } 1960 \text { and } \\
1970\end{array}$ & $\begin{array}{c}\text { Just } 1960 \text { and } \\
1980\end{array}$ & $\begin{array}{c}\text { Just } 1960 \text { and } \\
1970\end{array}$ & $\begin{array}{c}\text { Just } 1940 \text { and } \\
1980\end{array}$ & $\begin{array}{c}\text { Just } 1940 \text { and } \\
1970\end{array}$ \\
\hline Life Expectancy & $\begin{array}{c}2.09 \\
(0.53)\end{array}$ & $\begin{array}{c}2.00 \\
(0.42)\end{array}$ & $\begin{array}{c}1.88 \\
(0.41)\end{array}$ & $\begin{array}{c}1.97 \\
(0.47)\end{array}$ & $\begin{array}{c}1.72 \\
(0.50)\end{array}$ & $\begin{array}{c}0.75 \\
(0.47)\end{array}$ & $\begin{array}{c}1.37 \\
(0.59)\end{array}$ & $\begin{array}{c}0.30 \\
(0.57)\end{array}$ & $\begin{array}{c}1.55 \\
(0.25)\end{array}$ & $\begin{array}{c}1.30 \\
(0.31)\end{array}$ \\
\hline Number of observations & 230 & 94 & 92 & 70 & 230 & 230 & 94 & 94 & 92 & 92 \\
\hline Number of countries & 115 & 47 & 46 & 35 & 115 & 115 & 47 & 47 & 46 & 46 \\
\hline
\end{tabular}

OLS regressions with a full set of year and country fixed effects. Robust standard errors, adjusted for clustering by country, in parentheses.

Panels $A$ and $C$ are unbalanced panels with one observation per decade. Panels $B$ and $D$ are long-difference specifications with observations for only the beginning and end dates. Dependent variable is log population in Panels $A$ and $B$ and log total births in Panels $C$ and $D$. Independent variable in all regressions is log life expectancy at birth. In columns 1-4, the dependent variable and independent variable are for the same time period; in columns $5-10$, the dependent variable is for $t+10$ or $t+20$ as indicated, while the independent variable is for time t. "All countries" are those for which we have data on the dependent and independent variables. Base sample is countries for which we have disease data.

Assignment of countries to low and middle income categories is based on 1940 income per capita; see text and Appendix A for details and definitions. 
Table 3

Life Expectancy, GDP and GDP per capita: OLS Estimates

\begin{tabular}{|c|c|c|c|c|c|c|c|c|c|c|}
\hline & \multirow{2}{*}{$\begin{array}{c}\text { All Countries } \\
\text { No leads } \\
(1)\end{array}$} & \multicolumn{2}{|c|}{ Base Sample } & \multirow{2}{*}{$\begin{array}{c}\text { Low \& Middle } \\
\text { Income } \\
\text { Countries Only } \\
\text { No leads } \\
(4)\end{array}$} & \multicolumn{2}{|c|}{ All Countries } & \multicolumn{4}{|c|}{ Base Sample } \\
\hline & & $\begin{array}{c}\text { No leads } \\
\text { (2) }\end{array}$ & $\begin{array}{c}\text { No leads } \\
\text { (3) }\end{array}$ & & $\begin{array}{c}10 \text { year lead } \\
\text { (5) }\end{array}$ & $\begin{array}{c}20 \text { year lead } \\
\text { (6) }\end{array}$ & $\begin{array}{c}10 \text { year lead } \\
(7)\end{array}$ & $\begin{array}{c}20 \text { year lead } \\
(8)\end{array}$ & $\begin{array}{c}10 \text { year lead } \\
\text { (9) }\end{array}$ & $\begin{array}{c}20 \text { year lead } \\
(10)\end{array}$ \\
\hline \multicolumn{11}{|c|}{ Panel A: Dependent variable is log GDP } \\
\hline & $\begin{array}{l}\text { Panel, 1960- } \\
2000\end{array}$ & $\begin{array}{l}\text { Panel, } 1960- \\
\quad 2000\end{array}$ & $\begin{array}{l}\text { Panel, 1940- } \\
\quad 1980\end{array}$ & $\begin{array}{l}\text { Panel, } 1940- \\
\quad 1980\end{array}$ & $\begin{array}{l}\text { Panel, } 1960- \\
\quad 1990\end{array}$ & $\begin{array}{l}\text { Panel, } 1960- \\
\quad 1980\end{array}$ & $\begin{array}{l}\text { Panel, 1960- } \\
\quad 1990\end{array}$ & $\begin{array}{l}\text { Panel, } 1960- \\
1980\end{array}$ & $\begin{array}{l}\text { Panel, } 1940- \\
\quad 1980\end{array}$ & $\begin{array}{l}\text { Panel, 1940- } \\
\quad 1980\end{array}$ \\
\hline Log Life Expectancy & $\begin{array}{c}1.35 \\
(0.49)\end{array}$ & $\begin{array}{c}1.70 \\
(0.45)\end{array}$ & $\begin{array}{l}0.73 \\
(0.35)\end{array}$ & $\begin{array}{c}0.65 \\
(0.42)\end{array}$ & $\begin{array}{c}1.09 \\
(0.44)\end{array}$ & $\begin{array}{c}0.29 \\
(0.62)\end{array}$ & $\begin{array}{c}1.37 \\
(0.37)\end{array}$ & $\begin{array}{l}0.97 \\
(0.52)\end{array}$ & $\begin{array}{l}0.73 \\
(0.24)\end{array}$ & $\begin{array}{l}0.90 \\
(0.30)\end{array}$ \\
\hline Number of observations & 600 & 294 & 283 & 228 & 480 & 360 & 235 & 176 & 283 & 283 \\
\hline Number of countries & 120 & 59 & 59 & 48 & 120 & 120 & 59 & 59 & 59 & 59 \\
\hline \multicolumn{11}{|c|}{ Panel B: Dependent variable is log GDP } \\
\hline & $\begin{array}{l}\text { Just } 1960 \text { and } \\
2000\end{array}$ & $\begin{array}{l}\text { Just } 1960 \text { and } \\
2000\end{array}$ & $\begin{array}{l}\text { Just } 1940 \text { and } \\
1980\end{array}$ & $\begin{array}{c}\text { Just } 1940 \text { and } \\
1980\end{array}$ & $\begin{array}{l}\text { Just } 1960 \text { and } \\
1990\end{array}$ & $\begin{array}{l}\text { Just } 1960 \text { and } \\
1980\end{array}$ & $\begin{array}{c}\text { Just } 1960 \text { and } \\
1990\end{array}$ & $\begin{array}{l}\text { Just } 1960 \text { and } \\
1980\end{array}$ & $\begin{array}{c}\text { Just } 1940 \text { and } \\
1980\end{array}$ & $\begin{array}{c}\text { Just } 1940 \text { and } \\
1980\end{array}$ \\
\hline Log Life Expectancy & $\begin{array}{c}1.17 \\
(0.80)\end{array}$ & $\begin{array}{c}1.55 \\
(0.49)\end{array}$ & $\begin{array}{c}0.78 \\
(0.58)\end{array}$ & $\begin{array}{c}0.65 \\
(0.73)\end{array}$ & $\begin{array}{c}1.07 \\
(0.59)\end{array}$ & $\begin{array}{c}0.39 \\
(0.76)\end{array}$ & $\begin{array}{c}1.61 \\
(0.48)\end{array}$ & $\begin{array}{c}1.11 \\
(1.02)\end{array}$ & $\begin{array}{c}0.75 \\
(0.39)\end{array}$ & $\begin{array}{c}0.92 \\
(0.47)\end{array}$ \\
\hline Number of observations & 240 & 118 & 94 & 72 & 240 & 240 & 118 & 116 & 94 & 94 \\
\hline Number of countries & 120 & 59 & 47 & 36 & 120 & 120 & 59 & 58 & 47 & 47 \\
\hline \multicolumn{11}{|c|}{ Panel C: Dependent variable is log GDP per capita } \\
\hline & $\begin{array}{l}\text { Panel, 1960- } \\
1990\end{array}$ & $\begin{array}{l}\text { Panel, 1960- } \\
1990\end{array}$ & $\begin{array}{l}\text { Panel, 1940- } \\
1980\end{array}$ & $\begin{array}{c}\text { Panel, 1940- } \\
1980\end{array}$ & $\begin{array}{c}\text { Panel, 1960- } \\
1990\end{array}$ & $\begin{array}{l}\text { Panel, 1960- } \\
1980\end{array}$ & $\begin{array}{l}\text { Panel, 1960- } \\
1990\end{array}$ & $\begin{array}{c}\text { Panel, 1960- } \\
1980\end{array}$ & $\begin{array}{c}\text { Panel, 1940- } \\
1980\end{array}$ & $\begin{array}{c}\text { Panel, 1940- } \\
1980\end{array}$ \\
\hline Log Life Expectancy & $\begin{array}{l}-0.10 \\
(0.48)\end{array}$ & $\begin{array}{l}0.003 \\
(0.46)\end{array}$ & $\begin{array}{l}-0.44 \\
(0.30)\end{array}$ & $\begin{array}{l}-0.44 \\
(0.23)\end{array}$ & $\begin{array}{l}-0.63 \\
(0.51)\end{array}$ & $\begin{array}{l}-1.31 \\
(0.69)\end{array}$ & $\begin{array}{c}0.03 \\
(0.50)\end{array}$ & $\begin{array}{r}-0.001 \\
(0.75)\end{array}$ & $\begin{array}{l}-0.57 \\
(0.28)\end{array}$ & $\begin{array}{l}-0.33 \\
(0.39)\end{array}$ \\
\hline Number of observations & 600 & 294 & 283 & 228 & 480 & 360 & 235 & 176 & 283 & 283 \\
\hline Number of countries & 120 & 59 & 59 & 48 & 120 & 120 & 59 & 59 & 59 & 59 \\
\hline \multicolumn{11}{|c|}{ Panel D: Dependent variable is log GDP per capita } \\
\hline & $\begin{array}{l}\text { Just } 1960 \text { and } \\
2000\end{array}$ & $\begin{array}{l}\text { Just } 1960 \text { and } \\
2000\end{array}$ & $\begin{array}{l}\text { Just } 1940 \text { and } \\
1980\end{array}$ & $\begin{array}{c}\text { Just } 1940 \text { and } \\
1980\end{array}$ & $\begin{array}{l}\text { Just } 1960 \text { and } \\
1990\end{array}$ & $\begin{array}{c}\text { Just } 1960 \text { and } \\
1980\end{array}$ & $\begin{array}{c}\text { Just } 1960 \text { and } \\
1990\end{array}$ & $\begin{array}{c}\text { Just } 1960 \text { and } \\
1980\end{array}$ & $\begin{array}{l}\text { Just } 1940 \text { and } \\
1980\end{array}$ & $\begin{array}{c}\text { Just } 1940 \text { and } \\
1980\end{array}$ \\
\hline Log Life Expectancy & $\begin{array}{l}-0.42 \\
(0.82)\end{array}$ & $\begin{array}{l}-0.19 \\
(0.76)\end{array}$ & $\begin{array}{l}-0.81 \\
(0.42)\end{array}$ & $\begin{array}{l}-0.13 \\
(0.69)\end{array}$ & $\begin{array}{l}-0.84 \\
(0.70)\end{array}$ & $\begin{array}{l}-1.31 \\
(0.85)\end{array}$ & $\begin{array}{c}0.18 \\
(0.82)\end{array}$ & $\begin{array}{l}-0.48 \\
(1.18)\end{array}$ & $\begin{array}{l}-0.96 \\
(0.43)\end{array}$ & $\begin{array}{c}-0.70 \\
(0.50)\end{array}$ \\
\hline Number of observations & 240 & 118 & 94 & 54 & 240 & 240 & 118 & 116 & 94 & 94 \\
\hline Number of countries & 120 & 59 & 47 & 27 & 120 & 120 & 59 & 58 & 47 & 47 \\
\hline
\end{tabular}

OLS regressions with a full set of year and country fixed effects. Robust standard errors, adjusted for clustering by country, in parentheses.

Panels $A$ and $C$ are unbalanced panels with one observation per decade. Panels $B$ and $D$ are long-difference specifications with observations for only the beginning and end dates. Dependent variable is log total GDP in Panels A and B and log GDP per capita in Panels C and D.

Independent variable in all regressions is log life expectancy at birth. In columns 1-4, the dependent variable and independent variable are for the same time period; in columns 5-10, the dependent variable is for $t+10$ or $t+20$ as indicated, while the independent variable is for time $t$. "All countries" are those for which we have data on the dependent and independent variables. Base sample is countries for which we have disease data. Assignment of countries to low and middle income categories is based on 1940 income per capita; see text and Appendix A for details and definitions. 
Table 4

The Effect of Interventions on Disease Mortality (zeroth stage)

\begin{tabular}{|c|c|c|c|c|c|c|c|}
\hline \multirow{4}{*}{ Panel A: diseases are -- } & \multicolumn{7}{|c|}{$\begin{array}{c}\text { Dependent Variable is mortality per } 100,000 \text { from disease } i \text { in country } j \text { at } \\
\text { period } t\end{array}$} \\
\hline & Base Sample & Base Sample & Base Sample & Without TB & $\begin{array}{c}\text { Without } \\
\text { pneumonia } \\
\end{array}$ & $\begin{array}{l}\text { Without } \\
\text { malaria } \\
\end{array}$ & $\begin{array}{c}\text { Without } \\
\text { influenza }\end{array}$ \\
\hline & \multicolumn{7}{|c|}{ Panel, 1930-1960 } \\
\hline & $(1)$ & $(2)$ & $(3)$ & (4) & $(5)$ & $(6)$ & $(7)$ \\
\hline Intervention & $\begin{array}{l}-46.04 \\
(9.40)\end{array}$ & $\begin{array}{l}-43.33 \\
(10.36)\end{array}$ & $\begin{array}{l}-46.04 \\
(9.40)\end{array}$ & $\begin{array}{l}-33.93 \\
(8.66)\end{array}$ & $\begin{array}{l}-36.31 \\
(8.99)\end{array}$ & $\begin{array}{l}-48.57 \\
(9.23)\end{array}$ & $\begin{array}{l}-48.62 \\
(9.69)\end{array}$ \\
\hline Lagged Intervention & & $\begin{array}{l}-4.59 \\
(8.05)\end{array}$ & & & & & \\
\hline Lead Intervention & & & $\begin{array}{l}20.57 \\
(9.47)\end{array}$ & & & & \\
\hline R-squared & 0.52 & 0.47 & 0.47 & 0.49 & 0.48 & 0.48 & 0.48 \\
\hline Number of observations & 1479 & 1479 & 1479 & 1327 & 1364 & 1361 & 1328 \\
\hline Panel B: diseases are -- & $\begin{array}{l}\text { Just scarlet } \\
\text { fever }\end{array}$ & Just typhoid & $\begin{array}{c}\text { Just } \\
\text { diphtheria }\end{array}$ & Just TB & Just pneumonia & Just malaria & $\begin{array}{c}\text { Just } \\
\text { influenza }\end{array}$ \\
\hline Intervention & $\begin{array}{l}-0.25 \\
(0.10)\end{array}$ & $\begin{array}{l}-8.84 \\
(3.01)\end{array}$ & $\begin{array}{l}-2.47 \\
(0.92)\end{array}$ & $\begin{array}{l}-108.51 \\
(22.91)\end{array}$ & $\begin{array}{r}-137.92 \\
(26.96)\end{array}$ & $\begin{array}{r}-19.97 \\
(9.67)\end{array}$ & $\begin{array}{l}-14.95 \\
(11.37)\end{array}$ \\
\hline R-squared & 0.56 & 0.71 & 0.63 & 0.72 & 0.82 & 0.58 & 0.61 \\
\hline Number of observations & 140 & 148 & 147 & 152 & 115 & 118 & 151 \\
\hline Number of countries & 49 & 49 & 49 & 49 & 49 & 49 & 49 \\
\hline
\end{tabular}

OLS regressions with a full set of disease, year, and country fixed effects. Robust standard errors, adjusted for clustering by country-disease pair, in parentheses. Unbalanced panels with data for 1930, 1940, 1950 and 1960. Data are stacked; dependent variable is deaths per 100,000 from disease i in country j at year t. Base sample is 15 infectious diseases plus cancer and malignant tumors. Independent variables: dummy for intervention (e.g., for malaria equals 1 for 1950 and 1960, zero otherwise), dummy for lead intervention (e.g., for malaria equals 1 for 1940, 1950 and 1960), dummy for lagged intervention (e.g., for malaria equals 1 for 1960). 
Table 5

First Stage Estimates: Predicted Mortality and Life Expectancy

\begin{tabular}{|c|c|c|c|c|c|c|c|c|c|c|c|c|}
\hline \multicolumn{13}{|c|}{ Dependent Variable is log life expectancy } \\
\hline & \multicolumn{8}{|c|}{ Baseline predicted mortality } & \multicolumn{2}{|c|}{ Using global mortality rate } & $\begin{array}{l}\text { Alternative } \\
\text { timing }\end{array}$ & $\begin{array}{c}\mathrm{TB} \text {, malaria, and } \\
\text { pneumonia } \\
\text { mortality only }\end{array}$ \\
\hline & \multicolumn{2}{|c|}{ Base Sample } & \multirow{2}{*}{$\begin{array}{c}\text { Including } \\
\text { Eastern } \\
\text { Europe } \\
(3) \\
\end{array}$} & \multirow{2}{*}{$\begin{array}{c}\text { Low and } \\
\text { Middle Income } \\
\text { Countries Only }\end{array}$} & \multirow{2}{*}{$\begin{array}{c}\begin{array}{c}\text { Balanced Panel } \\
\text { Sample }\end{array} \\
(5) \\
\end{array}$} & \multirow{2}{*}{$\begin{array}{c}\text { Base Sample, } \\
\text { Interaction with } \\
\text { Institutions }\end{array}$} & \multirow{2}{*}{$\begin{array}{c}\text { Base Sample, } \\
\text { Interaction with } \\
\text { Initial (1930) log } \\
\text { GDP p.c. } \\
(7)\end{array}$} & \multirow{2}{*}{ 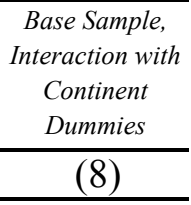 } & \multirow{2}{*}{$\frac{\text { Base Sample }}{(9)}$} & \multirow{2}{*}{$\begin{array}{c}\text { Low and } \\
\text { Middle Income } \\
\text { Countries Only } \\
(10)\end{array}$} & \multicolumn{2}{|c|}{ Base Sample } \\
\hline & $(1)$ & $(2)$ & & & & & & & & & $(11)$ & $(12)$ \\
\hline Panel A & $\begin{array}{l}\text { Panel, 1940- } \\
1980\end{array}$ & $\begin{array}{c}\text { Panel, 1930- } \\
1980\end{array}$ & $\begin{array}{l}\text { Panel, 1940- } \\
1980\end{array}$ & $\begin{array}{l}\text { Panel, 1940- } \\
\quad 1980\end{array}$ & $\begin{array}{c}\text { Balanced Panel, } \\
1940-1980\end{array}$ & $\begin{array}{l}\text { Panel, 1940- } \\
1980\end{array}$ & Panel, 1940-1980 & $\begin{array}{l}\text { Panel, 1940- } \\
1980\end{array}$ & $\begin{array}{l}\text { Panel, 1940- } \\
1980\end{array}$ & $\begin{array}{l}\text { Panel, 1940- } \\
1960\end{array}$ & $\begin{array}{l}\text { Panel, 1940- } \\
1980\end{array}$ & $\begin{array}{l}\text { Panel, 1940- } \\
1980\end{array}$ \\
\hline Predicted Mortality & $\begin{array}{l}-0.33 \\
(0.06)\end{array}$ & $\begin{array}{l}-0.36 \\
(0.06)\end{array}$ & $\begin{array}{l}-0.34 \\
(0.06)\end{array}$ & $\begin{array}{l}-0.23 \\
(0.08)\end{array}$ & $\begin{array}{l}-0.32 \\
(0.06)\end{array}$ & $\begin{array}{l}-0.27 \\
(0.07)\end{array}$ & $\begin{array}{l}-0.24 \\
(0.10)\end{array}$ & $\begin{array}{l}-0.25 \\
(0.07)\end{array}$ & $\begin{array}{l}-0.41 \\
(0.08)\end{array}$ & $\begin{array}{l}-0.26 \\
(0.10)\end{array}$ & $\begin{array}{l}-0.33 \\
(0.06)\end{array}$ & $\begin{array}{l}-0.35 \\
(0.08)\end{array}$ \\
\hline R-squared & 0.93 & 0.93 & 0.92 & 0.93 & 0.94 & 0.94 & 0.95 & 0.95 & 0.93 & 0.93 & 0.93 & 0.93 \\
\hline $\begin{array}{l}\text { Number of observations } \\
\text { Number of countries }\end{array}$ & $\begin{array}{c}283 \\
59 \\
\end{array}$ & $\begin{array}{c}316 \\
59 \\
\end{array}$ & $\begin{array}{c}312 \\
65 \\
\end{array}$ & $\begin{array}{c}228 \\
48 \\
\end{array}$ & $\begin{array}{c}230 \\
46 \\
\end{array}$ & $\begin{array}{c}271 \\
56\end{array}$ & $\begin{array}{c}243 \\
49 \\
\end{array}$ & $\begin{array}{c}283 \\
59 \\
\end{array}$ & $\begin{array}{c}263 \\
59 \\
\end{array}$ & $\begin{array}{c}208 \\
48 \\
\end{array}$ & $\begin{array}{c}283 \\
59 \\
\end{array}$ & $\begin{array}{c}283 \\
59 \\
\end{array}$ \\
\hline Panel B & $\begin{array}{c}\text { Just } 1940 \text { and } \\
1980\end{array}$ & $\begin{array}{c}\text { Just } 1930 \text { and } \\
1980\end{array}$ & $\begin{array}{c}\text { Just } 1940 \text { and } \\
1980\end{array}$ & $\begin{array}{c}\text { Just } 1940 \text { and } \\
1980\end{array}$ & $\begin{array}{c}\text { Just } 1940 \text { and } \\
1980\end{array}$ & $\begin{array}{c}\text { Just } 1940 \text { and } \\
1980\end{array}$ & $\begin{array}{c}\text { Just } 1940 \text { and } \\
1980\end{array}$ & $\begin{array}{c}\text { Just } 1940 \text { and } \\
1980\end{array}$ & $\begin{array}{c}\text { Just } 1940 \text { and } \\
1960\end{array}$ & $\begin{array}{c}\text { Just } 1940 \text { and } \\
1960\end{array}$ & $\begin{array}{l}\text { Just } 1940 \text { and } \\
1980\end{array}$ & $\begin{array}{l}\text { Just } 1940 \text { and } \\
1980\end{array}$ \\
\hline Predicted Mortality & $\begin{array}{l}-0.44 \\
(0.09)\end{array}$ & $\begin{array}{l}-0.53 \\
(0.11)\end{array}$ & $\begin{array}{l}-0.46 \\
(0.06)\end{array}$ & $\begin{array}{l}-0.31 \\
(0.12)\end{array}$ & $\begin{array}{l}-0.45 \\
(0.09)\end{array}$ & $\begin{array}{l}-0.35 \\
(0.10)\end{array}$ & $\begin{array}{l}-0.25 \\
(0.13)\end{array}$ & $\begin{array}{l}-0.30 \\
(0.11)\end{array}$ & $\begin{array}{l}-0.40 \\
(0.12)\end{array}$ & $\begin{array}{l}-0.29 \\
(0.17)\end{array}$ & $\begin{array}{l}-0.45 \\
(0.09)\end{array}$ & $\begin{array}{l}-0.49 \\
(0.11)\end{array}$ \\
\hline R-squared & 0.95 & 0.95 & 0.95 & 0.95 & 0.95 & 0.95 & 0.96 & 0.96 & 0.95 & 0.94 & 0.95 & 0.95 \\
\hline Number of observations & 94 & 66 & 106 & 72 & 92 & 94 & 94 & 94 & 94 & 72 & 94 & 94 \\
\hline Number of countries & 47 & 33 & 53 & 36 & 46 & 47 & 47 & 47 & 47 & 36 & 47 & 47 \\
\hline
\end{tabular}

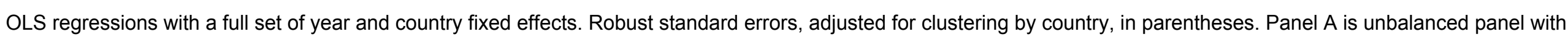

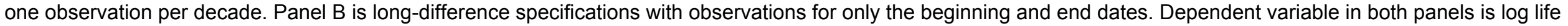

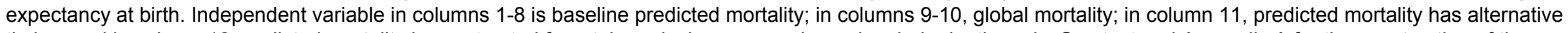

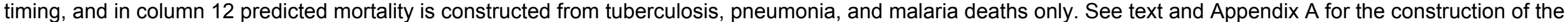

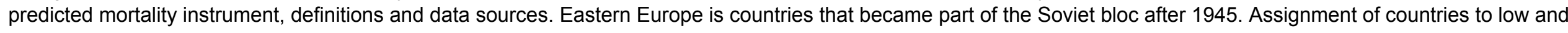
middle income categories is based on 1940 income per capita.

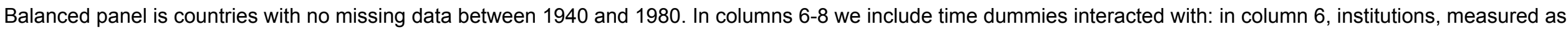

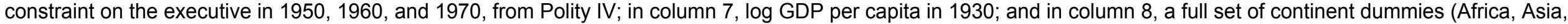
Americas, Europe; Oceania is the omitted category). 


\section{Table 6}

First Stage Estimates: Mean Reversion and Robustness

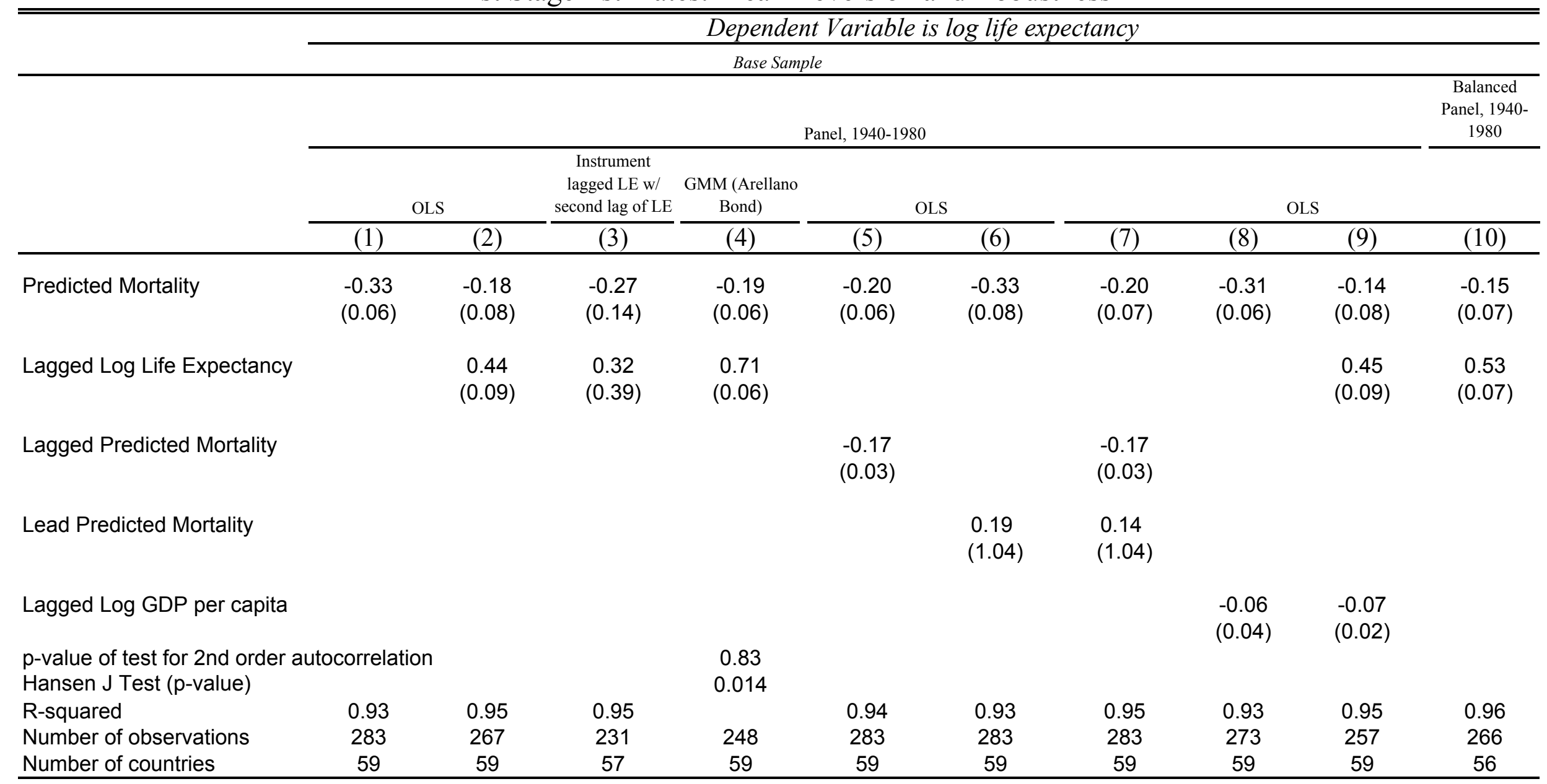

OLS (columns 1-2 and 5-10) and 2SLS (columns 3-4) regressions with a full set of year and country fixed effects. Robust standard errors, adjusted for clustering by country, in parentheses. All columns are unbalanced panels with one observation per decade, using base sample countries. Dependent variable in is log life expectancy at birth. Independent variables vary by column; lagged values are 10 years earlier and lead predicted mortality is 10 years ahead.

Assignment of countries to low and middle income categories is based on 1940 income per capita. In column 3, the second lag of log life expectancy is used as an instrument for lagged log life expectancy. In column 4, GMM of Arellano-Bond uses all available lags of log life expectancy as instruments. Balanced panel is countries with no missing data between 1940 and 1980. 


\section{Table 7}

Falsification Exercise and Reduced Forms

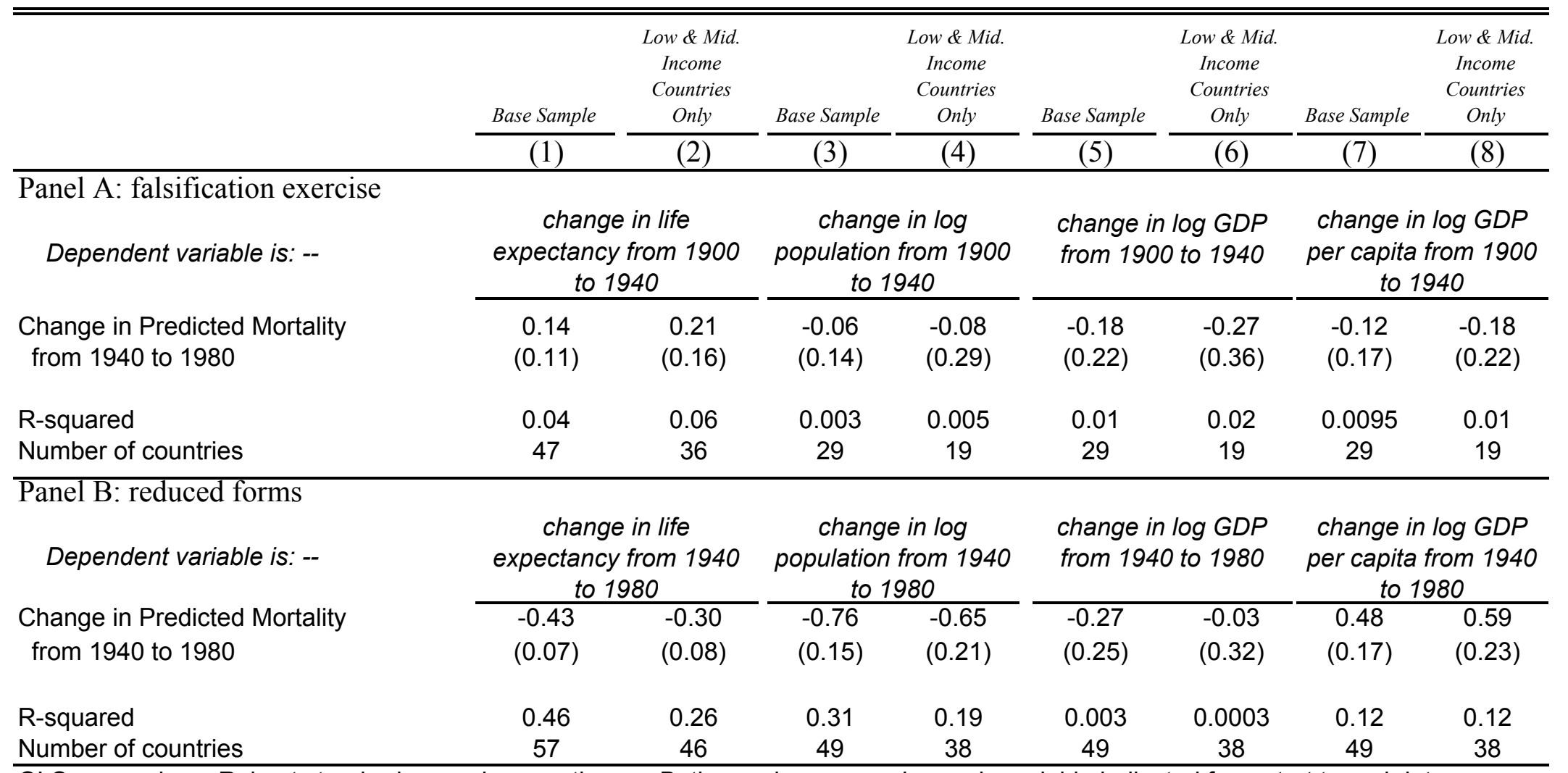

OLS regressions. Robust standard errors in parentheses. Both panels regress change in variable indicated from start to end date on change in predicted mortality from 1940 to 1980 . Predicted mortality is deaths per 100 population. Panel A uses subset of base sample for which data on all outcome variables are available and for which there is no discontinuity in boundaries of country during the relevant period. 
Table 8

The Effect of Life Expectancy on Log Population: 2SLS Estimates

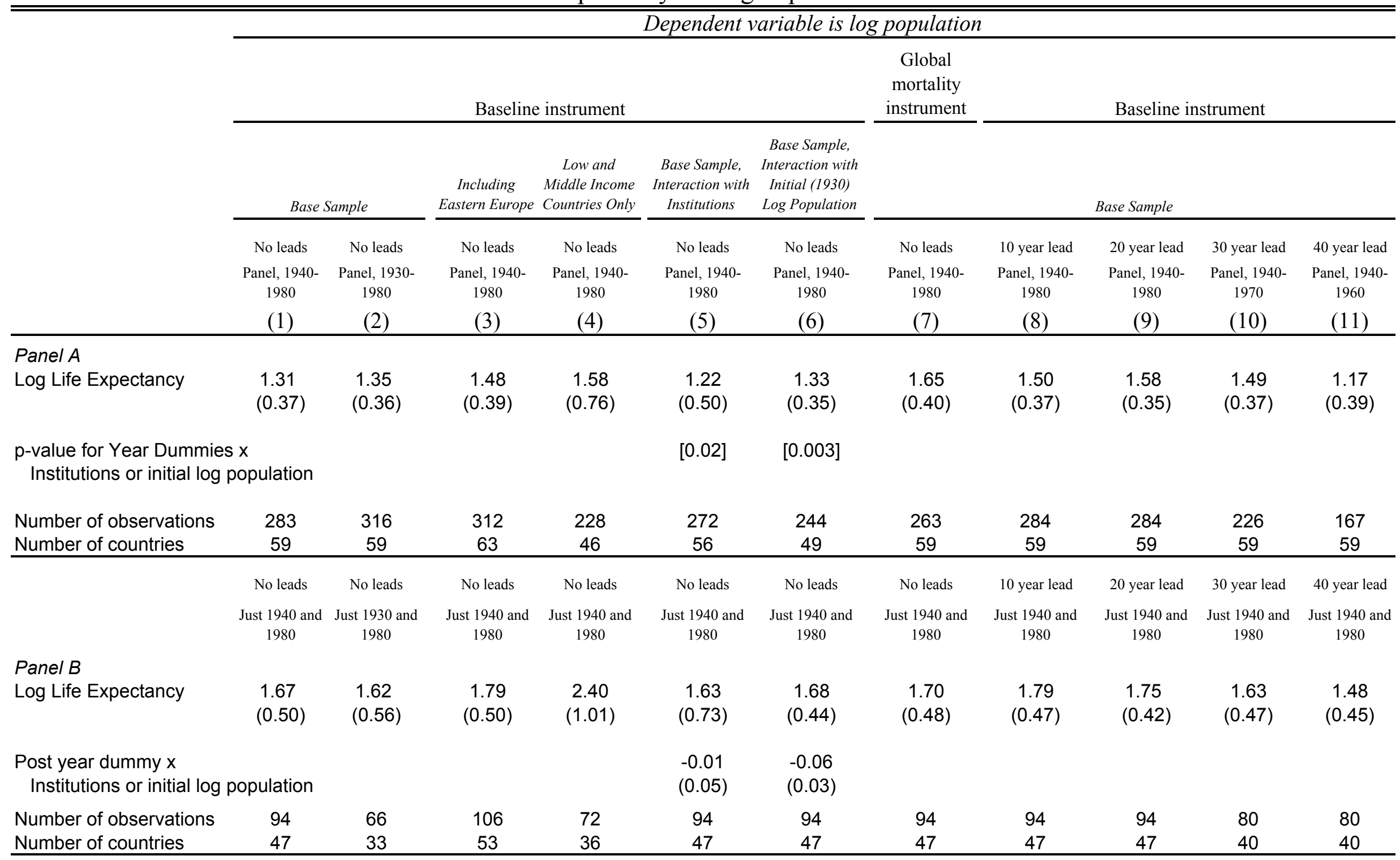

2SLS regressions with a full set of year and country fixed effects. Robust standard errors, adjusted for clustering by country, in parentheses. Panel $\mathrm{A}$ is unbalanced panel with one observation per decade. Panel B is long-difference specification with observations for only the beginning and end dates. Dependent variable in both panels is log total population. Independent variable in both panels is log life expectancy at birth. In columns 1-6 and 8-11, log life expectancy is instrumented by predicted mortality (baseline instrument), and in column 7 it is instrumented by global mortality. First stages are in Table 5. In columns 1-7, the dependent and independent variables are for the same time period; in columns $8-11$, the dependent variable is $t+10, t+20$ etc., as indicated, while the independent variable is at time t. Columns 5 and 6 include year dummies interacted with: institutions, in column 5, as average of constraint on executive in 1950, 1960, and 1970 from Polity IV, where scores range from 1 to 7 and non-independent countries are assigned score of 1 ; and initial log population, in column 6 , is for 1930. See text and Appendix A for construction of the mortality instruments, definitions, and data sources. 
Table 9

The Effect of Life Expectancy on Log Births: 2SLS Estimates

\begin{tabular}{|c|c|c|c|c|c|c|c|c|c|c|c|}
\hline & \multicolumn{11}{|c|}{ Dependent variable is log total births } \\
\hline & \multicolumn{6}{|c|}{ Baseline instrument } & $\begin{array}{c}\text { Global } \\
\text { mortality } \\
\text { instrument } \\
\end{array}$ & \multicolumn{4}{|c|}{ Baseline instrument } \\
\hline & \multicolumn{2}{|c|}{ Base Sample } & $\begin{array}{l}\text { Including } \\
\text { Eastern } \\
\text { Europe }\end{array}$ & $\begin{array}{l}\text { Low and } \\
\text { Middle Income } \\
\text { Countries } \\
\text { Only }\end{array}$ & $\begin{array}{l}\text { Base Sample, } \\
\text { Interaction } \\
\text { with } \\
\text { Institutions } \\
\end{array}$ & $\begin{array}{c}\text { Base Sample, } \\
\text { Interaction with } \\
\text { Initial (1930) } \\
\text { Log Births } \\
\end{array}$ & & & Base Sample & & \\
\hline & No leads & No leads & No leads & No leads & No leads & No leads & No leads & 10 year lead & 20 year lead & 30 year lead & 40 year lead \\
\hline & $\begin{array}{l}\text { Panel, 1940- } \\
1980\end{array}$ & $\begin{array}{c}\text { Panel, 1930- } \\
1980\end{array}$ & $\begin{array}{l}\text { Panel, 1940- } \\
1980\end{array}$ & $\begin{array}{l}\text { Panel, 1940- } \\
1980\end{array}$ & $\begin{array}{l}\text { Panel, 1940- } \\
1980\end{array}$ & $\begin{array}{l}\text { Panel, 1940- } \\
1980\end{array}$ & $\begin{array}{l}\text { Panel, 1940- } \\
1980\end{array}$ & $\begin{array}{l}\text { Panel, 1940- } \\
1980\end{array}$ & $\begin{array}{l}\text { Panel, 1940- } \\
1980\end{array}$ & $\begin{array}{l}\text { Panel, 1940- } \\
1980\end{array}$ & $\begin{array}{c}\text { Panel, 1940- } \\
1980\end{array}$ \\
\hline & (1) & (2) & (3) & (4) & (5) & (6) & (7) & (8) & (9) & (10) & (11) \\
\hline \multicolumn{12}{|l|}{ Panel A } \\
\hline Log Life Expectancy & $\begin{array}{c}2.39 \\
(0.69)\end{array}$ & $\begin{array}{c}2.16 \\
(0.60)\end{array}$ & $\begin{array}{c}2.59 \\
(0.72)\end{array}$ & $\begin{array}{c}3.10 \\
(1.49)\end{array}$ & $\begin{array}{c}2.32 \\
(1.01)\end{array}$ & $\begin{array}{c}2.27 \\
(0.60)\end{array}$ & $\begin{array}{c}2.46 \\
(0.60)\end{array}$ & $\begin{array}{c}1.66 \\
(0.38)\end{array}$ & $\begin{array}{c}1.81 \\
(0.50)\end{array}$ & $\begin{array}{c}1.03 \\
(0.52)\end{array}$ & $\begin{array}{c}0.04 \\
(0.53)\end{array}$ \\
\hline \multicolumn{3}{|c|}{$\begin{array}{l}p \text {-value for Year Dummies } x \\
\text { Institutions or initial log births }\end{array}$} & & & [0.33] & [0.03] & & & & & \\
\hline Number of observations & 233 & 264 & 261 & 178 & 233 & 221 & 231 & 234 & 187 & 140 & 93 \\
\hline Number of countries & 47 & 47 & 53 & 36 & 47 & 45 & 47 & 47 & 47 & 47 & 47 \\
\hline & No leads & No leads & No leads & No leads & No leads & No leads & No leads & 10 year lead & 20 year lead & 30 year lead & 40 year lead \\
\hline & $\begin{array}{c}\text { Just } 1940 \text { and } \\
1980\end{array}$ & $\begin{array}{c}\text { Just } 1930 \text { and } \\
1980\end{array}$ & $\begin{array}{c}\text { Just } 1940 \text { and } \\
1980\end{array}$ & $\begin{array}{c}\text { Just } 1940 \text { and } \\
1980\end{array}$ & $\begin{array}{c}\text { Just } 1940 \text { and } \\
1980\end{array}$ & $\begin{array}{c}\text { Just } 1940 \text { and } \\
1980\end{array}$ & $\begin{array}{c}\text { Just } 1940 \text { and } \\
1980\end{array}$ & $\begin{array}{c}\text { Just } 1940 \text { and } \\
1980\end{array}$ & $\begin{array}{c}\text { Just } 1940 \text { and } \\
1970\end{array}$ & $\begin{array}{c}\text { Just } 1940 \text { and } \\
1960\end{array}$ & $\begin{array}{c}\text { Just } 1940 \text { and } \\
1950\end{array}$ \\
\hline \multicolumn{12}{|l|}{ Panel B } \\
\hline Log Life Expectancy & $\begin{array}{l}2.53 \\
(0.73)\end{array}$ & $\begin{array}{l}2.03 \\
(0.87)\end{array}$ & $\begin{array}{c}2.66 \\
(0.73)\end{array}$ & $\begin{array}{c}2.92 \\
(1.40)\end{array}$ & $\begin{array}{c}2.40 \\
(1.12)\end{array}$ & $\begin{array}{c}2.53 \\
(0.70)\end{array}$ & $\begin{array}{c}2.50 \\
(0.73)\end{array}$ & $\begin{array}{c}1.62 \\
(0.46)\end{array}$ & $\begin{array}{c}1.52 \\
(0.54)\end{array}$ & $\begin{array}{c}0.87 \\
(0.58)\end{array}$ & $\begin{array}{c}0.05 \\
(0.53)\end{array}$ \\
\hline \multicolumn{3}{|c|}{$\begin{array}{l}\text { Post year dummy } x \\
\text { Institutions or initial log births }\end{array}$} & & & $\begin{array}{l}-0.02 \\
(0.09)\end{array}$ & $\begin{array}{l}-0.06 \\
(0.05)\end{array}$ & & & & & \\
\hline Number of observations & 90 & 88 & 98 & 68 & 90 & 88 & 90 & 90 & 90 & 90 & 90 \\
\hline Number of countries & 45 & 44 & 49 & 34 & 45 & 44 & 45 & 45 & 45 & 45 & 45 \\
\hline
\end{tabular}

2SLS regressions with a full set of year and country fixed effects. Robust standard errors, adjusted for clustering by country, in parentheses. Panel $A$ is unbalanced panel with one observation per decade. Panel B is long-difference specification with observations for only the beginning and end dates. Dependent variable in both panels is log total births. Independent variable in both panels is log life expectancy at birth. In columns 1-6 and 8-11, log life expectancy is instrumented by predicted mortality (baseline instrument), and in column 7 it is instrumented by global mortality. First stages are in Table 5. In columns 1-7, the dependent and independent variables are for the same time period; in columns $8-11$, the dependent variable is $t+10, t+20$ etc., as indicated, while the independent variable is at time t. Columns 5 and 6 include year dummies interacted with: institutions, in column 5 , as average of constraint on executive in 1950, 1960, and 1970 from Polity IV, where scores range from 1 to 7 and non-independent countries are assigned score of 1 ; and initial log births, in column 6 , is for 1930. See text and Appendix A for construction of the mortality instruments, definitions, and data sources. 
Table 10

The Effect of Life Expectancy on Log GDP: 2SLS Estimates

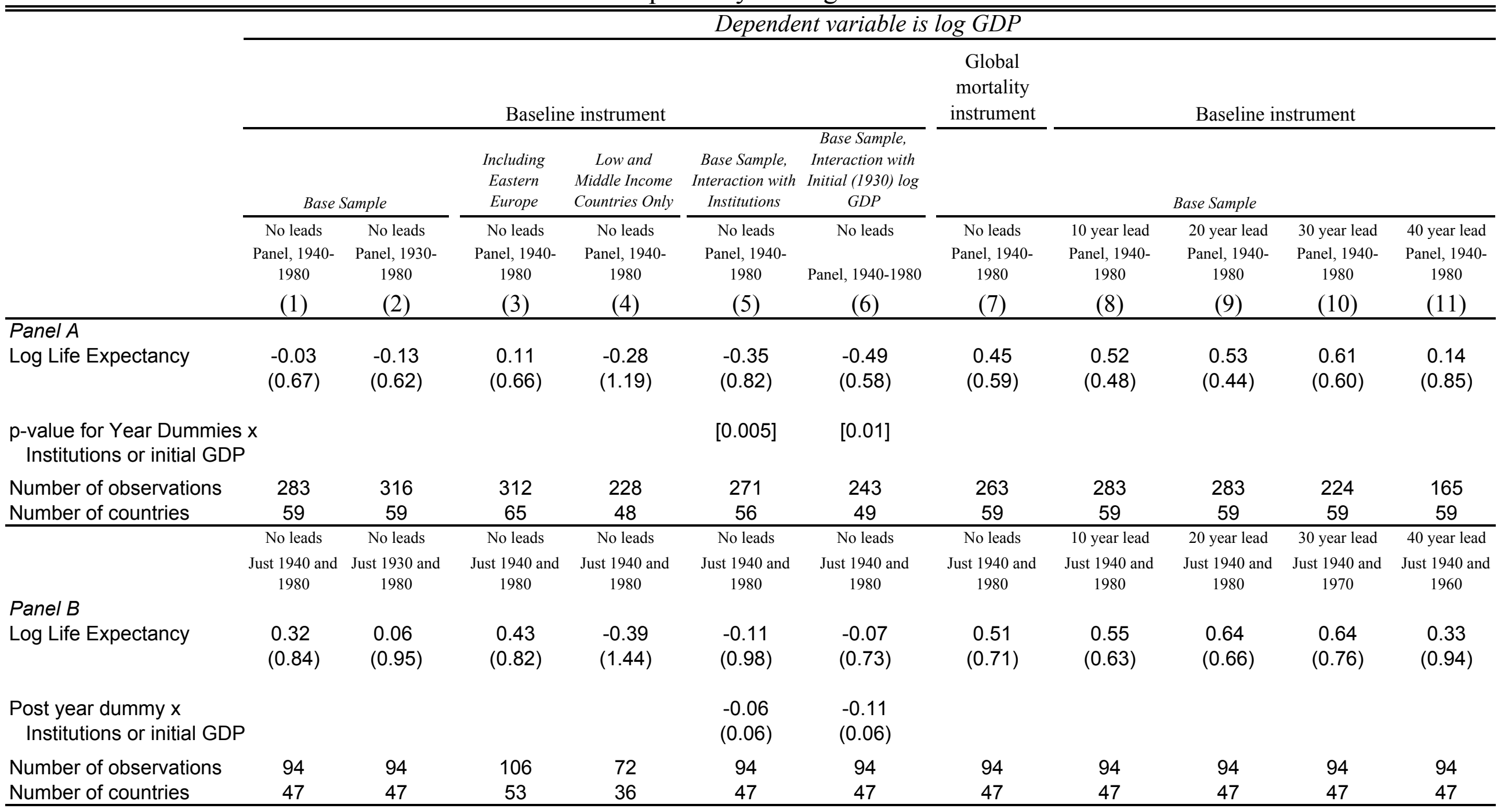

2SLS regressions with a full set of year and country fixed effects. Robust standard errors, adjusted for clustering by country, in parentheses. Panel A is unbalanced panel with one observation per decade. Panel B is long-difference specification with observations for only the beginning and end dates. Dependent variable in both panels is log GDP. Independent variable in both panels is log life expectancy at birth. In columns 1-6 and 8-11, log life expectancy is instrumented by predicted mortality (baseline instrument), and in column 7 it is instrumented by global mortality. First stages are in Table 5. In columns 1-7, the dependent and independent variables are for the same time period; in columns 8-11, the dependent variable is $t+10, t+20$ etc., as indicated, while the independent variable is at time t. Columns 5 and 6 include year dummies interacted with: institutions, in column 5, as average of constraint on executive in 1950, 1960, and 1970 from Polity IV, where scores range from 1 to 7 and non-independent countries are assigned score of 1; and initial GDP, in column 6, is for 1930. See text and Appendix A for construction of the mortality instruments, definitions, and data sources. 
The Effect of Life Expectancy on Log GDP per capita: 2SLS Estimates

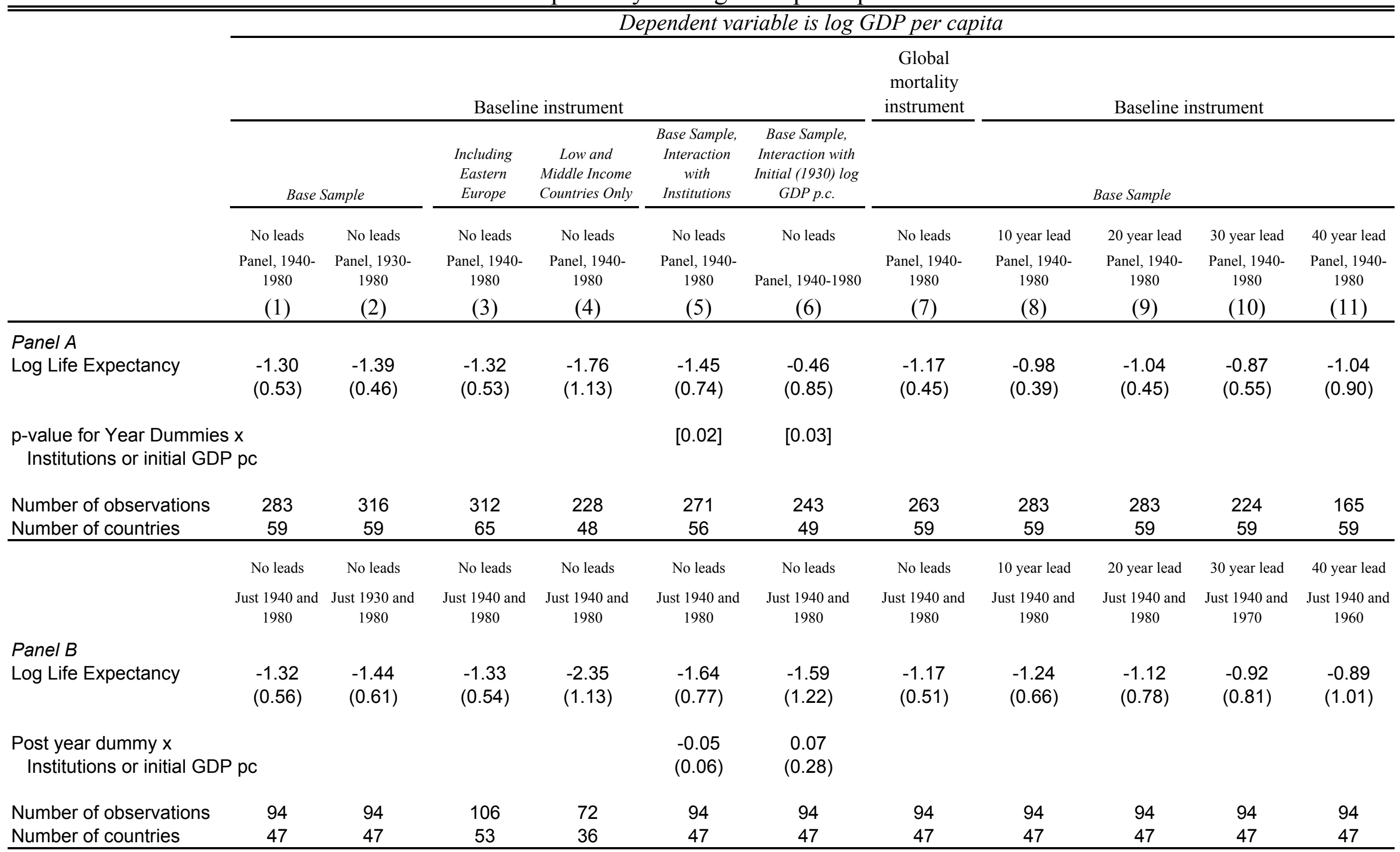

2SLS regressions with a full set of year and country fixed effects. Robust standard errors, adjusted for clustering by country, in parentheses. Panel A is unbalanced panel with one observation per decade. Panel B is long-difference specification with observations for only the beginning and end dates. Dependent variable in both panels is log GDP per capita. Independent variable in both panels is log life expectancy at birth. In columns 1-6 and 8-11, log life expectancy is instrumented by predicted mortality (baseline instrument), and in column 7 it is instrumented global mortality. First stages are in Table 5. In columns 1-7, the dependent and independent variables are for the same time period; in columns $8-11$, the dependent variable is $t+10, t+20$ etc., as indicated, while the independent variable is at time $t$. Columns 5 and 6 include year dummies interacted with: institutions, in column 5, as average of constraint on executive in 1950, 1960, and 1970 from Polity IV, where scores range from 1 to 7 and non-independent countries are assigned score of 1 ; and initial GDP per capita, in column 6, is for 1930. See text and Appendix A for construction of the mortality instruments, definitions, and data sources. 
Table 12

The Effect of Life Expectancy on Years of Schooling: 2SLS Estimates

\begin{tabular}{|c|c|c|c|c|c|c|c|c|c|}
\hline \multicolumn{10}{|c|}{ Dependent variable is years of schooling } \\
\hline & OLS & $\begin{array}{c}\text { Baseline } \\
\text { instrument }\end{array}$ & $\begin{array}{c}\text { Baseline } \\
\text { instrument }\end{array}$ & OLS & $\begin{array}{l}\text { Baseline } \\
\text { instrument }\end{array}$ & $\begin{array}{c}\text { Baseline } \\
\text { instrument }\end{array}$ & OLS & $\begin{array}{c}\text { Baseline } \\
\text { instrument }\end{array}$ & $\begin{array}{c}\text { Baseline } \\
\text { instrument }\end{array}$ \\
\hline & \multicolumn{2}{|c|}{ Base Sample } & $\begin{array}{c}\text { Low and } \\
\text { Middle Income } \\
\text { Countries Only }\end{array}$ & \multicolumn{2}{|c|}{ Base Sample } & $\begin{array}{c}\text { Low and } \\
\text { Middle Income } \\
\text { Countries Only }\end{array}$ & \multicolumn{2}{|c|}{ Base Sample } & $\begin{array}{c}\text { Low and Middle } \\
\text { Income } \\
\text { Countries Only }\end{array}$ \\
\hline & $\begin{array}{c}10 \text { year lead } \\
\text { Panel, 1950- } \\
1980\end{array}$ & $\begin{array}{c}10 \text { year lead } \\
\text { Panel, 1950- } \\
1980\end{array}$ & $\begin{array}{c}10 \text { year lead } \\
\text { Panel, 1950- } \\
1980\end{array}$ & $\begin{array}{c}20 \text { year lead } \\
\text { Panel, 1950- } \\
1970\end{array}$ & $\begin{array}{c}20 \text { year lead } \\
\text { Panel, 1950- } \\
1970\end{array}$ & $\begin{array}{c}20 \text { year lead } \\
\text { Panel, 1950- } \\
1970\end{array}$ & $\begin{array}{c}30 \text { year lead } \\
\text { Panel, 1950- } \\
1960\end{array}$ & $\begin{array}{c}30 \text { year lead } \\
\text { Panel, 1950- } \\
1960\end{array}$ & $\begin{array}{c}30 \text { year lead } \\
\text { Panel, 1950- } \\
1960\end{array}$ \\
\hline & $(1)$ & $(2)$ & $(3)$ & $(4)$ & $(5)$ & $(6)$ & $(7)$ & $(8)$ & $(9)$ \\
\hline Log Life Expectancy & $\begin{array}{l}-0.50 \\
(1.45)\end{array}$ & $\begin{array}{l}-0.42 \\
(4.15)\end{array}$ & $\begin{array}{l}-0.73 \\
(5.92)\end{array}$ & $\begin{array}{l}-0.14 \\
(1.63)\end{array}$ & $\begin{array}{c}0.07 \\
(4.51)\end{array}$ & $\begin{array}{c}1.10 \\
(6.52)\end{array}$ & $\begin{array}{c}5.01 \\
(1.65)\end{array}$ & $\begin{array}{c}1.40 \\
(3.67)\end{array}$ & $\begin{array}{l}-1.40 \\
(5.17)\end{array}$ \\
\hline Number of observations & 212 & 212 & 168 & 159 & 159 & 126 & 106 & 106 & 84 \\
\hline
\end{tabular}

OLS and 2SLS regressions with a full set of year and country fixed effects. Robust standard errors, adjusted for clustering by country, in parentheses. Unbalanced panel with one observation per decade. Dependent variable is years of schooling. Independent variable is log life expectancy at birth. In columns 2, 3, 5, 6, 8 and 9, log life expectancy is instrumented by predicted mortality (baseline instrument). First stages are in Table 5. In columns 1-3, the dependent and independent variables are for the same time period; in columns 4-9, the dependent variable is $t+10, t+20$, and $t+30$ as indicated, while the independent variable is at time $t$. See text and Appendix A for construction of the predicted mortality instrument, definitions and data sources. 
Table 13

The Effect of Life Expectancy on Population and Log GDP, Alternative Samples: 2SLS Estimates, with First Stages

\begin{tabular}{|c|c|c|c|c|c|c|c|c|c|c|c|c|}
\hline \multirow[t]{3}{*}{ Instrument: } & Baseline & $\begin{array}{c}\text { Global } \\
\text { Mortality }\end{array}$ & Baseline & $\begin{array}{c}\text { Global } \\
\text { Mortality }\end{array}$ & Baseline & $\begin{array}{c}\text { Global } \\
\text { Mortality }\end{array}$ & Baseline & $\begin{array}{c}\text { Global } \\
\text { Mortality }\end{array}$ & Baseline & $\begin{array}{c}\text { Global } \\
\text { Mortality }\end{array}$ & Baseline & $\begin{array}{c}\text { Global } \\
\text { Mortality }\end{array}$ \\
\hline & \multicolumn{2}{|c|}{ Base Sample plus Africa } & \multicolumn{2}{|c|}{ Base Sample plus Africa } & \multicolumn{2}{|c|}{$\begin{array}{c}\text { Base Sample without countries } \\
\text { most affected by WWII }\end{array}$} & \multicolumn{2}{|c|}{ Base Sample plus Africa } & \multicolumn{2}{|c|}{ Base Sample plus Africa } & \multicolumn{2}{|c|}{$\begin{array}{c}\text { Base Sample without countries } \\
\text { most affected by WWII }\end{array}$} \\
\hline & $\begin{array}{c}\text { No leads } \\
\text { Panel, 1940- } \\
1980 \\
\text { (1) }\end{array}$ & $\begin{array}{c}\text { No leads } \\
\text { Panel, 1940- } \\
1980 \\
(2)\end{array}$ & $\begin{array}{c}30 \text { year lead } \\
\text { Panel, 1940- } \\
1980 \\
\text { (3) }\end{array}$ & $\begin{array}{c}30 \text { year lead } \\
\text { Panel, 1940- } \\
1980 \\
(4)\end{array}$ & $\begin{array}{c}\text { No leads } \\
\text { Panel, 1940- } \\
1980 \\
(5)\end{array}$ & $\begin{array}{c}\text { No leads } \\
\text { Panel, 1940- } \\
1980 \\
(6)\end{array}$ & $\begin{array}{c}\text { No leads } \\
\text { Panel, 1940- } \\
1980 \\
(7)\end{array}$ & $\begin{array}{c}\text { No leads } \\
\text { Panel, 1940- } \\
1980 \\
(8)\end{array}$ & $\begin{array}{c}30 \text { year lead } \\
\text { Panel, 1940- } \\
1980 \\
(9)\end{array}$ & $\begin{array}{c}30 \text { year lead } \\
\text { Panel, 1940- } \\
1980 \\
(10)\end{array}$ & $\begin{array}{c}\text { No leads } \\
\text { Panel, 1940- } \\
1980 \\
(11)\end{array}$ & $\begin{array}{c}\text { No leads } \\
\text { Panel, 1940- } \\
1980 \\
(12)\end{array}$ \\
\hline Panel A: Dependent variable - & \multicolumn{6}{|c|}{ Log population } & \multicolumn{6}{|c|}{$\log G D P$} \\
\hline Log Life Expectancy & $\begin{array}{l}1.35 \\
(0.37)\end{array}$ & $\begin{array}{l}1.77 \\
(0.35)\end{array}$ & $\begin{array}{l}3.87 \\
(2.42)\end{array}$ & $\begin{array}{l}2.63 \\
(0.93)\end{array}$ & $\begin{array}{l}1.26 \\
(0.39)\end{array}$ & $\begin{array}{l}1.55 \\
(0.38)\end{array}$ & $\begin{array}{l}-0.12 \\
(0.63)\end{array}$ & $\begin{array}{l}0.03 \\
(0.49)\end{array}$ & $\begin{array}{l}-0.80 \\
(2.11)\end{array}$ & $\begin{array}{l}-0.09 \\
(1.09)\end{array}$ & $\begin{array}{l}-0.22 \\
(0.70)\end{array}$ & $\begin{array}{l}0.33 \\
(0.59)\end{array}$ \\
\hline \multicolumn{13}{|c|}{ Panel B: Dependent variable is log life expectancy (first stage regression) } \\
\hline Predicted Mortality & $\begin{array}{l}-0.34 \\
(0.06)\end{array}$ & $\begin{array}{l}-0.39 \\
(0.06)\end{array}$ & $\begin{array}{l}-0.29 \\
(0.06)\end{array}$ & $\begin{array}{l}-0.34 \\
(0.07)\end{array}$ & $\begin{array}{l}-0.33 \\
(0.07)\end{array}$ & $\begin{array}{l}-0.44 \\
(0.08)\end{array}$ & $\begin{array}{l}-0.34 \\
(0.06)\end{array}$ & $\begin{array}{l}-0.39 \\
(0.06)\end{array}$ & $\begin{array}{l}-0.29 \\
(0.06)\end{array}$ & $\begin{array}{l}-0.34 \\
(0.07)\end{array}$ & $\begin{array}{l}-0.33 \\
(0.07)\end{array}$ & $\begin{array}{l}-0.44 \\
(0.08)\end{array}$ \\
\hline R-squared & 0.96 & 0.97 & 0.97 & 0.97 & 0.94 & 0.95 & 0.96 & 0.97 & 0.97 & 0.97 & 0.94 & 0.95 \\
\hline Number of observations & 445 & 445 & 343 & 343 & 238 & 238 & 445 & 445 & 343 & 343 & 238 & 238 \\
\hline Number of countries & 102 & 102 & 102 & 102 & 54 & 54 & 102 & 102 & 102 & 102 & 54 & 54 \\
\hline
\end{tabular}

All regressions have full set of year and country fixed effects. Robust standard errors, adjusted for clustering by country, in parentheses. Unbalanced panel with one observation per decade. Panel A is 2SLS results; dependent variable in columns 1-6 is log population and in columns 7-12 is log GDP; independent variable is log life expectancy at birth. Panel B is corresponding first stage, with predicted mortality as the instrument. In odd columns, log life expectancy is instrumented by predicted mortality (baseline instrument), and in even columns it is instrumented by global mortality. For the second stage, columns 1-2, 5-6, 7-8, and 11-12, the dependent and independent variables are for the same time period; in columns 3-4 and 9-10, the dependent variable is $t+30$, while the independent variable is at time t. For columns 1-4 and 7-10, data on post-1950 Africa are added to our base sample. For columns 5-6 and 11-12, data on countries most affected demographically by World War II are excluded (Austria, China, Finland, Germany, and Italy). See text and Appendix A for construction of the mortality instruments, definitions, and data sources. 


\section{Appendix Table A1}

\section{Key Data used in Base Sample}

\begin{tabular}{|c|c|c|c|c|c|c|c|}
\hline Country & $\begin{array}{c}\text { Initial } \\
\text { Income }\end{array}$ & Year & $\begin{array}{c}\text { Predicted } \\
\text { Mortality }\end{array}$ & $\begin{array}{c}\text { Life } \\
\text { Expectancy }\end{array}$ & Population & Total GDP & $\begin{array}{c}\text { GDP per } \\
\text { capita }\end{array}$ \\
\hline Argentina & Middle & 1940 & 0.205 & 56.5 & 14,169 & 58,963 & 4,161 \\
\hline Argentina & & 1980 & 0.000 & 69.6 & 28,370 & 232,802 & 8,206 \\
\hline Australia & Rich & 1940 & 0.232 & 66.8 & 7,042 & 43,422 & 6,166 \\
\hline Australia & & 1980 & 0.000 & 74.4 & 14,616 & 210,642 & 14,412 \\
\hline Austria & Middle & 1940 & 0.299 & 60.2 & 6,705 & 26,547 & 3,959 \\
\hline Austria & & 1980 & 0.000 & 72.7 & 7,549 & 103,874 & 13,759 \\
\hline Bangladesh & Poor & 1940 & 0.668 & 29.9 & 41,966 & 25,044 & 597 \\
\hline Bangladesh & & 1980 & 0.000 & 48.5 & 88,077 & 48,239 & 548 \\
\hline Belgium & Rich & 1940 & 0.156 & 61.8 & 8,346 & 38,072 & 4,562 \\
\hline Belgium & & 1980 & 0.000 & 73.2 & 9,847 & 142,458 & 14,467 \\
\hline Brazil & Poor & 1940 & 0.525 & 36.7 & 41,114 & 51,381 & 1,250 \\
\hline Brazil & & 1980 & 0.000 & 62.7 & 122,958 & 639,093 & 5,198 \\
\hline Canada & Rich & 1940 & 0.121 & 64.2 & 11,688 & 62,744 & 5,368 \\
\hline Canada & & 1980 & 0.000 & 74.7 & 24,593 & 397,814 & 16,176 \\
\hline Chile & Middle & 1940 & 0.803 & 42.0 & 5,093 & 16,596 & 3,259 \\
\hline Chile & & 1980 & 0.000 & 69.3 & 11,094 & 63,654 & 5,738 \\
\hline China & Poor & 1940 & 0.291 & 43.9 & 518,770 & 291,603 & 562 \\
\hline China & & 1980 & 0.000 & 65.3 & 981,235 & $1,046,781$ & 1,067 \\
\hline Colombia & Middle & 1940 & 0.535 & 37.9 & 9,174 & 17,386 & 1,895 \\
\hline Colombia & & 1980 & 0.000 & 65.9 & 26,583 & 113,375 & 4,265 \\
\hline Costa Rica & Middle & 1940 & 0.667 & 49.3 & 620 & 1,093 & 1,763 \\
\hline Costa Rica & & 1980 & 0.000 & 72.7 & 2,299 & 11,290 & 4,911 \\
\hline Denmark & Rich & 1940 & 0.121 & 65.5 & 3,832 & 19,606 & 5,116 \\
\hline Denmark & & 1980 & 0.000 & 74.3 & 5,123 & 78,010 & 15,227 \\
\hline Ecuador & Poor & 1940 & 0.930 & 39.3 & 2,466 & 3,344 & 1,546 \\
\hline Ecuador & & 1980 & 0.000 & 63.3 & 7,920 & 32,706 & 4,129 \\
\hline El Salvador & Poor & 1940 & 0.970 & 34.5 & 1,630 & 1,811 & 1,111 \\
\hline El Salvador & & 1980 & 0.000 & 57.1 & 4,566 & 10,748 & 2,354 \\
\hline Finland & Middle & 1940 & 0.223 & 57.3 & 3,698 & 11,909 & 3,220 \\
\hline Finland & & 1980 & 0.000 & 73.2 & 4,780 & 61,890 & 12,949 \\
\hline France & Middle & 1940 & 0.279 & 60.0 & 41,000 & 165,729 & 4,042 \\
\hline France & & 1980 & 0.000 & 74.3 & 53,870 & 813,763 & 15,106 \\
\hline Germany & Rich & 1940 & 0.183 & 63.5 & 69,835 & 377,284 & 5,403 \\
\hline Germany & & 1980 & 0.000 & 72.6 & 78,298 & $1,105,099$ & 14,114 \\
\hline Greece & Middle & 1940 & 0.409 & 54.4 & 7,280 & 16,183 & 2,223 \\
\hline Greece & & 1980 & 0.000 & 74.4 & 9,643 & 86,505 & 8,971 \\
\hline Guatemala & Middle & 1940 & 0.806 & 30.4 & 2,200 & 6,033 & 2,742 \\
\hline Guatemala & & 1980 & 0.000 & 57.4 & 7,235 & 26,632 & 3,681 \\
\hline Honduras & Poor & 1940 & 0.609 & 32.5 & 1,150 & 1,334 & 1,160 \\
\hline Honduras & & 1980 & 0.000 & 60.0 & 3,635 & 7,014 & 1,930 \\
\hline India & Poor & 1940 & 1.126 & 30.0 & 321,565 & 265,455 & 686 \\
\hline India & & 1980 & 0.000 & 54.4 & 679,000 & 637,202 & 938 \\
\hline Indonesia & Poor & 1940 & 0.877 & 34.3 & 70,175 & 86,682 & 1,235 \\
\hline Indonesia & & 1980 & 0.000 & 54.8 & 147,490 & 275,805 & 1,870 \\
\hline Ireland & Middle & 1940 & 0.306 & 59.8 & 2,958 & 9,028 & 3,052 \\
\hline Ireland & & 1980 & 0.000 & 72.7 & 3,401 & 29,047 & 8,541 \\
\hline Italy & Middle & 1940 & 0.816 & 58.7 & 44,341 & 155,424 & 3,505 \\
\hline
\end{tabular}




\begin{tabular}{|c|c|c|c|c|c|c|c|}
\hline Country & $\begin{array}{c}\text { Initial } \\
\text { Income }\end{array}$ & Year & $\begin{array}{l}\text { Predicted } \\
\text { Mortality }\end{array}$ & $\begin{array}{c}\text { Life } \\
\text { Expectancy }\end{array}$ & Population & Total GDP & $\begin{array}{c}\text { GDP per } \\
\text { capita }\end{array}$ \\
\hline Italy & & 1980 & 0.000 & 73.9 & 56,451 & 742,299 & 13,149 \\
\hline Korea, Rep. & Poor & 1940 & 0.185 & 48.7 & 15,627 & 22,536 & 1,442 \\
\hline Korea, Rep. & & 1980 & 0.000 & 66.8 & 38,124 & 156,846 & 4,114 \\
\hline Malaysia & Poor & 1940 & 0.317 & 42.6 & 5,434 & 6,945 & 1,278 \\
\hline Malaysia & & 1980 & 0.000 & 66.9 & 13,764 & 50,333 & 3,657 \\
\hline Mexico & Middle & 1940 & 0.621 & 43.6 & 20,393 & 37,767 & 1,852 \\
\hline Mexico & & 1980 & 0.000 & 66.8 & 68,686 & 431,983 & 6,289 \\
\hline Myanmar & Poor & 1940 & 0.621 & 36.6 & 16,594 & 12,274 & 740 \\
\hline Myanmar & & 1980 & 0.000 & 52.1 & 33,283 & 27,381 & 823 \\
\hline Netherlands & Rich & 1940 & 0.180 & 67.4 & 8,879 & 42,898 & 4,831 \\
\hline Netherlands & & 1980 & 0.000 & 75.7 & 14,144 & 207,979 & 14,705 \\
\hline New Zealand & Rich & 1940 & 0.214 & 67.7 & 1,636 & 10,308 & 6,300 \\
\hline New Zealand & & 1980 & 0.000 & 73.2 & 3,170 & 39,141 & 12,347 \\
\hline Nicaragua & Poor & 1940 & 0.476 & 34.5 & 830 & 1,139 & 1,372 \\
\hline Nicaragua & & 1980 & 0.000 & 58.7 & 2,804 & 6,043 & 2,155 \\
\hline Norway & Middle & 1940 & 0.214 & 67.3 & 2,973 & 12,152 & 4,088 \\
\hline Norway & & 1980 & 0.000 & 75.7 & 4,086 & 61,811 & 15,129 \\
\hline Pakistan & Poor & 1940 & 0.813 & 30.0 & 28,169 & 20,137 & 715 \\
\hline Pakistan & & 1980 & 0.000 & 55.1 & 85,219 & 98,907 & 1,161 \\
\hline Panama & Middle & 1940 & 0.595 & 42.4 & 697 & 1,199 & 1,721 \\
\hline Panama & & 1980 & 0.000 & 70.1 & 1,956 & 9,961 & 5,091 \\
\hline Paraguay & Middle & 1940 & 0.364 & 46.6 & 1,111 & 1,947 & 1,752 \\
\hline Paraguay & & 1980 & 0.000 & 66.8 & 3,193 & 10,549 & 3,304 \\
\hline Peru & Middle & 1940 & 0.832 & 40.6 & 6,298 & 11,483 & 1,823 \\
\hline Peru & & 1980 & 0.000 & 60.4 & 17,295 & 72,723 & 4,205 \\
\hline Philippines & Poor & 1940 & 0.976 & 47.3 & 16,585 & 26,326 & 1,587 \\
\hline Philippines & & 1980 & 0.000 & 61.1 & 50,940 & 121,012 & 2,376 \\
\hline Portugal & Middle & 1940 & 0.623 & 50.3 & 7,675 & 12,396 & 1,615 \\
\hline Portugal & & 1980 & 0.000 & 71.4 & 9,778 & 78,655 & 8,044 \\
\hline Spain & Middle & 1940 & 0.387 & 50.2 & 25,757 & 53,585 & 2,080 \\
\hline Spain & & 1980 & 0.000 & 75.5 & 37,488 & 344,987 & 9,203 \\
\hline Sri Lanka & Poor & 1940 & 0.617 & 42.3 & 6,134 & 7,673 & 1,251 \\
\hline Sri Lanka & & 1980 & 0.000 & 68.2 & 14,900 & 27,550 & 1,849 \\
\hline Sweden & Rich & 1940 & 0.125 & 66.7 & 6,356 & 30,873 & 4,857 \\
\hline Sweden & & 1980 & 0.000 & 75.9 & 8,310 & 124,130 & 14,937 \\
\hline Switzerland & Rich & 1940 & 0.144 & 64.1 & 4,226 & 27,032 & 6,397 \\
\hline Switzerland & & 1980 & 0.000 & 75.8 & 6,385 & 119,909 & 18,779 \\
\hline Thailand & Poor & 1940 & 0.506 & 42.6 & 15,513 & 12,820 & 826 \\
\hline Thailand & & 1980 & 0.000 & 63.6 & 47,026 & 120,116 & 2,554 \\
\hline United Kingdom & Rich & 1940 & 0.270 & 65.0 & 48,226 & 330,638 & 6,856 \\
\hline United Kingdom & & 1980 & 0.000 & 73.8 & 56,314 & 728,224 & 12,931 \\
\hline United States & Rich & 1940 & 0.132 & 63.8 & 132,637 & 929,737 & 7,010 \\
\hline United States & & 1980 & 0.000 & 73.7 & 227,726 & $4,230,558$ & 18,577 \\
\hline Uruguay & Middle & 1940 & 0.344 & 56.5 & 1,965 & 7,193 & 3,661 \\
\hline Uruquay & & 1980 & 0.000 & 70.4 & 2,920 & 19,205 & 6.577 \\
\hline Venezuela, RB & Middle & 1940 & 0.496 & 33.9 & 3,784 & 15,307 & 4,045 \\
\hline Venezuela, RB & & 1980 & 0.000 & 68.3 & 14,768 & 149,735 & 10,139 \\
\hline
\end{tabular}


Figure 1: Log life expectancy at birth for initially rich, middle-income and poor countries

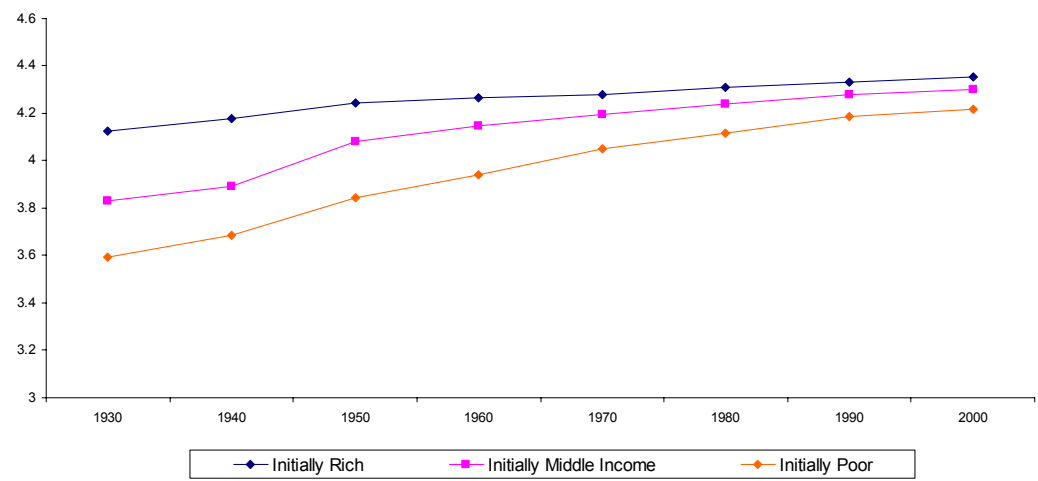

Figure 2: Log GDP per capita for initially rich, middle-income and poor countries

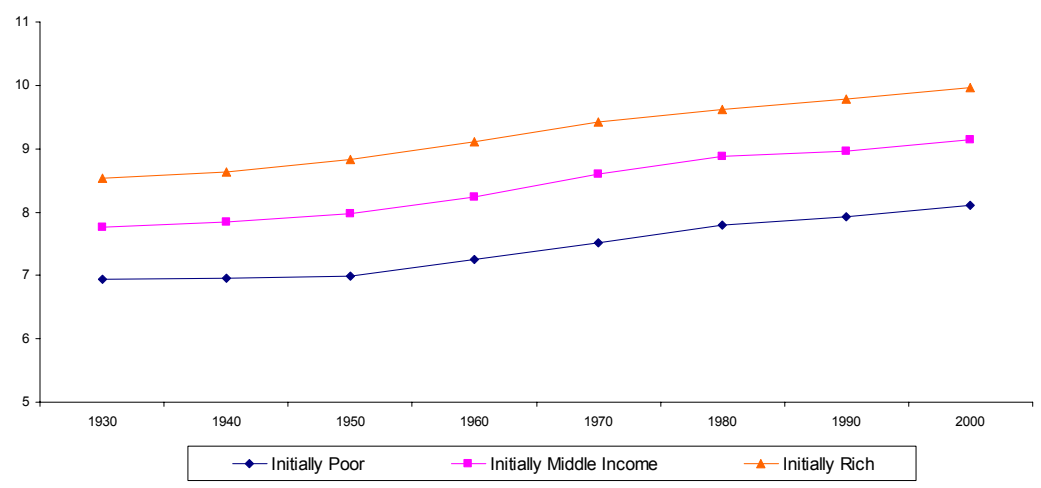


Figure 3: Change in log life expectancy and change in predicted mortality, 1940-80, base sample

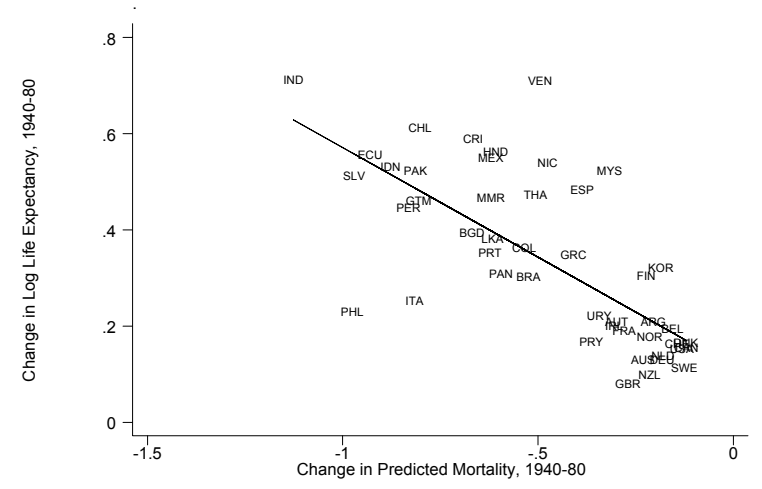

Figure 4: Change in log life expectancy and change in predicted mortality, 1940-80, low and middle-income countries

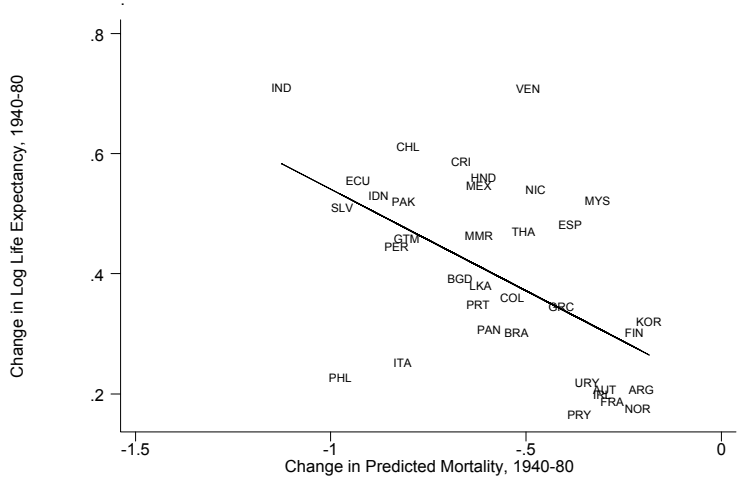


Figure 5: Change in log life expectancy, 1900-40, and change in predicted mortality, 1940-80, base sample

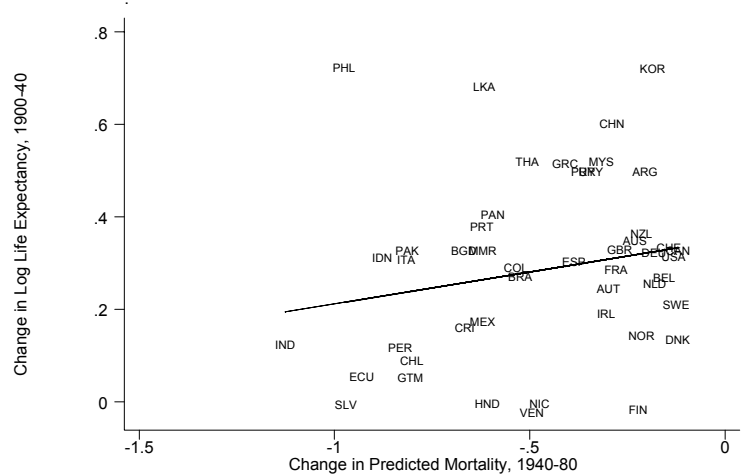

Figure 6: Change in log life expectancy, 1900-40, against change in predicted mortality, 1940-80, low and middle-income countries

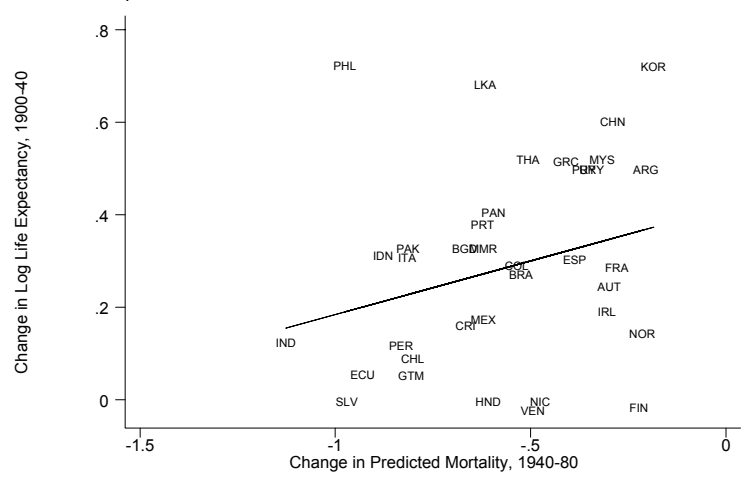


Figure 7: Change in log life expectancy, 1930-40, and change in predicted mortality, 1940-80, base sample

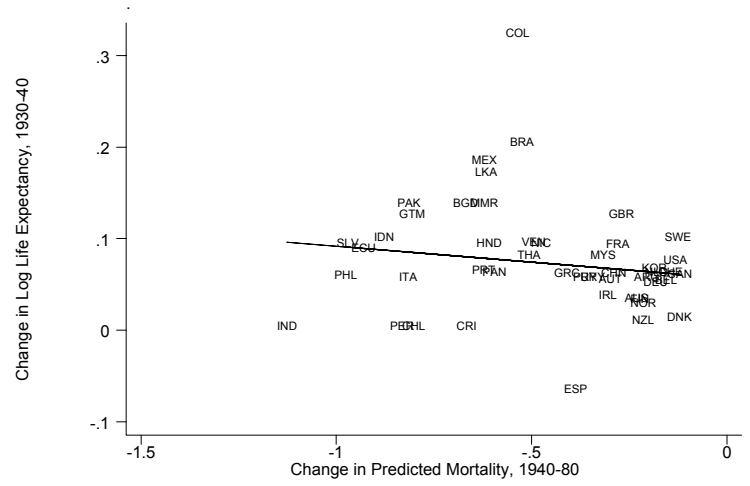

Figure 8: Change in log life expectancy, 1930-40, and change in predicted mortality, 1940-80, low and middle-income countries

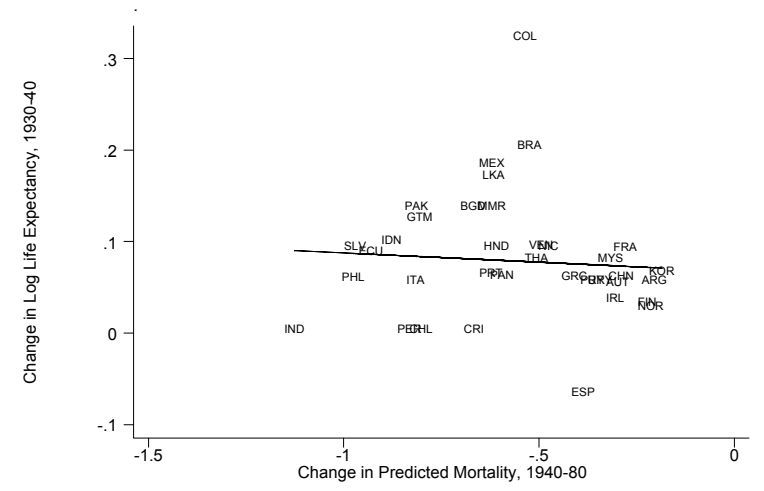


Figure 9: Change in log population and change in predicted mortality, 1940-80, base sample

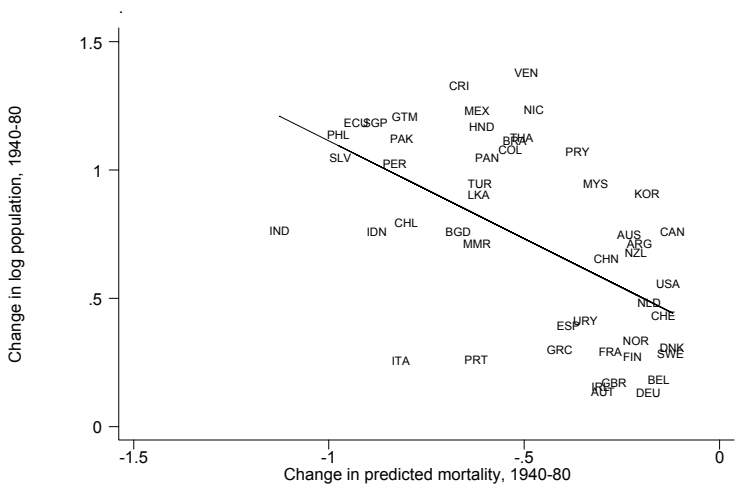

Figure 10: Change in log total GDP and change in predicted mortality, 1940-80, base sample

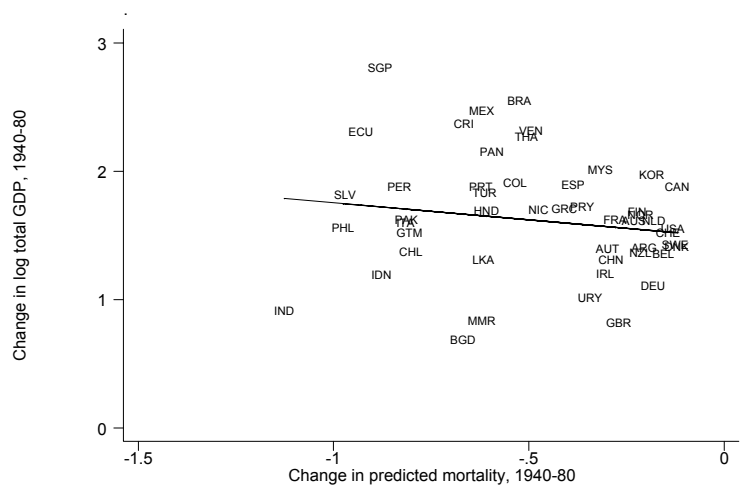


Figure 11: Change in log GDP per capita and change in predicted mortality, 194080 , base sample

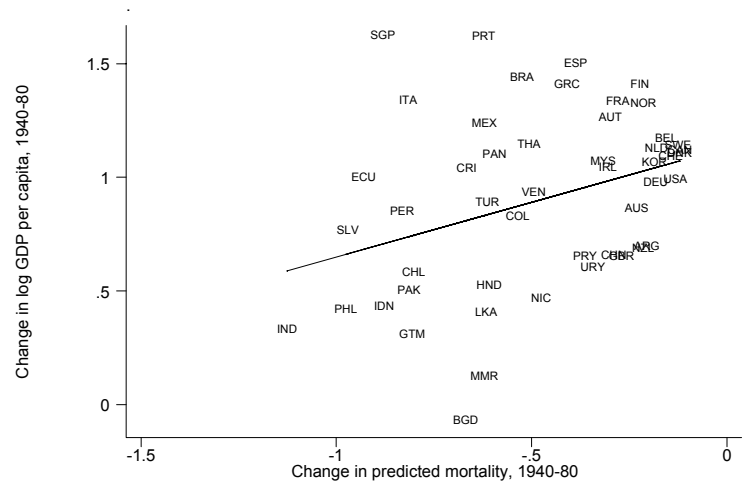




\section{Appendix C: Not For Publication}

This appendix explains in detail the construction and sources of our life expectancy estimates for 1930 and 1940. It also contains a number of tables of additional results referred to in the main text.

\section{Sources}

The underlying data sources are national authorities. We take the data as reported to and republished by the United Nations. However, the UN does not appear to have produced a comprehensive set of data for the pre-1950 period; later publications sometimes revised estimates, but they also dropped earlier data.

At regular intervals, the UN's Demographic Yearbooks focused on mortality and we concentrate our attention on these issues. ${ }^{1}$ The UN's own advice on accessing early data is helpful but not sufficient. Specifically, the introduction (p. 1) of the United Nations Demographic Yearbook 1978, Historical Supplement (Special Issue), published in 1979 (but really dealing with data only since 1950), suggests that readers should refer to the Demographic Yearbook 1948 for "many of the same tables showing annual data for the period 1932 to 1947" and should use this in conjuction with the historical supplement. ${ }^{2}$ This advice is not sufficient, however, because the UN added and revised historical data, as far as we can determine, in its Demographic Yearbooks through $1968 .^{3}$

We also pay close attention to Preston's (1975) data as this represents what a leading scholar decided could be used alongside the UN's data (at a time when the UN's historical data had been revised and extended). Preston's (1975, Table A-2) estimates are "in the 1930s" but the exact date ranges from the late 1920s to the early 1940s; we use his data for either 1930 or 1940, depending on which is closer (and sometimes as part of an interpolation, as explained below). Preston's most frequently used source is the U.N. Demographic Yearbook 1967 (UN 1968) but he also provides additional data from other country-specific work on life tables. We also note when Preston uses the same data as the U.N., as this is an important indication of external validation. In some cases, Preston uses other data when the U.N. estimates are available.

IVS is our abbreviation for International Vital Statistics, published by the Federal Security Agency (1947); life expectancy data are on pp. 220-225. We use these data to fill gaps where possible and more generally to provide a further external validation of pre-war sources.

We report alternative estimates from the UN (for different years), Preston, and IVS so readers can see the range of available data.

\section{Coding Rules}

Our decision rule for how to combine data from alternative sources for our main data series is as follows.

1. We look for male and female life expectancy data from the same time period and calculate an unweighted average (to match our post-1950 data that we take directly from the UN's on-line database). ${ }^{4}$

\footnotetext{
${ }^{1}$ The U.N. Demographic Yearbook 1948 (United Nations 1949) reports life expectancy at birth on pp. 514523. The U.N. Demographic Yearbook 1951 (United Nations 1951) reports life exectancy at birth on pp. 526-539. The U.N Demographic Yearbook 1961 (United Nations 1961) reports life expectancy at birth on pp. 622-641. The U.N. Demographic Yearbook 1967 (United Nations 1968) reports life expectancy at birth on pp. 704-741.

${ }^{2}$ Life expectancy at birth for both males and females, generally from 1950-55, in 5 year intervals, is on pp. 542-563 of this historical supplement.

${ }^{3}$ The publication date for the UN Demographic Yearbooks does not always match the year covered by the Yearbook, and this can be confusing. For example, UN (1949) is the Demographic Yearbook for 1948 (a one year lag in publication), but UN (1951) is the Demographic Yearbook for 1951, UN (1961) is the Demographic Yearbook for 1961 and UN (1968) is the Demographic Yearbook for 1967.

${ }^{4}$ We have looked at the implications of using only male life expectancy. This does not significantly affect our results.
} 
2. Preston's main source is the U.N. Demographic Yearbook for 1967 (UN 1968), but he supplements this with clearly identified and referenced country studies that he regards as comparable (or better than what the UN published). We also start with the UN Demographic Yearbook as our default source, as this is more comprehensive, but prefer Preston when he has data for a year close to 1930 or 1940 (as appropriate). We use IVS primarily as another source of validiation and to fill a few gaps. If the U.N. Demographic Yearbooks have different data in different editions, we use the latest Yearbook (we note agreement or disagreement between alternative UN estimates below) through 1967 - this appears to be the most recent year for which retrospective pre-1950 were systematically available.

3. When we have data from before and after our reference dates (1930 and 1940), we interpolate by assuming a linear trend (which amounts to an "even-paced changed" with the same annual average change in life expectancy over the period for which we are interpolating). If data are available for a range of years, we take the midpoint for the purpose of calculating the trend. If the midpoint is halfway through a year (e.g., the midpoint of 1930-33 is halfway through 1931), we treat this as half a year. The formula is:

$$
X_{t}=\left(\frac{X_{t-s}+X_{t+k}}{k+s}\right)
$$

where $X$ is a life expectancy, $t$ is the reference year (1930 or 1940) and we have data from $s$ years before the reference year and also from $k$ years after the reference year. For example, if the life expectancy estimates are 50 for 1925 and 60 for 1935, we calculate life expectancy in 1930 as $(50+60) / 10 .{ }^{5}$

4. When the available data are only for shortly after our reference years and when we have two datapoints to calculate a reasonable rate of change, we extrapolate backwards. In our main sample, we only do one extrapolation for Portugal (for a period of 18 months), and in the additional in Eastern European sample, we extrapolate for Czechoslovakia (for half a year) and Poland (for 18 months). The extrapolation formula is:

$$
X_{t}=X_{t+p}-(p-t)\left(\frac{X_{t+k}-X_{t+p}}{k-p}\right)
$$

where $p$ is the date closest to $t$. For example, if the life expectancy estimates are 51 for 1931 and 60 for 1940, then for 1930 we calculate the per annum change as (60-51)/9 and subtract this from the estimate for 1931 to obtain a life expectancy of 50 in 1930.

5. For European countries affected by World War II in or before 1940, we prefer data from 1938 or 1937 where available; we interpolate these data to 1940. We rely on Urlanis (2003) for an assessment of the demographic impact from the war; where this was small, we prefer data for 1940.

6. If the data are drawn from a country that subsequently divided (e.g., India), we use these data for all the new countries that emerged.

7. In a few cases (El Salvador, Ecuador and Honduras), when data are not available for a country, but we have similar disease conditions, crude death rates and age structure of the population between neighboring countries, we average the life expectancy in neighboring countries with similar disease conditions. If an estimate is missing for a neighbor (typically for 1930), then we do not compute the average for that year but leave it as missing. Estimates relying on information from neighbors are dropped in additional robustness checks.

\section{$3 \quad$ Life Expectancy by Country in our Base Sample}

Most of the pre-1950 data we use are reported to two digits and we use them in this form in our calculations. However, since the post-1950 UN data is reported with one digit, we round all our data to

\footnotetext{
${ }^{5}$ In robustness checks, we have constructed alternative data using log-interpolation. Instead of equation (C1), this uses$$
x_{t}=\left(\frac{x_{t-s}+x_{t+k}}{k+s}\right) \text {, }
$$

where $x$ is $\log$ life expectancy. The results with log-interpolation are similar.
} 
one digit in the appendix table and in the regressions. All life expectancies are at birth unless otherwise stated.

The panel base sample refers to noncommunist base sample, which contains 47 countries from 1940 and an additional 12 countries from 1950. "Long differences" refers to the sample that has data for 1940 and 1980; this comprises 47 countries. To include a country in our base sample we need data for 1940; to be in the 1930-1940 falsification tests we also need data for 1930; this sample is consequently smaller.

The following 12 countries are in our panel but not in our long differences, i.e., we have data from 1950 but not before: Algeria, Bolivia, Egypt, Iran, Lebanon, Morocco, Tunisia, Turkey, Singapore, South Africa, Turkey, and Vietnam. Life expectancy data for these countries are from the UN on-line database only.

The detail by country is as follows

1. Argentina (in base sample for panel and long differences)

UN (1967, p. 716 and 1961, p. 626) has life expectancy in 1914 of 45.2 for males and 47.5 for females, for an average of $46.35 .^{6}$ For 1947 , life expectancy for males is 56.9 and for females is 61.4 , for an average of 59.15. Using our linear interpolation equation $(\mathrm{C} 1)$, the improvement of 12.8 years over 33 years translates to 0.39 years of extra life for each year. This yields a life expectancy of 52.6 in 1930 and of 56.5 in 1940.

We use 52.6 for 1930 and 56.5 for 1940 .

2. Australia (in base sample for panel and long differences)

United Nations (1949, p. 520 and 1951, p. 538) for 1932-34 has 63.48 (male) and 67.14 (female), average of 65.31; for 1946-48, it has 66.07 (male) and 70.63 (female), average of $68.35 .^{7}$ United Nations (1968, p. 738) also reports life expectancy for 1920-22 as 59.15 (male) and 63.31 (female), for an average of 61.23 .

Taking the mid-year in each of these ranges and assuming an even pace of life expectancy increase, from 1921 to 1933 (12 years) of 0.34 years per elapsed year implies life expectancy in 1930 (after 9 years) of 64.29. A similar calculation from 1933 to 1947 (14 years) gives 0.22 years more life expectancy per elapsed year; this implies life expectancy in 1940 (after 7 years) of 66.83.

We use 64.3 for 1930 and 66.8 for 1940 .

3. Austria (in base sample for panel and long differences)

United Nations (1949, p. 516, and 1951, p. 532) for 1930-33 has 54.5 (male) and 58.5 (female), for an average of 56.50. IVS (p. 220) and Preston use the same numbers. For 1901-1905, UN 1949 has male life expectancy of 39.14 and female life expectancy of 41.06 (also in UN 1968, p. 722), average of 40.10; in the 28.5 year period from 1903 to half way through 1931 there was an average improvement of 0.58 years of life expectancy per elapsed year. This implies life expectancy in 1930 was 55.63 (calculating back from the midpoint of 1930-33).

There are no data for the late 1930s or 1940 in any of our sources. The next available number from the UN is for 1949-51, for which life expectancy is 61.91 (male) and 66.97 (female), for an average of 64.44. In the 18.5 years from half way through 1931 to 1950, there was a life expectancy improvement of 0.43 on average per elapsed year. This implies life expectancy in 1940 (after 8.5 years) was 60.16.

We use 55.6 for 1930 and 60.2 for 1940 .

4. Bangladesh (in base sample for panel and long differences)

We use the same estimates as for India. Standard errors in all regressions are clustered by unit of observation for original life expectancy data (i.e., pre-independence India) to account for this.

We use 26.8 for 1930 and 29.9 for 1940 .

5. Belgium (in base sample for panel and long differences)

United Nations (1949, p. 516, and 1951, p. 532; 1968, p. 722) for 1928-32 has 56.02 (male) and 59.79 (female), for an average of 57.91. Preston and IVS (p. 220) use the same numbers. The next

\footnotetext{
${ }^{6}$ Argentina is not in UN (1949) and Preston (1975) does not have data. The IVS (p.220) reports life expectancy only for 1914; at birth this was 51.7 for the native population and 46.44 in the city of Buenos Aires (both estimates are for "both sexes").

${ }^{7}$ IVS (p. 220) and Preston (1975) use the same estimates (for 1932-34), but IVS notes that this is "except aboriginals".
} 
available estimates are for 1946-49, with life expectancy from UN 1968 (p. 722) given as 62.04 (male) and 67.26 (female), average of 64.65 .

Over the 17.5 years from 1930 (midpoint of 1928-32) to half way through 1947 (midpoint of 194649), the average improvement in life expectancy was 0.39 years per elapsed year. This implies life expectancy in 1940 (after 10 years) was 61.76 .

We use 57.9 for 1930 and 61.8 for 1940.

6. Brazil (in base sample for panel and long differences)

For this country, there is some discrepancy in the various UN sources. UN (1948 and 1951, p. 528) gives 37.43 as life expectancy for "both sexes" in 1920, while UN (1968, p. 716) has life expectancy for "both sexes" as 39.25 on average over the 1890-1920 period. UN (1961, p. 628 and 1968, p. 716) gives life expectancy for 1940-50, as 39.3 (male) and 45.5 (female), for an average of $42.40 .{ }^{8}$ Taking these latter data as representing 1945 (the midpoint) and taking the UN's 1890-1920 as representing 1905 (prefering the later, presumably revised estimate from UN 1968), over the 40 year period there was an average improvement in life expectancy of (42.4-39.25)/40 or 0.08 years per elapsed year. This implies life expectancy in 1930 (after 25 years) of 41.22 and in 1940 (after 35 years) of 42.05 .

Instead of the UN data for 1940, Preston (1975) prefers life expectancy estimates of 36.06 (male) and 37.25 (female), the average is 36.66; these data are from Arriaga (1968). Comparing with the earlier UN estimates suggests a worsening of life expectancy from 1905 to 1940 of 0.07 years per elapsed year. This would put life expectancy in 1930 at $37.40 .{ }^{9}$ We prefer the Preston estimate for 1940 as he has a country specific source that he regards as comparable with but better than the available UN estimate. We also prefer the calculation for 1930 that uses Preston's 1940 estimate.

We use 37.4 for 1930 and 36.7 for 1940 .

7. Canada (in base sample for panel and long differences)

United Nations (1949, p. 514) gives, for 1930-32, male life expectancy of 60.0 and female life expectancy of 62.1, with an average of 61.05; for 1940-42, it gives male life expectancy of 62.96 and female life expectancy of 66.30 , for an average of 64.63 . UN 1968, p. 710, has tiny adjustments to just the 1940-42 numbers: 62.95 male and 66.29 female, for an average of $64.62 .{ }^{10}$

Preston (1975) uses 59.09 (male) and 61.58 (female) for 1931, for an average of 60.34; the source is Preston, Keyfitz, and Schoen 1972. We prefer the Preston estimate as he chooses a country specific study over the UN estimate.

The average annual change in life expectancy from 1931 to 1941 (midpoint of 1940-42) is 0.43 years. This implies that life expectancy in 1940 was 64.19 , while in 1930 it was 59.91.

We use 59.9 for 1930 and 64.2 for 1940 .

8. Chile (in base sample for panel and long differences)

UN (1949 and 1951, p. 528) reports life expectancy as 35.4 male and 37.7 female in 1930 (average 36.55), and as 37.9 male and 39.8 female in 1940 (average 38.85); these data were also used by IVS. ${ }^{11}$ But there was a major revision of these data. UN (1961, p. 628, and 1968, p. 716) has life expectancy of 40.40 male and 41.03 female in 1930, average of 40.72, and 40.91 male and 43.16 female in 1940 ,

\footnotetext{
${ }^{8}$ The table note says "for population born in Brazil" and "based on mortality rates implied from apparent survivorship rates between censuses."

${ }^{9}$ IVS (p. 220) gives higher estimates, but this is presumably because it only reports data for two major cities. Male life expectancy in Rio de Janeiro 1939-41 is given as 40.77 and female life expectancy as 46.27. In Sao Paolo for the same period male life expectancy is 46.71 and female is 51.77. IVS also gives alternative estimates of 43.04 for both sexes (not broken out separately) for Rio in 1939-40 and 50.13 for both sexes in Sao Paolo in 1939-40. For 1920-21, the "both sexes" life expectancy in Rio is given as 41; for Sao Paolo the equivalent estimate is 42.67. IVS also reports life expectation for "native population" in 1890-1920 as 39.25 (both sexes). Natives here likely means non-immigrants.

${ }^{10}$ IVS (p. 220) has very similar estimates. Male life expectancy in 1941 ("except Yukon and Northwest Territories") was 62.95, while female life expectancy was 66.29. The same source gives male life expectancy as 58.46 in 1931 and female life expectancy as 60.23, for an average of 59.35. For males, life expectancy was 59.32 in 1929-31 and for females it was 61.59 , for an average of 60.46 .

${ }^{11}$ IVS also reports "both sexes" life expectancy as 41.2 in 1939 and 38.8 in 1929-32, suggesting that mortality fluctuated considerably from year-to-year at that time.
} 
average of $42.04 .^{12}$ Preston uses these revised data for 1940 .

We use 40.7 for 1930 and 42.0 for 1940 .

9. China (in base sample for panel only) $)^{13}$

No life expectancy data for mainland China are available from the UN or our other sources. We therefore use estimates from Taiwan (Formosa) which was a province of China before 1950. Crude death rates indicate that this is a reasonable proxy. ${ }^{14}$

UN (1968, p. 718) has life expectancy for 1926-30 as 38.76 (male) and 43.13 (female), average of 40.95. For 1936-40, the same source gives 41.08 (male) and 45.73 (female), average of 43.41. See also United Nations (1949, p. 514, 1951, p. 530, and 1961, p. 628).

From 1928 (midpoint of 1926-30) to 1938 (midpoint 1936-40), the average annual increase in life expectancy was 0.25 . This implies life expectancy in 1930 was 41.45 , while in 1940 it was 43.91 .

We use 41.5 for 1930 and 43.9 for 1940.

10. Colombia (in base sample for panel and long differences)

The earliest data in our UN sources (e.g., 1968, p. 716) are for 1950-52, with life expectancy of 44.18 (male) and 45.95 (female), average of 45.07.

Preston (1975) has estimates of life expectancy of 36.04 (male) and 37.19 (female) for 1938; average of 36.62 (his source is Arriaga). ${ }^{15}$ In the 13 years from 1938 to 1951 (midpoint of 1950-52) the average annual increase in life expectancy was 0.65. Interpolating implies life expectancy in 1940 was 37.92. We have not found any reasonable basis for calculating a 1930 estimate.

We use 37.9 for 1940 and have no data for 1930 .

11. Costa Rica (in base sample for panel and long differences)

UN (1968, p. 710) reports life expectancy in 1949-51 of 54.65 for males and 57.05 for females, average of 55.85, but there is no earlier UN data and Preston does not have an estimate. However, IVS, p. 220, reports life expectancy for both sexes (not broken out separately) of 40.69 for 1927 .

Using our interpolation formula, (C1), the improvement between 1927 and 1950 (midpoint of 1949 and 1951) translates into an annual increase in life expectancy of 0.66 years, and implies that life expectancy in 1940 was 49.26 , while in 1930 it was 42.67 .

We use 42.7 for 1930 and 49.3 for 1940

12. Denmark (in base sample for panel and long differences)

UN (1951, p. 532 and 1968, p. 724) gives life expectancy for 1926-30 as 60.9 (male) and 62.6 (female), average of $61.75 .{ }^{16}$ This source also reports life expectancy for 1931-35 as 62.0 (male) and 63.8 (female), average of 62.9 (also in UN 1949, p. 516); Preston uses the 1931-35 data, but that is probably just because he was seeking data "in the 1930s". We prefer the 1926-30 estimates as this allows us to interpolate (rather than extrapolate backwards).

UN (1968, p. 724) gives life expectancy for 1936-40 as 63.5 (male) and 65.8 (female), average of 64.65. The same source gives life expectancy for 1941-45 as 65.62 (male) and 67.7 (female), average of 66.66; also in UN 1949, p. 516. ${ }^{17}$ Urlanis indicates only a small demographic effect of the war in Denmark, but we prefer the 1936-40 data in any case as they include the year 1940 .

Between 1928 (midpoint of 1926-30) and 1938 (midpoint of 1936-40), the average annual increase in life expectancy was 0.29 years. This implies life expectancy in 1930 of 62.33 .

Between 1938 (midpoint of 1936-40) and 1943 (midpoint of 1941-45), the average annual increase in life expectancy was 0.4 years. This implies life expectancy in 1940 of 65.45 .

\footnotetext{
${ }^{12}$ The relevant footnote says "revised to take account of estimated underregistration of births."

${ }^{13}$ The on-line UN database has no value for life expectancy in China in 1980. We interpolate between 1970 and 1990 , to get a life expectancy of 65.31 .

${ }^{14}$ The crude death rate on the mainland was 16 in 1950-54 and in Taiwan it was 10.

${ }^{15}$ There is a big difference with IVS, p. 220, which for 1939-41, reports male life expectancy at 46.3 and has no estimate for females. We prefer Preston because he uses a country-specific study and has data on females.

${ }^{16} \mathrm{UN}$ (1949, p. 516) gives life expectancy for 1901-05 as 52.9 (male) and 56.2 (female); for 1911-15 as 56.2 (male) and 59.2 (female); and for 1921-25 as 60.3 (male) and 61.9 (female).

${ }^{17}$ There is a slight discrepancy with IVS (p. 220), which for Denmark "except Faroe Islands" for 1936-40, gives male life expectancy as 63.5 and female life expectancy as 65.8. The IVS estimates for 1931-35 match those of the UN.
} 


\section{We use 62.3 for 1930 and 65.5 for 1940}

13. Ecuador (in base sample for panel and long differences)

We average of the estimates for Colombia (37.9 in 1940 and no data for 1930) and Peru (39.0 in 1930 and 40.6 in 1940). ${ }^{18}$

We use 39.3 for 1940 and have no estimate for 1930.

14. El Salvador (in base sample for panel and long differences)

We use an average of the estimates for Guatemala (30.4 for 1940 and no data for 1930) and Nicaragua (34.5 in 1940 and no data for 1930). ${ }^{19}$

We use 32.5 for 1940 and have no estimate for $1930 .^{20}$

15. Finland (in base sample for panel and long differences)

United Nations (1949, p. 516, 1951, p. 532, and 1968, p. 726) for 1921-30 has 50.68 (male) and 55.14 (female), average of 52.91; for 1931-40 it has 54.45 (male) and 59.55 (female), average of 57.0; UN (1968, p. 728) for 1941-45 has 54.62 (male) and 61.14 (female), average of 57.88 ("excluding war losses"). ${ }^{21}$ The 1931-40 and 1941-45 data are also in UN (1961, p. 632); the note indicates these estimates exclude deaths of civilians and members of the armed forces due to military operations. ${ }^{22}$ Preston (1975) uses 54.32 (male) and 59.48 (female) from 1936-40, which is from the UN (1968, p. 726); average of 56.9 .

Between half way through 1925 (midpoint of 1921-30) and half way through 1935 (midpoint of 1931-40) there was an average annual increase in life expectancy of (57-52.91)/10, i.e., 0.41 years. This implies life expectancy in 1930 was $1.84+52.91=54.75$.

Between 1938 (midpoint of 1936-40) and 1943 (midpoint of 1941-45) there was an average annual increase in life expectancy of (57.88-56.9)/5, i.e., 0.20. This implies life expectancy in 1940 was 57.3. (Alternatively, if we extrapolate using the earlier rate of change in life expectancy, this would imply life expectancy in 1940 of 57.72 ).

We use $\mathbf{5 4 . 8}$ for 1930 and $\mathbf{5 7 . 3}$ for $\mathbf{1 9 4 0}$.

16. France (in base sample for panel and long differences)

United Nations (1951, p. 534, 1968, p. 726) for 1928-33 has 54.30 (male) and 59.02 (female), average of 56.66. For 1933-38 the same source has 55.94 (male) and 61.64 (female), average of 58.79. ${ }^{23}$ There are no data for exactly 1940 but for 1946-49 the UN (1968, p. 726) gives life expectancy as 61.86 (males) and 67.43 (females), average of 64.65 .

The midpoint of 1928-33 is halfway through 1930 and so we use the 1928-33 data for our 1930 estimate. Over the 12 years from halfway through 1935 (mid-point of 1933-38) to halfway through 1947 (midpoint of 1946-49) there was an average increase of 0.49 years of life expectancy per elapsed year. This implies life expectancy in 1940, assuming a linear trend, was 60.02.

Preston (1975) uses UN data of 55.12 (male) and 60.33 (female) from 1928-38; average of 57.73. We prefer the 1928-33, 1933-38 and 1946-49 UN data as they cover narrower windows that are closer to 1930 (and 1940).

We use 56.7 for 1930 and 60.0 for 1940 .

17. Germany (in base sample for panel and long differences)

United Nations (1951, p. 534, and 1968, p. 726) for 1924-26 of 55.97 (male) and 58.82 (female), average of 57.40. The same source for 1932-34 has life expectancy of 59.86 (male) and 62.81 (female),

\footnotetext{
${ }^{18}$ In 1935-39, the crude death rate in Ecuador was 24.6, while in Colombia it was 16.2 and in Peru it was 15.5. However, by 1950-54, Ecuador's crude death rate was much closer to that of Colombia and Peru (within 3 per 1,000).

${ }^{19}$ In 1935-39, the crude death rate in El Salvador was 21.1, while in Guatemala it was 26.8 and in Nicaragua it was 15.0 .

${ }^{20}$ The earliest estimate in the UN sources is UN (1968, p. 710), which has life expectancy estimates for El Salvador in 1949-51 of 49.94 (male) and 52.40 (female). This implies a large, but plausible jump in life expectancy during the 1940s.

${ }^{21}$ These data are also in IVS (p. 222).

${ }^{22} \mathrm{UN}$ (1949, p. 516) also has life expectancy for 1901-10 of 45.33 (male) and 48.1 (female), and for 1911-20 it has 43.41 (male) and 49.12 (female).

${ }^{23}$ The IVS (p. 220) has similar data, with slight discrepancies at the second decimal place.
} 
average of 61.34; Preston and IVS use the same data. Interpolating between these two periods, over 8 years (1925 to 1933) there was an average annual increase of 0.49 years. This implies life expectancy in 1930 was 59.85 .

The next available German data are for 1946-47, with male life expectancy at 57.72 and female life expectancy at 63.44 (UN, 1968, p. 728), but these data must large large effects of the recently ended war (Urlanis). There are also data for 1949-51, with life expectancy at 64.56 (male) and 68.48 (female), average of 66.52. ${ }^{24}$ We therefore prefer to interpolate between 1932-34 and 1949-51 to obtain an estimate for 1940. Over the 17 year period from 1933 (midpoint of 1932-34) to 1950 (midpoint of 1949-51) there was an average annual life expectancy improvemen of $0.30 .{ }^{25}$ This implies, with a linear trend, that life expectancy in 1940 was 63.47.

We use 59.9 for 1930 and 63.5 for 1940 .

18. Greece (in base sample for panel and long differences)

UN (1968, p. 728) has life expectancy for 1926-30 of 44.95 (male) and 47.46 (female), average of $46.21 .^{26}$ For 1940 the same source puts life expectancy at 52.94 (male) and 55.80 (female), average of 54.37; Preston also uses these data.

In the 12 years between 1928 (midpoint of 1926-30) and 1940, there was an annual average increase in life expectancy of 0.68 years. This implies life expectancy in 1930 was 47.57 .

We use $\mathbf{4 7 . 6}$ for 1930 and $\mathbf{5 4 . 4}$ for $\mathbf{1 9 4 0}$.

19. Guatemala (in base sample for panel and long differences)

UN (1957, section following p. p.564) reports life expectancy for Guatemala in 1921 as 28.22 years (male and female).

From United Nations (1949, p. 514, and 1951), covering 1939-41, we have life expectancy estimates of 35.97 for males and 37.09 for females; average of 36.53, but these are not for the whole country. ${ }^{27}$ The UN (1968, p. 710) reports data for the whole of Guatemala only from 1949-51.

Preston (1975) uses life expectancy of 30.25 (male) and 30.46 (female) for 1940; average of 30.36 (from Arriaga). We prefer his estimates as they appear to cover the whole country, and also because Preston choose Arriaga's estimates over the UN numbers (which were available to him).

We use 30.4 for 1940 and do not have an estimate for 1930.

20. Honduras (in base sample for panel and long differences)

Based on crude death rates, we use the average of Guatemala (30.4 for 1940 and no data for 1930) and Nicaragua (34.5 in 1940 and no data for 1930). ${ }^{28}$

We use 32.5 for 1940 and have no estimate for 1930.

21. India (in base sample for panel and long differences)

The United Nations (1949, p. 516, and 1951, p. 530) for 1921-31 gives male life expectancy of 26.91 and female life expectancy of 26.56, average of 26.74 (this is for "pre-partition India, including Burma"); these numbers are also used in IVS (p. 220), which says they are for "British India". ${ }^{29}$

Preston (1975) uses 26.9 (male) and 26.6 (female) from 1931 data; average of 26.75. His source is Dandekar (1972) a country-specific source (although the data are obviously almost identical to those from the UN for 1921-31.) Between the 1921-31 estimate (midpoint 1926) and the 1931 estimate, there was an average annual increase in life expectancy of 0.002 years. Interpolating, this implies life expectancy in 1930 was 26.75 (to 2 significant figures).

UN (1961, p. 630 and 1968, pp. 718-720) has life expectancy for 1941-50 of 32.45 (male) and 31.66 (female), average of 32.06. Using this for the midpoint, halfway through 1945, the average annual

\footnotetext{
${ }^{24}$ The immediate post-war data are divided by the UN into Eastern Germany, Federal Republic of Germany, Berlin and West Berlin. Here we are using the numbers for the Federal Republic.

${ }^{25}$ This is a lower annual increase in life expectancy than in France, for example. But given the differential effects of the war (see Urlanis), this does not seem unreasonable.

${ }^{26}$ From IVS (p. 220) male life expectancy in 1928 was 49.09 and female life expectancy was 50.89.

${ }^{27}$ The note says "Department of Guatemala only".

${ }^{28}$ In 1935-39, the crude death rate in Honduras was 16.2, while in Guatemala it was 26.8 and in Nicaragua it was 15.0 .

${ }^{29}$ The same 1949 source gives the following data for 1891-1901, 23.63 (male) and 23.96 (female); and for 1901-1911, 22.59 and 23.31.
} 
improvement in life expectancy was 0.37 years over the 14.5 years after 1931 . This implies life expectancy in 1940 was 30.05 .

We use 26.8 for 1930 and 30.0 for 1940 .

22. Indonesia (in base sample for panel and long differences)

There are no data in the UN Demographic Yearbooks or the IVS for Indonesia. Preston uses 32.5 (male) and 32.5 (female) for 1930-35; average of 32.5 (from a country-specific source, Nitisastro, 1970).

The UN on-line database gives 37.5 for average life expectancy in 1950-55. Using this for halfway through 1952 (the midpoint) implies that the average annual life expectancy increase in the 19.5 years after 1933 was 0.26 . This implies life expectancy in 1940 was 34.29.

We use 34.3 for 1940 and have no estimate for 1930 .

23. Ireland (in base sample for panel and long differences)

UN (1968, p. 730) has life expectancy in 1925-27 as 57.37 (male) and 57.93 (female), average of 57.65. The same source has life expectancy in 1935-37 of 58.20 (male) and 59.62 (female), average of 58.91; Preston uses these data. ${ }^{30}$ Taking the midpoints of these windows, between 1926 and 1936 there was an average annual increase in life expectancy of 0.13 . This implies life expectancy in 1930 was $58.15 .^{31}$

UN (1961, p. 634, and 1968, p. 730) for 1940-42 has 59.01 (male) and 61.02 (female), for an average of 60.02. Between 1941 (midpoint of 1940-42) and 1936, there was an annual average increase in life expectancy of 0.22 years, implying that life expectancy in 1940 was 59.80. There were no large demographic effects of the war on Ireland.

We use $\mathbf{5 8 . 2}$ for $\mathbf{1 9 3 0}$ and $\mathbf{5 9 . 8}$ for $\mathbf{1 9 4 0 .}$

24. Italy (in base sample for panel and long differences)

United Nations (1951, p. 534 and 1968, p. 730) for 1921-22 has life expectancy of 49.27 (male) and 50.75 (female), average of 50.01. The same source for 1930-32 has 53.76 (male) and 56.0 (female), average of 54.88; and for 1935-37 it has female (only) life expectancy of 57.49. ${ }^{32}$ After that, the next available data are for 1950-53, when life expectancy is given as 63.75 (male) and 67.23 (female), average of 65.49 .

Preston (1975) uses the UN's data, but has an estimate of male life expectancy which is not UN (1968). ${ }^{33}$ His estimates are 55.25 (male) and 57.49 (female) for 1935-37; average of 56.37. Using this for the midpoint of 1936 and assuming a linear trend to halfway through 1951 (midpoint of 1950-53) gives an annual average improvement in life expectancy over 15.5 years of 0.59 . This implies life expectancy in 1940 was 58.72 .

Between halfway through 1921 (midpoint of 1921-22) and 1931, there was an annual average increase in life expectancy of 0.51 years. This implies life expectancy in 1930 was 54.37.

We use 54.4 for 1930 and 58.7 for 1940 .

25. Korea (in base sample for panel and long differences)

United Nations (1951, p. 530 and 1968, p. 720) for 1938 gives male life expectancy of 47.20 and female life expectancy of 50.59, for an average of 48.9. Korea is not in Preston or IVS.

The UN's on-line database has an estimate of life expectancy (average for male and female combined) of 47.5 for $1950-55$. This estimate is presumably affected by the Korean war. ${ }^{34}$

In the 14.5 years between 1938 and halfway through 1952, the average annual decrease in life expectancy was 0.1 years. This implies life expectancy in 1940 was 48.7 .

We use 48.7 for 1940 and do not have an estimate for 1930.

\footnotetext{
${ }^{30}$ From IVS (p. 222), life expectancy was 59.01 (male) and 61.02 (female) in 1940-42, 58.20 (male) and 59.62 (female) in 1935-37, and 57.37 (male) and 57.93 (female) in 1925-27.

${ }^{31}$ United Nations (1951, p. 534) has somewhat different estimates. For 1921-30 this source has 56.2 (male) and 61 (female), average of 58.6; and for 1931-40 it has 60.9 (male) and 65.6 (female), average of 63.25. However, these estimates are not repeated in UN (1968), so we presume they were revised and we prefer the numbers in UN (1968).

${ }^{32}$ IVS (p. 222) also reports the 1930-32 data.

${ }^{33}$ IVS, p. 222, also only has female life expectancy.

${ }^{34}$ The next estimate, from UN (1968, p. 720) is for 1955-60 - 51.12 (male) and 53.73 (female), average of 52.43. But this is quite far into the treatment period, according to our reading of the history.
} 
26. Malaysia (in base sample for panel and long differences)

Based on crude death rates, we use the estimate of Thailand and adjust our standard errors for clustering accordingly. ${ }^{35}$

We use 42.6 for 1940 and do not have an estimate for 1930 .

27. Mexico (in base sample for panel and long differences)

UN (1968, p. 712) has life expectancy in 1930 as 35.45 (male) and 37.08 (female), average of 36.27. For 1940, the same source reports life expectancy as 57.96 (male) and 40.42 (female). But the 1940 male datapoint must be a typo - for all other ages, the estimates are essentially unchanged from 1935 (male life expectancy of 38.94); probably the estimate for males should be 37.96, giving an average of 43.58. From IVS (p. 222) male life expectancy at birth was 37.19 in 1929-1933 and 32.44 in 1930.

Preston (1975) uses 38.94 (male) and 41.89 (female) for 1935; average of 40.42 (from the UN). We prefer the UN estimates for the exact dates of 1930 and 1940.

We use 36.3 for 1930 and 43.6 for 1940 .

28. Myanmar, previously known as Burma (in base sample for panel and long differences)

The UN (1968, p. 718) reports life expectancy in Burma for 1921-31 as 30.61 (male) and 31.0 (female), average of 30.81. The same source gives life expectancy in 1954 as 40.8 (male) and 43.8 (female), average of $42.30 .{ }^{36}$ Interpolating between 1926 (midpoint of 1921-31) to 1954, this yields an average annual increase of 0.41 additional years, and implies that life expectancy in 1930 was 32.45 and in 1940 was 36.56 .

We use 32.5 for 1930 and 36.6 for 1940 .

29. Netherlands (in base sample for panel and long differences)

United Nations (1951, p. 536, and 1968, p. 732) for 1921-30 has 61.9 (male) and 63.5 (female), average of 62.7; for 1931-40 it has 65.5 (male) and 67.2 (female), average of 65.6 ("excluding war losses"); IVS (p. 222) has very similar estimates and Preston uses exactly these numbers. ${ }^{37}$ For 1947-49, UN (1968, p. 732) gives life expectancy as 69.40 (male) and 71.50 (female), average of 70.45 .

From halfway through 1925 (midpoint of 1921-30) to halfway through 1935 (midpoint of 1931-40), there was an annual average increase in life expectancy of 0.29 years. This implies life expectancy in 1930 was 63.9 .

From halfway through 1935 (midpoint of 1931-40) to 1948 (midpoint of 1947-49), there was an annual average increase in life expectancy of 0.39 years. This implies life expectancy in 1940 was 67.35 .

We use 63.9 in 1930 and 67.4 in 1940.

30. New Zealand (in base sample for panel and long differences)

United Nations (1951, p. 538 and 1968, p. 740) has life expectancy for 1925-27 of 63.99 (male) and 66.57 (female), average of 65.28; and for 1931 of 65.04 (male) and 67.88 (female), average of 66.46. For 1934-38, the same source gives life expectancy as 65.46 (male) and 68.45 (female), average of 66.96 (IVS uses these numbers), while for 1950-52 life expectancy was 67.19 (male) and 71.29 (female), average of $69.24 .^{38}$

Between 1926 (midpoint 1925-27) and 1931, the average annual increase in life expectancy was 0.25 years. This implies life expectancy in 1930 was 66.21 .

Between 1935 (midpoint of 1934-38) and 1951 (midpoint of 1950-52), the average annual increase in life expectancy was 0.14. This implies life expectancy in 1940 was 67.67.

We use 66.2 in 1930 and 67.7 in 1940.

31. Nicaragua (in base sample for panel and long differences)

Early data for this country are not in the UN Yearbooks or IVS. However, Preston (1975) has life expectancy of 33.88 (male) and 35.09 (female) for 1940 (from Arriaga), for an average of 34.49.

We use 34.5 in 1940 and have no estimate for 1930 .

\footnotetext{
${ }^{35}$ In West Malaysia (the Malay Peninsula), crude death rates were 20.8 in 1935-39; in Thailand during the same time period they were 16.4 .

${ }^{36}$ The UN's on-line database gives life expectancy for 1950-55 as 36.9 (both sexes).

${ }^{37}$ The same source gives male life expectancy (only) "excluding war losses" of 65.7 for 1931-40, indicating that the war losses adjustment is very small.

${ }^{38}$ Preston has for 1934-38, 65.04 (male) and 68.45 (female); but the male number seems to be an error (compared with UN 1951).
} 
32. Norway (in base sample for panel and long differences)

United Nations (1951, p. 536 and 1968, p. 732) for 1921/22-1930/31 has 60.98 (male) and 63.84 (female), for an average of 62.41 ; IVS also uses these data. The same source gives life expectancy in $1931 / 32-1940 / 41$ as 64.08 (male) and 67.55 (female), average of 65.82 ; Preston uses these data. In UN (1968, p. 732), life expectancy in 1945-48 was 67.76 (male) and 71.68 (female), average of 69.72.

From 1926 (midpoint of 1921/22-1930/31) to 1936 (midpoint of 1931/32-1940/41), the average annual increase in life expectancy was 0.34. This implies life expectancy in 1930 was 63.77 .

From 1936 (midpoint of 1931/32-1940/41) to halfway through 1946 (midpoint of 1945-48), the average annual increase in life expectancy was 0.37. This implies life expectancy in 1940 was 67.31 .

We use 63.8 in 1930 and 67.3 in 1940.

33. Pakistan (in base sample for panel and long differences)

We use the same estimates as for India. Standard errors in all regressions are clustered by unit of observation for original life expectancy data (i.e., pre-independence India) to account for this.

We use 26.8 for 1930 and 30.0 for 1940 .

34. Panama (in base sample for panel and long differences)

From United Nations (1949, p. 514, and 1968, p. 712), covering 1941-43, we have life expectancy of 50.54 for males and 53.46 for females, average of 52.0. Preston (1975), in contrast, has life expectancy of 41.50 (male) and 43.26 (female) for 1940, average of 42.38, from Arriaga. We prefer Preston's number as it is for exactly 1940 and from a country specific source that he preferred to the UN data (which was available to him).

For 1940 we use 42.4 and for 1930 we have no estimate.

35. Paraguay (in base sample for panel and long differences)

Based on crude death rates, we average the estimates of neighboring Argentina (52.6 for 1930 and 56.5 for 1940).and Brazil (37.4 for 1930 and 36.7 for 1940). ${ }^{39}$

We use 45.0 for 1930 and 46.6 for 1940 .

36. Peru (in base sample for panel and long differences)

There are no data in the UN Yearbooks or in Preston. However, IVS (p. 222), which gives "both sexes" life expectancy (for the city of Lima) as 38.97 in 1933-35. From the on-line UN data, life expectancy in 1950-55 was 43.9. Interpolating between 1934 (midpoint of 1933-35) to half way through 1952 (midpoint of 1950-55) implies an average annual increase of 0.27 years. This implies life expectancy in 1940 was 40.61 .

We use 40.6 in 1940 and do not have an estimate for $\mathbf{1 9 3 0 .}$

37. Philippines (in base sample for panel and long differences)

UN (1968, p722) has life expectancy of 25.17 (male) and 26.07 (female) in 1918, average of 25.62; it also has life expectancy of 44.80 (male) and 47.72 (female) for 1938; average of 46.26 (these data are also used by Preston). UN (1961, p. 630 and 1968, p. 722) has male life expectancy of 48.81 and female life expectancy of 53.36 in 1946-49, for an average of 51.09.

Interpolating from 1918 to 1938, there was an annual average increase of 1.02 years. This implies life expectancy in 1930 was 38.0.

From 1938 to halfway through 1947 (midpoint of 1946-49), there was an annual average increase in life expectancy of 0.51 years. This implies life expectancy in 1940 was 47.28.

We use 38.0 for 1930 and 47.3 for 1940 .

38. Portugal (in base sample for panel and long differences)

United Nations (1951, p. 536, and 1968, p. 734) for 1939-42 has 48.58 (male) and 52.82 (female), average of 50.7; IVS uses these data ("including the Azores and Madeira islands"). For 1949-52, UN (1968, p. 734) has life expectancy of 55.52 (male) and 60.50 (female), average of 58.01.

Between halfway through 1940 (midpoint 1939-42) and halfway through 1950 (midpoint 1949-52), there was an average annual increase in life expectancy of 0.73 years. This implies life expectancy in 1940, extrapolating backwards from 1939-42 to 1940, was 50.33.

We use 50.3 for 1940 and do not have an estimate for 1930.

\footnotetext{
${ }^{39}$ In 1950-54, the first years for which data are available, crude death rates in Paraguay were 11.2, while in Argentina they were 8.8 and in Brazil they were 20.6 (the latter is for 1940-54).
} 
39. Spain (in base sample for panel and long differences)

United Nations (1968, p. 734) for 1930 has life expectancy of 48.38 (male) and 51.60 (female), average of 49.99; Preston uses very similar data from the UN for 1930-31. The same source gives life expectancy for 1940 as 47.12 (male) and 53.24 (female), average of 50.18 (presumably reflecting the effects of the civil war).

We use 50.0 for 1930 and 50.2 for 1940 .

40. Sri Lanka (in base sample for panel and long differences)

UN (1968, p. 718) has life expectancy for 1920-22 of 32.72 (male) and 30.67 (female), average of 31.70. The same source has life expectancy of 46.79 (male) and 44.72 (female) for 1945-47, average of 45.76 .

Interpolating from 1921 to 1946, there was an average annual increase of 0.56 years of life expectancy. This implies life expectancy in 1930 was 36.76 , while in 1940 it was 42.34 .

\section{We use 36.8 in 1930 and 42.3 in 1940.}

41. Sweden

United Nations (1951, p. 536) has data for: 1921-30, 60.97 (male) and 63.16 (female), average of 62.07; for 1931-40, 63.76 (male) and 66.13 (female), average of 64.95; for 1941-45, 67.06 (male) and 69.71 (female), average of 68.39. The UN (1968, p. 734) gives life expectancy as 64.30 (male) and 66.92 (female) in 1936-40, average of 65.61; these data are also used by the IVS. Sweden did not have significant war losses (Urlanis).

Preston (1975) uses 62.02 (male) and 64.11 (female) for the narrower window of 1928-32; average of 63.07 (from Keyfitz and Flieger). We use these data for 1930 as that is the exact midpoint of his window and because Preston preferred these numbers to estimates from the UN.

Between 1938 (midpoint of 1936-40) and 1943 (midpoint of 1941-45), there was an average annual incrase in life expectancy of 0.56 years. This implies life expectancy in 1940 was 66.72.

\section{We use 63.0 in 1930 and 66.7 in 1940.}

42. Switzerland

UN (1968, p. 736) has life expectancy for 1920-21 as 54.48 (male) and 57.70 (female), average of 56.09. United Nations (1951, p. 536) has life expectancy for 1929-32 as 59.17 (male) and 63.05 (female), average of 61.11 (Preston uses this estimate); for 1933-37 as 60.7 (male) and 64.6 (female), average of 62.65; for 1939-44 as 62.68 (male) and 66.96 (female), average of 64.82. Switzerland had no significant war losses (Urlanis). IVS also uses these data.

Between halfway through 1920 (midpoint of 1920-21) and halfway through 1930 (midpoint 1929-32), the average annual increase in life expectancy was 0.50 years. This implies life expectancy in 1930 was 60.86 .

Between 1935 (midpoint 1933-37) and half way through 1942 (midpoint 1939-44), the average annual increase in life expectancy was 0.29. This implies life expectancy in 1940 was 64.10.

\section{We use 60.9 for 1930 and 64.1 for 1940 .}

43. Thailand

Preston and the IVS have no data. United Nations (1949, p. 516 and 1951, p. 530) gives life expectancy at birth for Siam, 1937-38, as 36.73 for male and 43.3 for female, average of 40.02 . These data are only "For Bangkok municipal area." 40

The next available data are for 1947-48 - UN (1968, p. 722) gives life expectancy for that period as 48.69 (male) and 51.90 (female), average of 50.30. In the 10 years between halfway through 1937 (midpoint of 1937-38) and halfway through 1947 (midpoint of 1947-48), the average annual increase in life expectancy was 1.03 years. This implies life expectancy in 1940 was 42.59 .

\section{We use 42.6 for 1940 and do not have an estimate for 1930 .}

44. United Kingdom (England and Wales) ${ }^{41}$

UN (1968, p. 736) has life expectancy for 1920-22 of 55.62 (male) and 59.58 (female), average of 57.60. United Nations (1951, p. 536, and 1968, p. 736) has life expectancy for 1930-32 as 58.74 (male)

\footnotetext{
${ }^{40} \mathrm{UN}$ (1961, p. 632) has life expectancy for 1947-48 of 48.69 (male) and 51.9 (female), for an average of 50.3.

${ }^{41}$ We do not use the data for Scotland or Northern Ireland.
} 
and 62.88 (female), average of 60.81 (Preston uses these data); and for 1948, 66.39 (male) and 71.15 (female), average of 68.77 .

Between 1921 (midpoint of 1920-22) and 1931 (midpoint of 1930-32), the average annual increase in life expectancy was 0.32 years. This implies life expectancy in 1930 was 60.49 .

Interpolating between 1931 (midpoint of 1930-32) and 1948, there was an average annual increase in life expectancy of 0.47 years. This implies life expectancy in 1940 was 65.02 .

We use 60.5 for 1930 and 65.0 for 1940 .

45. USA

United Nations (1951, p. 528, and 1968, p. 714) gives 57.71 (male) and 60.99 (female), average 59.35, for 1929-31 and 61.60 (male) and 65.89 (female) for 1939-41, average 63.75, (the 1939-41 data are also in UN 1949, p. 514$).{ }^{42}$

Preston uses 59.2 (male) and 62.8 (female), average of 61.00, for 1929-38 (from US official statistics). However, his window is so broad that we prefer the UN data, for which the midpoints are the exact dates of interest.

We use 59.4 for 1930 and 63.8 for 1940 .

46. Uruguay

There are no life expectancy estimates in our sources. However, from the UN (1967) we know that crude death rates were quite similar to those in a neighbor, Argentina. ${ }^{43}$ We therefore use the life expectancy estimates of Argentina (52.6 for 1930 and 56.5 for 1940).

We use 52.6 for 1930 and $\mathbf{5 6 . 5}$ for 1940 .

47. Venezuela

Preston reports life expectancy of 33.29 (male) and 34.47 (female) for 1936; average of 33.88. In the UN on-line database, for 1950-55, life expectancy is 55.1 (average of both sexes).

Between 1936 and halfway through 1952, the average annual increase in life expectancy was 1.29 years. This implies life expectancy in 1940 was 39.02 .

We use 33.9 for 1940 and have no estimate for 1930.

\section{Life Expectancy Data by Country in Eastern Europe}

For robustness checks, we include the available data from Eastern Europe, which includes six additional countries: Bulgaria, Czechoslovakia (Czech Republic), Hungary, Poland, Romania, and the USSR (Russian Federation).

1. Bulgaria

United Nations (1949, p. 516, and 1951, p. 532) for 1925-28 gives life expectancy of 45.92 (male) and 46.64 (female), for an average of 53.55 ("excluding Southern Dobruja" says a note in UN 1951; there is no note in UN 1949); IVS uses these data. ${ }^{44}$ The UN on-line database for 1950-55 reports life expectancy for both sexes as 64.1. Bulgaria is not in Preston.

From halfway through 1926 (midpoint of 1925-28) to halfway through 1952 (midpoint of 1950-55), the average annual increase in life expectancy was 0.41 years. This implies life expectancy in 1930 was 54.97, while in 1940 it was 59.09 .

We use 56.0 for 1930 and 59.1 for 1940 .

2. Czechoslovakia ${ }^{45}$

United Nations (1949, p. 516, and 1951, p. 532) for the period 1929-32 has life expectancy of 51.92 (male) and 55.18 (female), for an average of 53.55 ("including area ceded to USSR in 1947; excluding

\footnotetext{
${ }^{42} \mathrm{UN}$ (1949, p. 514) has male life expectancy in 1900-1902 as 47.88 and female life expectancy as 50.70. For 1909-1911, it has 49.86 and 53.24. But these data are only "for the ten death-registration States of 1900." IVS reports life expectancy broken down by "white," "negro," and "nonwhite."

${ }^{43}$ In 1935-39, crude death rates were 11.1 in Uruguay and 11.5 in Argentina.

${ }^{44}$ For 1899-1902, UN (1949) gives male life expectancy as 45.39 and female life expectancy as 40.33.

${ }^{45}$ There is a gap in the UN's on-line database, we fill this by assuming that life expectancy was unchanged between 1960 and 1970; both assumed equal to 69.76 .
} 
territory ceded by Hungary in 1947" says the 1951 note); IVS uses these data. ${ }^{46}$ Preston (1975) uses 54.92 (male) and 58.66 (female) for 1937, for an average of 56.79 (from the UN). From UN (1968, p. 724), life expectancy in 1949-51 was 60.93 (male) and 65.53 (female), for an average of 63.23.

From halfway through 1930 (midpoint 1929-32) to 1937, the average annual increase in life expectancy was 0.5 years. This implies life expectancy in 1930, extrapolating backwards half a year, was 53.05 .

From 1937 to 1950 (midpoint 1949-51), life expectancy increased 0.5 years on average per year. This implies life expectancy in 1940 was 58.29 .

We use 53.1 for 1930 and 58.3 for 1940 .

3. Hungary

UN (1968, p. 728) gives life expectancy in 1920-21 as 40.4 (male) and 42.6 (female), average of 41.50. Preston (1975) uses 48.27 (male) and 51.34 (female) for 1930-31, for an average of 49.81 (from the UN). ${ }^{47}$ United Nations (1951, p. 534) gives life expectancy for 1941 as 54.92 (male) and 58.22 (female), average of 56.57 ("including territory ceded to Czechoslovakia in 1947"). These estimates are repeated in UN (1961, p. 634 and 1968, p. 728), but they are marked as "provisional."

Between halfway through 1920 (midpoint of 1920-21) and halfway through 1930 (midpoint of 193031 ), the annual average increase in life expectancy was 0.83 years. This implies life expectancy in 1930 was 49.39 .

Between halfway through 1930 and 1941, life expectancy increased by 0.62 years on average. This implies life expectancy in 1940 was 55.95 .

We use 49.4 for 1930 and $\mathbf{5 6 . 0}$ for 1940 .

4. Poland

United Nations (1949, p. 520, 1951, p. 536 and 1968, p. 734) for 1931-32 has 48.2 (male) and 51.4 (female), average of 49.8; Preston and IVS use these data. For 1948, UN (1968, p. 734) reports life expectancy as 55.6 (male) and 62.5 (female), average of 59.05 .

Between halfway through 1931 (midpoint of 1931-32) and 1948, there was an annual average increase in life expectancy of 0.62 years. This implies life expectancy in 1930, extrapolating back 18 months, was 48.88 , and that life expectancy in 1940 was 55.07 .

We use 48.9 for 1930 and 55.1 for 1940 .

5. Romania

UN (1968, p. 734) reports life expectancy in 1932 for both sexes as 42.01. The UN's online database for 1950-55 reports life expectancy as 61.1.

Between 1932 and halfway through 1952 (midpoint 1950-55) there was an annual average increase in life expectancy of 0.93 years. This implies life expectancy in 1930 was 40.15 , while in 1940 it was 49.45 .

We use 40.2 for 1930 and 49.5 for 1940 .

6. Russia ("European part" of the USSR) ${ }^{48}$

United Nations (1951, p. 538 and 1968, p. 740) for 1926-27 has 41.93 (male) and 46.79 (female), average of 44.36; IVS uses these data. ${ }^{49}$ The on-line UN database has life expectancy for both sexes in 1950-55 of 67.3 .

From halfway through 1926 (midpoint of 1926-27) to halfway through 1952 (midpoint of 1950-55), the average annual increase in life expectancy was 0.88 . This implies life expectancy in 1930 was 47.44 , while in 1940 it was 56.24 .

We use 47.4 for 1930 and 56.2 for 1940 .

\footnotetext{
${ }^{46} \mathrm{UN}$ (1949) gives life expectancy for males of 38.89 in 1899-1902 and for females of 41.71 in the same period. ${ }^{47}$ IVS (p. 222) has very different numbers for 1930-31: 59.77 males and 63.74 for females.

${ }^{48}$ There is a gap in the UN on-line database which we fill by assuming that life expectancy was unchanged between 1960 and 1970.

${ }^{49}$ The same source gives similar, but slightly different numbers, for the RSFSR, Siberia, Ukrainian SSR and the Byelorussian SSR. For 1896-97, the same source has 41.93 (male) and 46.79 (female), average of 44.36.
} 


\section{$5 \quad$ Additional Life Expectancy Data}

Our sources provide life expectancy data for some additional countries, but we are not able to include them in our sample because we are currently missing other data (typically GDP, but sometimes population). For example, Preston (1975) has data for the Dominican Republic, Iceland and Japan. ${ }^{50}$ IVS has data on Estontia and Latvia. The UN Demographic Yearbook has data on British Guiana, Cyprus, Jamaica, Iceland and Puerto Rico.

\section{African Data}

There are only limited data on life expectancy in Africa south of the Sahara before 1950. For Angola, UN (1961, p. 622), reports "both sexes" life expectancy of 35 in 1940. For Mozambique in 1940, the same source gives "both sexes" life expectancy of 45 in 1940 (specifically, this is "African population ... living according to tribal customs.") The UN (1961, p. 622) reports both sexes life expectancy as 38 in 1948 for Ghana. For Mauritius, 1942-46, this source gives male life expectancy as 32.25 and female life expectancy as 33.83 .

Kuczynski (1948) contains a great deal of qualitative description of the disease burden, particularly for West Africa. His more limited information for East Africa suggests the disease burden may have been less, but his evidence is not conclusive. Overall, in terms of the mix of diseases, his evidence suggests that Africa is very similar to India around 1940, and we assume the same distribution of diseases in Africa as in India to calculate predicted mortality. ${ }^{51}$

Using our global mortality instrument does not require any such assumption, as in this case we take predicted mortality from a global average (however, we cannot add Africa to the calculation of that average due to lack of data.) For the sample including Africa, this instrument should therefore be preferred.

\section{Causes of Death}

Detailed breakdowns of causes of death, by country, are used as follows for our base sample. IVS here refer to Table 20 of International Vital Statistics (beginning on p.174). In some cases this source indicates when the sample is not national and we repeat that indication here. League of Nations refers to the data republished by World Health Organization (1951); this reports data for 1939-46 and we use the information for 1940 or nearest available year. ${ }^{52}$

1. Argentina, IVS for 1936

2. Australia, IVS for 1940 ("excluding aboriginals")

3. Austria, IVS for 1938

4. Bangladesh, same as for India

5. Belgium, IVS for 1940

6. Brazil, IVS for 1940 ("21 cities")

7. Canada, IVS for 1940 ("excluding Yukon and N.W.T. [North West Territories]")

8. Chile, IVS for 1940

9. China, League of Nations

\footnotetext{
${ }^{50}$ Japan's data are problematic because the country was at war for most of the 1930s, and this had a potentially significant effect on life expectancy.

${ }^{51}$ Controversially, this implies that the burden of malaria was the same as in India. It also implies that African malaria was not of a qualitatively different nature (e.g., there are some who argue it was impossible to eradicate African malaria using the technologies of the 1940s/1950s). However, as we are missing population and GDP data for Africa before 1950, this assumption does not much affect our estimates.

${ }^{52}$ The League of Nations reports death by disease in cities (with the number of cities varying by country); we construct an unweighted average of death rates by disease across all available cities. City level data are also available for places where we have country estimates of death by disease, and we have checked that the two sets of estimates are similar.
} 
10. Colombia, IVS for 1940

11. Costa Rica, IVS for 1940

12. Denmark, IVS for 1940

13. Ecuador, League of Nations

14. El Salvador, IVS for 1940

15. Finland, IVS for 1940

16. France, IVS for 1940

17. Germany, IVS for 1938

18. Greece, IVS for 1938

19. Guatemala, IVS for 1943

20. Honduras, League of Nations

21. India, League of Nations

22. Indonesia, League of Nations

23. Ireland, IVS for 1940

24. Italy, IVS for 1940

25. Korea, League of Nations

26. Malaysia, League of Nations

27. Mexico, IVS for 1940

28. Myanmar (Burma),

29. Netherlands, IVS for 1940

30. New Zealand, IVS for 1940 ("excluding Maoris")

31. Nicaragua, League of Nations

32. Norway, IVS for 1940

33. Pakistan, same as India

34. Panama, League of Nations

35. Paraguay, League of Nations

36. Peru, IVS for 1943 ("excluding jungle population")

37. Philippines, League of Nations

38. Portugal, League of Nations

39. Spain, IVS for 1940

40. Sri Lanka, League of Nations

41. Sweden, IVS for 1940

42. Switerland, IVS for 1940

43. Thailand, League of Nations

44. United Kingdom (England and Wales), IVS for 1940

45. USA, IVS for 1940, League of Nations

46. Uruguay, IVS for 1940, League of Nations

47. Venezuela, IVS for 1940 ("excluding tribal Indians")

For Eastern Europe we use the following sources:

1. Bulgaria, IVS for 1940 ("towns")

2. Czechoslovakia, IVS for 1937

3. Hungary, IVS for 1940

4. Poland, League of Nations

5. Romania, IVS for 1939

6. Russia/Soviet Union, League of Nations

For other death by disease data (in our extended sample), we use IVS for Egypt in 1940 ("Health Bureau Areas") and, where relevant, for South Africa, IVS for 1939 ("Europeans"). For all other countries, we use the League of Nations. ${ }^{53}$

\footnotetext{
${ }^{53}$ We do not use data from IVS for the following countries (because other data issues preclude us from including these countries in our samples): Iceland, IVS for 1940; Japan, IVS for 1940; Lithuania, IVS for 1939; Northern Ireland, IVS for 1940; and Scotland, IVS for 1940.
} 


\section{Additional References Used in Appendix C (for other refer- ences see main text)}

Arriaga, Eduardo E. (1968) New Life Tables for Latin American Populations in the Nineteenth and Twentieth Centuries, Population Monograph \#3, Institute of International Studies, University of California, Berkeley.

Dandekar, K. (1972) "Mortality and Longevity in India, 1901-61," in K.E.Vaidyanathan (ed.) Studies on Mortality in India, Grandhirgram Institute of Rural Health.

Nitisastro, Widjojo (1970) Population Trends in Indonesia, Cornell University Press.

Preston, Samuel H. (1975) "The Changing Relation Between Mortality and Level of Economic Development," Population Studies, 29(2), 231-248.

Preston, Samuel H., Nathan Keyfitz, and Robert Schoen (1972) Causes of Death: Life Tabels for National Population, Seminar Press, New York. 


\section{Appendix Table C1}

First Stage Estimates: Importance of Disease Composition

\begin{tabular}{|c|c|c|c|c|c|c|c|c|c|c|}
\hline & \multicolumn{10}{|c|}{$\begin{array}{l}\text { Dependent Variable is log life expectancy } \\
\text { to calculate predicted mortality are indicated in each column } \\
\text { Base Sample }\end{array}$} \\
\hline & All Diseases & $\begin{array}{c}\text { Without } \\
\text { Tuberculosis }\end{array}$ & $\begin{array}{l}\text { Without } \\
\text { Malaria }\end{array}$ & $\begin{array}{c}\text { Without } \\
\text { Pneumonia }\end{array}$ & $\begin{array}{l}\text { Without } \\
\text { Influenza }\end{array}$ & $\begin{array}{l}\text { Without } \\
\text { Typhoid }\end{array}$ & $\begin{array}{l}\text { Without Small } \\
\text { Pox }\end{array}$ & $\begin{array}{l}\text { Without } \\
\text { Typhus }\end{array}$ & $\begin{array}{l}\text { Without } \\
\text { Cholera }\end{array}$ & $\begin{array}{l}\text { Without } \\
\text { Measles }\end{array}$ \\
\hline & $(1)$ & $(2)$ & (3) & $(4)$ & $(5)$ & (6) & $(7)$ & $(8)$ & (9) & $(10)$ \\
\hline Panel A & $\begin{array}{l}\text { Panel, 1940- } \\
1980\end{array}$ & $\begin{array}{c}\text { Panel, 1940- } \\
1980\end{array}$ & $\begin{array}{l}\text { Panel, 1940- } \\
1980\end{array}$ & $\begin{array}{l}\text { Panel, 1940- } \\
1980\end{array}$ & $\begin{array}{l}\text { Panel, 1940- } \\
1980\end{array}$ & $\begin{array}{l}\text { Panel, 1940- } \\
1980\end{array}$ & $\begin{array}{l}\text { Panel, 1940- } \\
1980\end{array}$ & $\begin{array}{c}\text { Panel, 1940- } \\
1980\end{array}$ & $\begin{array}{l}\text { Panel, 1940- } \\
1980\end{array}$ & $\begin{array}{c}\text { Panel, 1940- } \\
1980\end{array}$ \\
\hline Predicted Mortality & $\begin{array}{l}-0.33 \\
(0.06)\end{array}$ & $\begin{array}{l}-0.41 \\
(0.07)\end{array}$ & $\begin{array}{c}-0.34 \\
(0.08)\end{array}$ & $\begin{array}{l}-0.45 \\
(0.14)\end{array}$ & $\begin{array}{l}-0.34 \\
(0.06)\end{array}$ & $\begin{array}{l}-0.33 \\
(0.07)\end{array}$ & $\begin{array}{l}-0.33 \\
(0.06)\end{array}$ & $\begin{array}{l}-0.33 \\
(0.06)\end{array}$ & $\begin{array}{l}-0.34 \\
(0.07)\end{array}$ & $\begin{array}{l}-0.34 \\
(0.06)\end{array}$ \\
\hline R-squared & 0.93 & 0.93 & 0.93 & 0.92 & 0.93 & 0.93 & 0.93 & 0.93 & 0.93 & 0.93 \\
\hline Number of observations & 283 & 283 & 283 & 283 & 283 & 283 & 283 & 283 & 283 & 283 \\
\hline Number of countries & 59 & 59 & 59 & 59 & 59 & 59 & 59 & 59 & 59 & 59 \\
\hline
\end{tabular}

Panel B

Just 1940 and Just 1940 and Just 1940 and Just 1940 and Just 1940 and Just 1940 and Just 1940 and Just 1940 and Just 1940 and Just 1940 and

Predicted Mortality

\begin{tabular}{|c|c|c|c|c|c|c|c|c|c|}
\hline 1980 & 1980 & 1980 & 1980 & 1980 & 1980 & 1980 & 1980 & 1980 & 1980 \\
\hline $\begin{array}{l}-0.45 \\
(0.09)\end{array}$ & $\begin{array}{l}-0.57 \\
(0.11)\end{array}$ & $\begin{array}{l}-0.47 \\
(0.11)\end{array}$ & $\begin{array}{c}-0.54 \\
(0.20)\end{array}$ & $\begin{array}{l}-0.45 \\
(0.09)\end{array}$ & $\begin{array}{l}-0.45 \\
(0.10)\end{array}$ & $\begin{array}{l}-0.45 \\
(0.10)\end{array}$ & $\begin{array}{l}-0.45 \\
(0.09)\end{array}$ & $\begin{array}{l}-0.46 \\
(0.10)\end{array}$ & $\begin{array}{l}-0.46 \\
(0.09)\end{array}$ \\
\hline 0.95 & 0.95 & 0.94 & 0.92 & 0.95 & 0.95 & 0.95 & 0.95 & 0.95 & 0.95 \\
\hline 94 & 94 & 94 & 94 & 94 & 94 & 94 & 94 & 94 & 94 \\
\hline 47 & 47 & 47 & 47 & 47 & 47 & 47 & 47 & 47 & 47 \\
\hline
\end{tabular}

Number of countries

OLS regressions with a full set of year and country fixed effects. Robust standard errors, adjusted for clustering by country, in parentheses. Panel A uses data from each 10 years in the indicated period, e.g., 1940-1980 is an unbalanced panel for 1940, 1950, 1960, 1970, and 1980; Panel B uses data from a balanced panel for just the start and end year indicated. Dependent variables: log life expectancy at birth. Independent variable: predicted mortality per 100 per annum. Base sample is countries for which we have disease data. Measure of predicted mortality in column 1 is baseline estimate, based on deaths from 15 infectious diseases. Other columns drop individual diseases from calculation of predicted mortality, as indicated in column heading. 


\section{Appendix Table C2}

The Effect of Life Expectancy on Log GDP per population of working age: 2SLS Estimates

\begin{tabular}{|c|c|c|c|c|c|c|c|c|c|c|c|}
\hline & \multicolumn{11}{|c|}{ Dependent variable is log GDP per capita } \\
\hline & \multicolumn{6}{|c|}{ Baseline instrument } & $\begin{array}{c}\text { Global } \\
\text { mortality } \\
\text { instrument }\end{array}$ & \multicolumn{4}{|c|}{ Baseline instrument } \\
\hline & \multicolumn{2}{|c|}{ Base Sample } & \multirow{2}{*}{$\begin{array}{c}\text { Including } \\
\text { Eastern Europe } \\
\text { No leads } \\
\text { Panel, 1940- } \\
1980 \\
(3) \\
\end{array}$} & \multirow{2}{*}{$\begin{array}{c}\text { Low and } \\
\text { Middle Income } \\
\text { Countries Only } \\
\text { No leads } \\
\text { Panel, 1940- } \\
1980 \\
(4) \\
\end{array}$} & \multirow{2}{*}{$\begin{array}{c}\text { Base Sample, } \\
\text { Interaction with } \\
\text { Institutions }\end{array}$} & \multirow{2}{*}{$\begin{array}{c}\text { Base Sample, } \\
\text { Interaction with } \\
\text { Initial (1930) } \\
\text { GDP per work. } \\
\text { age pop. } \\
\text { No leads } \\
\text { Panel, 1940- } \\
1980 \\
(6) \\
\end{array}$} & \multicolumn{5}{|c|}{ Base Sample } \\
\hline & $\begin{array}{c}\text { No leads } \\
\text { Panel, } 1940- \\
1980 \\
(1) \\
\end{array}$ & $\begin{array}{c}\text { No leads } \\
\text { Panel, 1930- } \\
1980 \\
(2) \\
\end{array}$ & & & & & $\begin{array}{c}\text { No leads } \\
\text { Panel, 1940- } \\
1980 \\
(7) \\
\end{array}$ & $\begin{array}{l}10 \text { year lead } \\
\text { Panel, } 1940- \\
1980 \\
(8) \\
\end{array}$ & $\begin{array}{c}20 \text { year lead } \\
\text { Panel, 1940- } \\
1980 \\
(9) \\
\end{array}$ & $\begin{array}{c}30 \text { year lead } \\
\text { Panel, 1940- } \\
1980 \\
(10) \\
\end{array}$ & $\begin{array}{c}40 \text { year lead } \\
\text { Panel, 1940- } \\
1980 \\
(11) \\
\end{array}$ \\
\hline \multicolumn{12}{|l|}{ Panel A } \\
\hline Log Life Expectancy & $\begin{array}{l}-1.43 \\
(0.64)\end{array}$ & $\begin{array}{l}-1.57 \\
(0.54)\end{array}$ & $\begin{array}{l}-1.42 \\
(0.63)\end{array}$ & $\begin{array}{l}-2.13 \\
(1.52)\end{array}$ & $\begin{array}{l}-1.76 \\
(0.94)\end{array}$ & $\begin{array}{l}-0.91 \\
(1.37)\end{array}$ & $\begin{array}{l}-1.26 \\
(0.49)\end{array}$ & $\begin{array}{l}-0.89 \\
(0.39)\end{array}$ & $\begin{array}{l}-1.05 \\
(0.47)\end{array}$ & $\begin{array}{l}-0.91 \\
(0.55)\end{array}$ & $\begin{array}{l}-1.23 \\
(1.02)\end{array}$ \\
\hline \multicolumn{3}{|c|}{$\begin{array}{l}\text { p-value for Year Dummies x } \\
\text { Institutions or Initial GDP per } \\
\text { working age population }\end{array}$} & & & [0.003] & {$[0.26]$} & & & & & \\
\hline Number of observations & 234 & 266 & 264 & 179 & 234 & 230 & 138 & 234 & 234 & 187 & 140 \\
\hline Number of countries & 47 & 47 & 53 & 36 & 47 & 46 & 46 & 47 & 47 & 47 & 47 \\
\hline & No leads & No leads & No leads & No leads & No leads & No leads & No leads & 10 year lead & 20 year lead & 30 year lead & 40 year lead \\
\hline & $\begin{array}{c}\text { Just } 1940 \text { and } \\
1980\end{array}$ & $\begin{array}{c}\text { Just } 1930 \text { and } \\
1980\end{array}$ & $\begin{array}{c}\text { Just } 1940 \text { and } \\
1980\end{array}$ & $\begin{array}{c}\text { Just } 1940 \text { and } \\
1980\end{array}$ & $\begin{array}{c}\text { Just } 1940 \text { and } \\
1980\end{array}$ & $\begin{array}{c}\text { Just } 1940 \text { and } \\
1980\end{array}$ & $\begin{array}{c}\text { Just } 1940 \text { and } \\
1980\end{array}$ & $\begin{array}{c}\text { Just } 1940 \text { and } \\
1980\end{array}$ & $\begin{array}{c}\text { Just } 1940 \text { and } \\
1980\end{array}$ & $\begin{array}{c}\text { Just } 1940 \text { and } \\
1970\end{array}$ & $\begin{array}{c}\text { Just } 1940 \text { and } \\
1960\end{array}$ \\
\hline \multicolumn{12}{|l|}{ Panel B } \\
\hline Log Life Expectancy & $\begin{array}{l}-1.35 \\
(0.63)\end{array}$ & $\begin{array}{l}-1.61 \\
(0.62)\end{array}$ & $\begin{array}{l}-1.33 \\
(0.61)\end{array}$ & $\begin{array}{l}-2.43 \\
(1.30)\end{array}$ & $\begin{array}{l}-1.82 \\
(0.88)\end{array}$ & $\begin{array}{l}-1.87 \\
(1.39)\end{array}$ & $\begin{array}{l}-1.20 \\
(0.57)\end{array}$ & $\begin{array}{l}-1.17 \\
(0.62)\end{array}$ & $\begin{array}{l}-1.18 \\
(0.77)\end{array}$ & $\begin{array}{l}-1.02 \\
(0.79)\end{array}$ & $\begin{array}{l}-1.14 \\
(1.16)\end{array}$ \\
\hline $\begin{array}{l}\text { Post year dummy x } \\
\text { Institutions or Initial GDF } \\
\text { working age population }\end{array}$ & per & & & & $\begin{array}{l}-0.08 \\
(0.07)\end{array}$ & $\begin{array}{l}-0.16 \\
(0.37)\end{array}$ & & & & & \\
\hline Number of observations & 92 & 92 & 104 & 70 & 92 & 92 & 92 & 92 & 92 & 92 & 92 \\
\hline Number of countries & 46 & 46 & 52 & 35 & 46 & 46 & 46 & 46 & 46 & 46 & 46 \\
\hline
\end{tabular}

2SLS regressions with a full set of year and country fixed effects. Robust standard errors, adjusted for clustering by country, in parentheses. Panel A is unbalanced panel with one observation per decade. Panel B is long-difference specification with observations for only the beginning and end dates. Dependent variable in both panels is log GDP per working age population. Independent variable in both panels is log life expectancy at birth. In columns 1-6 and 8-11, log life expectancy is instrumented by predicted mortality (baseline instrument), and in column 7 it is instrumented global mortality. First stages are in Table 5 . In columns 1-7, the dependent and independent variables are for the same time period; in columns $8-11$, the dependent variable is $t+10$, $t+20$ etc., as indicated, while the independent variable is at time t. Columns 5 and 6 include year dummies interacted with: institutions, in column 5 , as average of constraint on executive in 1950,1960 , and 1970 from Polity IV, where scores range from 1 to 7 and non-independent countries are assigned score of 1 ; and initial GDP per working age population, in column 6 , is for 1930. See text and Appendix A for construction of the mortality instruments, definitions, and data sources. 
Appendix Table C3

2SLS Estimates: robustness

\begin{tabular}{|c|c|c|c|c|c|c|c|c|}
\hline \multicolumn{9}{|c|}{ Dependent variable indicated for each panel separately } \\
\hline & $\begin{array}{c}\rho=0.4 \\
(1) \\
\end{array}$ & $\begin{array}{c}\rho=0.45 \\
(2)\end{array}$ & $\begin{array}{l}\rho=0.5 \\
(3) \\
\end{array}$ & $\begin{array}{c}\rho=0.55 \\
(4)\end{array}$ & $\begin{array}{l}\rho=0.6 \\
(5) \\
\end{array}$ & $\begin{array}{c}\rho=0.65 \\
(6)\end{array}$ & $\begin{array}{l}\rho=0.7 \\
(7) \\
\end{array}$ & $\begin{array}{c}\rho=0.75 \\
(8)\end{array}$ \\
\hline Panel A: Dependent variable is-- & \multicolumn{8}{|c|}{ Transformed log GDP per capita } \\
\hline Transformed Log Life Expectancy & $\begin{array}{l}-1.98 \\
(0.97)\end{array}$ & $\begin{array}{l}-2.01 \\
(1.03)\end{array}$ & $\begin{array}{l}-2.05 \\
(1.12)\end{array}$ & $\begin{array}{l}-2.10 \\
(1.22)\end{array}$ & $\begin{array}{l}-2.15 \\
(1.36)\end{array}$ & $\begin{array}{c}-2.22 \\
(1.54)\end{array}$ & $\begin{array}{l}-2.31 \\
(1.79)\end{array}$ & $\begin{array}{c}-2.44 \\
(2.15)\end{array}$ \\
\hline Panel B: Dependent variable is-- & \multicolumn{8}{|c|}{ Transformed log life expectancy } \\
\hline Predicted Mortality & $\begin{array}{l}-0.19 \\
(0.07)\end{array}$ & $\begin{array}{l}-0.18 \\
(0.07)\end{array}$ & $\begin{array}{l}-0.18 \\
(0.07)\end{array}$ & $\begin{array}{l}-0.16 \\
(0.06)\end{array}$ & $\begin{array}{l}-0.14 \\
(0.06)\end{array}$ & $\begin{array}{l}-0.13 \\
(0.06)\end{array}$ & $\begin{array}{l}-0.11 \\
(0.06)\end{array}$ & $\begin{array}{c}-0.10 \\
(0.06)\end{array}$ \\
\hline R-squared & 0.84 & 0.81 & 0.81 & 0.76 & 0.71 & 0.64 & 0.55 & 0.45 \\
\hline Number of observations & 257 & 257 & 257 & 257 & 257 & 257 & 257 & 257 \\
\hline Number of countries & 59 & 59 & 59 & 59 & 59 & 59 & 59 & 59 \\
\hline
\end{tabular}

2SLS regressions with a full set of year and country fixed effects. Robust standard errors, adjusted for clustering by country, in parentheses. Unbalanced panel with one observation per decade. In columns 1 through 8, transformed variables are defined as $x(t)-\rho x(t-1)$, where value of $\rho$ is indicated in the column heading. Second stage regression is in panel A, instrument is predicted mortality, and corresponding first stage is shown in panel B. 


\section{Appendix Table C4}

Interactions with Initial Conditions: 2SLS Estimates

\begin{tabular}{|c|c|c|c|c|c|c|c|c|c|c|}
\hline & \multicolumn{5}{|c|}{ Interaction with Log GDP per capita in 1930} & \multicolumn{5}{|c|}{ Interaction with investment as share of GDP in 1940s } \\
\hline & No lead & 10 year lead & 20 year lead & 30 year lead & 40 year lead & No lead & 10 year lead & 20 year lead & 30 year lead & 40 year lead \\
\hline & $(1)$ & $(2)$ & $(3)$ & $(4)$ & $(5)$ & $(6)$ & $(7)$ & $(8)$ & $(9)$ & $(10)$ \\
\hline \multicolumn{11}{|c|}{ Panel A: dependent variable is log population } \\
\hline \multirow[t]{2}{*}{ Log Life Expectancy } & 1.11 & 1.20 & 1.21 & 1.03 & 0.64 & 1.42 & 1.61 & 1.63 & 1.49 & 1.14 \\
\hline & $(0.48)$ & $(0.50)$ & $(0.47)$ & $(0.46)$ & $(0.46)$ & $(0.44)$ & $(0.45)$ & $(0.46)$ & $(0.54)$ & $(0.60)$ \\
\hline Log Life Expectancy & -0.17 & -0.25 & -0.31 & -0.37 & -0.41 & 0.01 & 0.01 & 0.002 & -0.01 & -0.02 \\
\hline x Interaction term & $(0.31)$ & $(0.31)$ & $(0.26)$ & $(0.24)$ & $(0.25)$ & $(0.03)$ & $(0.04)$ & $(0.04)$ & $(0.05)$ & $(0.05)$ \\
\hline Number of observations & 243 & 243 & 243 & 194 & 145 & 238 & 238 & 238 & 190 & 142 \\
\hline Number of countries & 49 & 49 & 49 & 49 & 49 & 48 & 48 & 48 & 48 & 48 \\
\hline \multicolumn{11}{|c|}{ Panel B: dependent variable is log total GDP } \\
\hline \multirow[t]{2}{*}{ Log Life Expectancy } & 0.78 & 0.28 & -0.40 & -0.78 & -1.63 & 0.92 & 0.88 & 0.16 & -0.15 & -0.92 \\
\hline & $(0.69)$ & $(0.75)$ & $(0.74)$ & $(0.90)$ & $(1.18)$ & $(0.58)$ & $(0.58)$ & $(0.62)$ & $(0.71)$ & $(0.83)$ \\
\hline \multirow{2}{*}{$\begin{array}{l}\text { Log Life Expectancy } \\
\text { x Interaction term }\end{array}$} & 0.69 & -0.22 & -0.78 & -1.15 & -1.37 & 0.13 & 0.04 & -0.06 & -0.12 & -0.15 \\
\hline & $(0.52)$ & $(0.60)$ & $(0.50)$ & $(0.54)$ & $(0.64)$ & $(0.04)$ & $(0.04)$ & $(0.03)$ & $(0.04)$ & $(0.06)$ \\
\hline Number of observations & 243 & 243 & 243 & 194 & 145 & 238 & 238 & 238 & 190 & 142 \\
\hline Number of countries & 49 & 49 & 49 & 49 & 49 & 48 & 48 & 48 & 48 & 48 \\
\hline \multicolumn{11}{|c|}{ Panel C: dependent variable is log GDP per capita } \\
\hline \multirow[t]{2}{*}{ Log Life Expectancy } & -0.36 & -0.93 & -1.61 & -1.81 & -2.27 & -0.48 & -0.74 & -1.47 & -1.64 & -2.06 \\
\hline & $(0.71)$ & $(0.74)$ & $(0.77)$ & $(0.87)$ & $(1.17)$ & $(0.51)$ & $(0.61)$ & $(0.64)$ & $(0.74)$ & $(1.11)$ \\
\hline \multirow{2}{*}{$\begin{array}{l}\text { Log Life Expectancy } \\
x \text { Interaction term }\end{array}$} & 0.79 & 0.02 & -0.47 & -0.78 & -0.96 & 0.12 & 0.03 & -0.06 & -0.11 & -0.14 \\
\hline & $(0.37)$ & $(0.46)$ & $(0.40)$ & $(0.42)$ & $(0.63)$ & $(0.04)$ & $(0.04)$ & $(0.04)$ & $(0.05)$ & $(0.09)$ \\
\hline Number of observations & 243 & 243 & 243 & 194 & 145 & 238 & 238 & 238 & 190 & 142 \\
\hline Number of countries & 49 & 49 & 49 & 47 & 47 & 48 & 48 & 48 & 48 & 48 \\
\hline
\end{tabular}

2SLS regressions with a full set of year and country fixed effects. Robust standard errors, adjusted for clustering by country, in parentheses. Unbalanced panels with one observation per decade. Dependent variable: in Panel A, log total population; in Panel B, log total GDP; in Panel C, log GDP per capita. Independent variable in all panels is log life expectancy at birth and interaction of log life expectancy with, in columns 1-5, log GDP per capita in 1940, and in columns 6-10, investment share of GDP in 1940s. All variables are demeaned so main effects are evaluated at sample mean. In all columns, instruments are predicted mortality (baseline instrument) and interaction of predicted mortality with either log GDP p.c. in 1930 (columns 1-5) or investment share of GDP 1940s (columns 6-10). First stages not reported to save space. In columns 1 and 6 , the dependent and independent variables are for the same time period; in columns $2-5$, and $7-10$, the dependent variable is $t+10$, $t+20$ etc., as indicated, while the independent variable is at time t. See text and Appendix A for details and definitions. 